\title{
Der osmanisch-türkische Typ
}

\section{Rollen der Andacht aus dem Umfeld von Derwischorden: Sieben Belegstücke aus dem Westteil des Osmanischen Reichs (17.Jh.)}

\subsection{Einleitende Bemerkungen ${ }^{1}$}

Bereits in einem frühen Stadium der Auseinandersetzung mit diesen Dokumenten in Rollenform liess sich eine Gruppe von Belegstücken identifizieren, die mutmasslich aus dem Osmanischen Reich stammen. ${ }^{2}$ Die hier näher vorzustellenden Belegstücke sind in der Regel ca. $4.5-5.0 \mathrm{~cm}$ breit und ungefähr $3-4 \mathrm{~m}$ lang; sie dürften hauptsächlich im 17. Jh. entstanden sein. Beim Beschreibstoff handelt es sich um ein dünnes, oft nahezu transparentes Papier. ${ }^{3}$ Dieser osmanisch-türkische Typ wird im folgenden anhand einer näheren Untersuchung von sieben Dokumenten präzisiert, die sich durch ein weitgehend identisches Grundmuster und eine grosse Anzahl gemeinsamer Gestaltungselemente auszeichnen. Es handelt sich um die folgenden Belegstücke: 4

1 Sämtliche in diesem Kapitel 6 aufgeführten InternetQuellen wurden zwischen dem 1. und 10. Januar 2015 zum letzten Mal aufgerufen.

2 Der vorliegende Abschnitt stellt die Langfassung eines Aufsatzes dar, der 2017 stark gekürzt veröffentlicht wurde. In Abweichung zum Vorgehen in den Kapiteln 4 und 5 wurden hier keine eigentlichen Katalogisate zu jedem einzelnen Belegstück erstellt; es hätte sich nicht gerechtfertigt, den in sich geschlossenen Text des Artikels wieder in seine Einzelteile zurückzuführen. Beim erwähnten Artikel handelt es sich um folgenden Beitrag: Nünlist, Rollen der Andacht aus dem Umfeld von Derwischorden.

3 Aus dem Osmanischen Reich sind auch Belegstücke bekannt, bei deren Beschreibstoff es sich um starkes Papier handelt. Sie werden hier nicht untersucht; vgl. dazu unten Anm. 9 und 11.

4 Ein zusätzliches, mit den hier berücksichtigten Exemplaren vergleichbares Belegstück soll sich in Wien befinden, wie aus einem Hinweis im Katalogtext zur Amulettrolle
1. Zentralbibliothek Zürich, Ms. or. $20 ; 4.7 \times 308$.o cm (Авв. 136-142). ${ }^{5}$

2. Universitätsbibliothek Leipzig, B. or. $328 ; 4.7 \times$ $349 \mathrm{~cm}$; datiert: 21. Rağab 1041/12. Februar 1632 (АвB. $143^{-146)}{ }^{6}$

aus Karlsruhe hervorgeht (vgl. gerade anschliessend Nr. 4, mit Anm. 8: Petrasch, Türkenbeute, 1991). Dieses Exemplar liess sich trotz Anfragen an zahlreiche Institutionen in Wien nicht identifizieren. Es liess sich auch nicht nachweisen im Katalog zur Ausstellung, die 1883 zum Gedächtnis an den Entsatz Wiens organisiert worden war (vgl. Katalog der Historischen Ausstellung der Stadt Wien 1883).

5 Nünlist, Handschriften 74-8o (Ms.or. 20). Diese Rolle wurde in einer gedrechselten Holzkapsel aufbewahrt; Höhe der Kapsel: 6.4 cm; Innendurchmesser: $2.5 \mathrm{~cm}$ (siehe auch Anm. 12). Dieses Belegstück wurde im Juni 2007 restauriert (Restaurierungsprotokoll vorhanden).

6 Fragmentarisch erhalten; der Anfang des Dokuments fehlt. Vgl. Fleischer, Catalogus $55^{2}$ (Nr. CCCLIII); siehe auch: http://www.islamic-manuscripts.net/receive/IslamHSBoo k_islamhs_ooo11058.

Die Datierung ergibt sich aus einem Kolophon ganz am Schluss der Rolle (goldene Schrift auf neutralem Hintergrund; Rechts, senkrecht, absteigend, und links, senk-

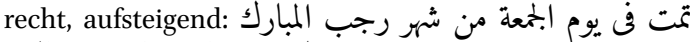
(ا ب بتاريخ سنة احد واربعون والف : Hier auch folgende Angaben zum mutmasslich ersten Besitzer des Dokuments: صاحبها الحاجى احمد الحقير الضعيف الحمتاج الى رحت المت اللطيف الكاتب الضعيف عبد :Danach Hinweis auf den Kopisten

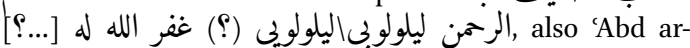
Raḥmān Laylūlūbī; die Entzifferung dieses Namens ist nicht gänzlich gesichert. Auf der Rückseite des Dokuments ein weiterer Eintrag mit dem Namen eines späteren Vorbesitzers: „Șāhibu-hū wa-māliku-hū 'Aywāz, (allen-

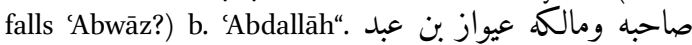
الله. Eine Person dieses Namens liess sich nicht nachweisen. Der Name 'Abwāz ist belegt in Nu'man Debbagade, Tuhfah al-sukuk. (Geschenk der gerichtlichen Dokumente. Sammlung von 670 Rechtssprüchen.) turc. Constantinopel, 1248/1832 (Österreichische Nationalbibliothek); darin S. 10.

(C) TOBIAS NÜNLIST, 2020 | DOI:10.1163/9789004429154_008

This is an open access chapter distributed under the terms of the CC BY-NC-ND 4.O license. 
3. Staatsbibliothek Berlin, Ms. or. oct. 403; 5.0 $\times$ $333.0 \mathrm{~cm}^{7}$

4. Badische Landesbibliothek, Karlsruhe, Hs. Rastatt 204; 5.0 ×395.0 cm, datierbar in die Zeit 1640-1648 (АВ B. 147-151). ${ }^{8}$

5. Bayerische Staatsbibliothek, München, Cod. arab. $206 ; 4.5 \times 360.0 \mathrm{~cm}$ (ABB. $15^{2-154)} .^{9}$

6. Württembergische Landesbibliothek, Stuttgart, Cod. or. $8^{\circ} 83 ; 4.4 \times 362.0 \mathrm{~cm}$; datiert: 20 . Dū l-Hiğğa 1093/2O. Dezember 1682 (АВB. 155$156) \cdot{ }^{10}$

7 Vgl. dazu Ahlwardt, Verzeichniss der arabischen Handschriften III, Nr. 3688. W. Ahlwardt datiert dieses Dokument in die Zeit um 1150/1737. Als Besitzer nennt sich ganz am Schluss ein gewisser Aḥmad („Ṣạhịib wa-mālik banda Ahmad“). Da dieses Dokument schlecht erhalten ist, war eine Untersuchung am Original nur ganz beschränkt möglich. Bei der Abfassung dieses Beitrags stand ausschliesslich ein Mikrofilm (schwarzweiss) zur Verfügung. Farbige scans liessen sich nicht beschaffen.

8 Dieses Belegstück wurde in einer silbernen Büchse aufbewahrt. Man beachte die Analyse dieser Rolle in Petrasch, Karlsruher Türkenbeute 382 f. (Nr. 319). Vgl. den Auszug daraus unter: http://www.tuerkenbeute.de/sam/ sam_sch/RA204_o2_de.php?vmSiteSession=b3b19o56a3 16ba748obeedoefb58b2ee. Zur Karlsruher Rolle siehe ausserdem bereits: Petrasch und Zimmermann, Türkenlouis 226 f. (Nr. 538). Überdies: Die Handschriften der Grossherzoglich-Badischen Hof- und Landesbibliothek in Karlsruhe. Teil 2: Orientalische Handschriften 29f. (Nr. 18). Allgemeine Angaben zur Karlsruher Türkenbeute in der Einleitung zu Petrasch, Die Türkenbeute (1997) IX-XXVII. Diese Rolle ist aufrufbar unter http://daten.digitale-sam mlungen.de/bsbooo3963o/image_1 (Stand 22. Januar 2020). Zur Ergänzung wird hingewiesen auf Cod. arab. 205, Cod. arab. 207 und Cod. turc. 41 und 42, aus derselben Bibliothek. Zu Cod. arab. 205, 206 und 207 siehe: Aumer, Die arabischen Handschriften der K. Hof- und Staatsbibliothek, alle S. 62. Zu Cod. turc. 41 und 42 siehe: Aumer, Verzeichniss der orientalischen Handschriften 13.

Die Rolle hat einen Kolophon mit folgenden Angaben zur

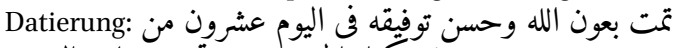
Hier auch ein

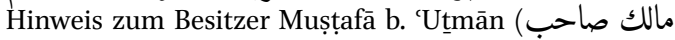
(حامد الله تعالى مصطفى بن عثمان.

Die Württembergische Landesbibliothek, Stuttgart, besitzt ausserdem sieben weitere Rollen aus dem islamischen Kulturraum, die vorliegend aber nicht näher vorgestellt werden. Es handelt sich um Cod. or. $8^{\circ} 13,14,34$, $55,71,84$ und 85 .
7. Historisches Museum, Budapest, втм ко 99. 119.3; 3.5-3.6×162.0 cm; fragmentarisch erhalten (АВ В. 157-159). ${ }^{11}$

Unter den angeführten Dokumenten stehen einander einerseits die drei Exemplare aus Zürich und Berlin sowie teilweise Leipzig und anderseits die drei Dokumente aus Karlsruhe, München und Stuttgart besonders nahe. Verschiedene von diesen sechs Rollen bekannte Elemente lassen sich auch auf dem Belegstück aus Budapest nachweisen. Dieses Exemplar ist allerdings einfacher gestaltet und dürfte unter den beigezogenen Dokumenten am frühesten entstanden sein. Die beiden Belegstücke aus Zürich und Karlsruhe werden jeweils in einem Behältnis aufbewahrt. Die andern untersuchten Rollen sind ohne Behältnis erhalten geblieben. ${ }^{12}$

Die weiteren Ausführungen sind in einem ersten Schritt deskriptiv orientiert und stellen die für den Inhalt und die Gestaltung der untersuchten Rollen wichtigen Elemente vor (Abschnitt 6.2). Sie gehen anschliessend der ideologischen Einordnung der Dokumente nach (Abschnitt 6.3) und versuchen darauf, den historischen Kontext zu erschliessen, in dem sie in Gebrauch gewesen waren und mutmasslich auch hergestellt wurden (Abschnitt 6.4). Ein letzter Teil (Abschnitt 6.5) fasst die Erkenntnisse zusammen.

11 Vereinzelt weist der vorliegende Beitrag zur Ergänzung auf das deutlich einfacher gestaltete Belegstück Duod. Arab. 5 aus der Ungarischen Nationalbibliothek, Budapest, hin.

12 Zur Frage nach der Zusammengehörigkeit von Rolle und Behältnis siehe Anm. 231. Die Rollen wurden ursprünglich ganz straff aufgewickelt in diesen engen Behältnissen aufbewahrt und standen unter sehr hoher Spannung. Es war wohl durchaus Absicht, diese Spannung zu erzeugen. Wenn man die Dokumente nach langer Zeit wieder öffnet, entlädt sich diese Spannung und das Dokument entrollt sich mit hoher Geschwindigkeit von selbst. Die darauf enthaltenen Schutzelemente werden dabei allen potentiellen Störenfrieden gewissermassen mit grosser Energie entgegengeschleudert. Aus konservatorischen Gründen werden derartige Dokumente heute zumeist nicht mehr in ihren ursprünglichen Behältnissen selbst aufbewahrt. 


\subsection{Bemerkungen zu Inhalt und Gestaltung der Rollen}

Die zu untersuchenden Rollen aus osmanischen Kontexten zeichnen sich, wie bereits angetönt, durch einen weitgehend identischen Aufbau aus. Allgemein formulierend lässt sich auf den beigezogenen Belegstücken eine Zweiteilung feststellen. Im ersten Teil der Rollen lassen sich verschiedene Textelemente erkennen. Sie sind zumeist in aufwendig ausgeführte Figuren und Symbole integriert. Diese gestalterischen Elemente tragen massgeblich zur ästhetisch ansprechenden Wirkung dieser Dokumente bei. Diese Aspekte werden erst später untersucht (vgl. Kapitel 6.2.2). Der zweite Teil der angeführten Rollen hingegen enthält hauptsächlich Text in $\dot{G} u b \bar{a} r$-Schrift. Hinweise $\mathrm{zu}$ diesem auf den beigezogenen Belegstücken zumeist ähnlich gestalteten Teil stehen in einem ersten Schritt im Vordergrund (Kapitel 6.2.1).

\subsubsection{Zweiter Teil der Rollen: Būṣīrīs Qașīdat al-Burda}

Es fällt auf, dass die Rollen aus Zürich (АВВ. 137) und Karlsruhe (АВB. 147) im zweiten Teil eine Kombination derselben Texte enthalten: Im breiten Mittelband (Breite des Schriftspiegels: $2.5 \mathrm{~cm}$ ) der beiden Dokumente steht Būṣīīs Qașīdat alBurda. Am linken und rechten Rand lassen sich auf einem schmalen Streifen (Breite je ca. $6 \mathrm{~mm}$ ) in $\dot{G} u b \bar{a} r$-Schrift (Höhe ca. $3 \mathrm{~mm}$ ) die Suren Yā-sìn (Q 36) bzw. al-Fath (Q 48, Der Sieg) erkennen. ${ }^{13}$ Die Kombination derselben Texte lässt sich überdies auf Cod. arab. 206 (München) beobachten; Q 36 und Q 48 beginnen hier allerdings bereits am Rollenanfang. ${ }^{14}$ Auch auf den beiden Seitenbän-

13 Auf dem Belegstück aus Zürich beginnt Q 36 am Anfang der Burda auf der rechten Seite und läuft danach auf das Ende des Dokuments zu. Der Text von Q 48 beginnt am Rollenende und läuft auf der linken Seite zurück zum Anfang der Qașidat al-Burda.

14 Cod. arab. 206 (München): Q 36 (Yā-Sinn) läuft auf diesem Belegstück auf der rechten Rollenseite in einem schmalen Band auf das Ende des Dokuments zu. Am Schluss der Rolle steht Q 36:77 (horizontaler Übergang zum rückwärtslaufenden Schriftband). Der Text läuft dann auf dern der Rolle Cod. or. $8^{\circ} 83$ (Stuttgart) wurden die beiden Suren 36 und 48 auf nahezu der gesamten Länge der Rolle kopiert; diese zwei Koranstellen enden auf diesem Exemplar erst kurz vor dem Schluss des Dokuments. Ganz am Ende dieses Belegstücks lässt sich ein zusätzliches Textelement erkennen. ${ }^{15}$ Auf dem Exemplar aus Leipzig (B. or. 328) lässt sich eine ähnliche Gestaltung feststellen (Авв. 143). Hier beginnt bei der Burda auf dem rechten Seitenband vorwärtslaufend Q 48. Sie wird auf dem rückwärtslaufenden Textband auf der linken Seite fortgesetzt und endet $85.5 \mathrm{~cm}$ unterhalb des Beginns der Mantelode (Burda). Danach schliesst sich ein Gebet zum Lob Muhammads an (Du'ẩ Habìb Allāh). Q 36 ist auf dem Dokument aus Leipzig in Abweichung zu den Parallelstücken also nicht kopiert. ${ }^{16}$ Auch auf dem Dokument aus dem Historischen Museum Budapest wurde im zweiten Teil Būṣīīs Qașìda notiert; auf diesem Exemplar fehlen jedoch die beiden Seitenbänder mit Suren 36 und 48 (АВ B. 158). ${ }^{17}$ Die soeben angeführten drei Texte (Burda, Suren 36 und 48) lassen sich anders angeordnet jedoch ebenso auf dem schlecht erhaltenen Belegstück aus Berlin nachweisen. ${ }^{18}$ Zusätzlich lässt sich die Mantelode auf

dem Schriftband auf der linken Seite zurück bis ans Ende der Sure. Zugleich beginnt am Rollenanfang auf der linken Seite Q 48 (al-Fath). Ihr Ende wird durch einen grossen roten Verstrenner markiert. Q 36 und Q 48 stossen jedoch nicht direkt aufeinander, sondern sind durch den Einschub von Q 112 (al-Ihlāss) voneinander getrennt. Die letzten drei Wörter von Q 112 (la-hū kufuwan ahad) befinden sich ausserhalb des Schriftbands.

15 Es handelt sich um Q 110. Auf der Gegenseite lässt sich eine kurze Lobpreisung Gottes und seiner Propheten erkennen. Ausserhalb des Schriftspiegels folgen unten die Schlussverse der Qașídat al-Burda.

16 Die Länge des Abschnitts mit der Burda misst auf dem Belegstück aus Leipzig ca. $255 \mathrm{~cm}$. Es fällt auf, dass eine horizontale Überleitung des vorwärtslaufenden ins rückwärtslaufende Schriftband ganz am Rollenende fehlt. Die Höhe der Schrift in den Seitenbändern beträgt ca. $2 \mathrm{~mm}$. Die schlechte Erhaltung des Dokuments hat zu bedeutenden Textverlusten geführt. Gerade am Anfang der Qașidat al-Burda lässt sich der Text allerdings noch erkennen.

18 Die Qașídat al-Burda ist auch auf Ms. or. oct. 403 (Berlin) im zweiten Teil der Rolle kopiert worden. Suren 36 und 
einer deutlich einfacher gestalteten Rolle aus der Ungarischen Nationalbibliothek feststellen. ${ }^{19}$ Es verdient Erwähnung, dass sich Būṣīīs Text bereits auf anders gestalteten Rollen belegen lässt, die vermutlich um 1400 entstanden sind und hier deshalb nicht näher untersucht werden. ${ }^{20}$

Būṣînīs Qașìdat al-Burda zählt zu den am weitest verbreiteten Schutzgebeten in der islamischen Welt. ${ }^{21}$ Būṣinī lebte im 13. Jh. und stammt aus Oberägypten. Zu seinen berühmtesten Werken zählen zwei Lobgedichte auf den Propheten Muhammad, die Hamziyya und die Burda. Būṣīīs Biographen berichten, dass er das Mantelgedicht verfasst habe, als er ernsthaft erkrankt und halbseitig gelähmt gewesen sei. Nachdem er das Werk beendet hatte, betete er zu Gott und flehte um Heilung. Darauf erschien ihm der Prophet im Traum, legte seine Hand auf seine Stirn und hüllte ihn in seinen Mantel, in seine burda eben, ein. Als Būṣīī erwachte, war er geheilt. Die Berichte über dieses Wunder verbreiteten sich wie ein Lauffeuer und trugen zur Berühmtheit der Mantelode bei. Dem Gedicht ist ein therapeutisches Element inhärent, das seine Popularität erklärt.

48 sind hier auf einem schmalen Seitenband notiert, das die gesamte Rolle einfasst. Da die Rolle am Anfang unvollständig erhalten ist, beginnt der Text auf dem vorwärtslaufenden Schriftband erst mit Vers 36:6. (Bl. 18 auf dem Mikrofilm der Rolle). Am Rollenende ist Q 36:67-68 zu erkennen (horizontaler Übergang); darauf läuft der Text auf der entgegengesetzten Seite der Rolle an deren Anfang zurück. Q 36 endet auf Bl.6 (Mikrofilm); direkt anschliessend beginnt Q 48. Da der Rollenanfang verloren ist, endet Q 48 mit Vers 25 (Anfang; Bl. 18 Mikrofilm). Der Schluss von Q 48 (Verse 25-29) fehlt.

19 Ungarische Nationalbibliothek, Budapest, Duod. Arab. 5 . Museum Dār al-Ātār al-Islāmiyya, Kuwait, aufmerksam, die beide grosse Teile der Qașidat al-Burda enthalten (DAI LNS 25 MS, mit Figur 41, S. 356).

21 Für die folgenden Ausführungen vgl. Sperl, 5o. Muhammad b. Saīì al-Būṣīīi (d. c. 1296): The Burda 389-411 (arabischer Text mit englischer Übersetzung) und 470-476 (Anmerkungen). Zur Qașidat al-Burda siehe ausserdem Homerin, al-Būṣīīi, in $E I^{3}$; Pinckney Stetkevych, From text to talisman: al-Būṣīî̀'s 'Qașīdat al-Burda'; al-Būṣīīī, Al-burda = (le manteau $)$, texte arabe traduit et commenté par H. Boubakeur.
Auch die zwei zumeist auf den beiden Seitenbändern entlang der Burda kopierten Suren 36 (Sürat Yā-sin) und 48 (Sūrat al-Fatḥ) weisen apotropäische Wirkung auf. Sure $Y \bar{a}-\sin$ bzw. Auszüge daraus lassen sich auf Amuletten häufig nachweisen. ${ }^{22}$ Sure $Y \bar{a}$-Sin befindet sich in der Mitte des Korans und ist deshalb als dessen Herz (Qalb alQur'ān) bekannt. ${ }^{23}$ Die Abschrift von Q 48 (al-Fath, Der Sieg) dürfte u. a. programmatischen Charakter haben und dem Träger der Rolle Erfolg im Kampf in Aussicht stellen. ${ }^{24}$

Es fällt auf, dass dieser zweite Rollenteil auf den beigezogenen Belegstücken nicht nur eine Kombination derselben Texte enthält, sondern auch weitgehend identisch gestaltet ist. Die folgende Beschreibung schenkt dem Dokument aus Zürich besondere Beachtung, auf dem dieser Abschnitt ca. $170 \mathrm{~cm}$ lang ist (inklusive Titelfeld von $2.3 \mathrm{~cm}$ Höhe; Авв. 137). Die Breite des Schriftspiegels beträgt $2.5 \mathrm{~cm}$. Jeder Vers wurde in einem Kästchen notiert, das gegenüber dem Rollenrand eine Neigung von etwa $45^{\circ}$ aufweist. In den Kästchen selbst verläuft der Text von rechts unten nach links oben. Durch die Neigung der Kästchen mit den Versen entstehen zur Linken und Rechten des Schriftspiegels kleine Dreiecke. Jeweils zwei Verse sind seitlich mit silbernen bzw. goldenen Dreiecken eingefasst. Auf der Zürcher Rolle wurde der Text der Qașidat al-Burda in voll vokalisiertem Gubār-Nash mit schwarzer Tinte kopiert.

Die Abschrift der Mantelode ist auf allen angeführten Belegstücken auf ganz ähnliche Weise ausgeführt worden. Es fällt jedoch auf, dass die Kästchen auf den Rollen aus Karlsruhe (АВв. 147) und Leipzig (АВВ. 143) deutlich steiler geneigt sind (ca. 60 $0^{\circ}$. Dieselbe Beobachtung trifft auf Cod.

22 Siehe dazu: Canaan, Decipherment 127-134, v.a. 129 (Abschnitt 2).

23 Vgl. op. cit. 131. Siehe ausserdem Bain, The late Ottoman En`am-ı şerif 53. Gemäss A. Bain handelt Q 36 auch ausführlich vom Jenseits. Es werde deshalb empfohlen, sie am Totenbett des Gläubigen zu rezitieren.

24 Zur Verwendung von Q 48 auf Talismanen vgl. Canaan, Decipherment 129.2. 
arab. 206 (München) ${ }^{25}$ und Cod. or. $8^{\circ} 83$ (Stuttgart) zu. Auch im zweiten Teil der Rolle aus dem Historischen Museum Budapest ist die Qașīdat al-Burda in Kästchen kopiert worden. Die Burda lässt sich überdies am Schluss des bereits erwähnten, deutlich einfacher ausgeführten Dokuments aus der Ungarischen Nationalbibliothek nachweisen. ${ }^{26}$ Die Verse des Gedichts sind in diesem Fall zwar nicht in die auf den Paralleldokumenten zu beobachtenden Kästchen notiert worden. Auch hier wurde jedoch die zuvor festgestellte Neigung des Texts beibehalten. Es sei bei dieser Gelegenheit in allgemeiner Form darauf hingewiesen, dass diese Schrägstellung von Textelementen den apotropäischen Charakter dieser Dokumente erhöhen soll.

\subsubsection{Zum ersten Teil der Rollen}

Der erste Teil der zu untersuchenden Rollen ist deutlich komplexer aufgebaut. Er enthält auf den einzelnen Belegstücken zahlreiche identische Elemente, die massgeblich zu ihrem hohen kunsthistorischen Wert beitragen. Nur die Rollen aus Karlsruhe, Stuttgart und München sind am Anfang vollständig oder nahezu vollständig erhalten. Bei den Belegstücken aus Zürich, Leipzig, Berlin und Budapest hingegen ist es zu Verlusten gekommen. Im Fall des Dokuments aus Berlin (Ms. or. oct. 403) sind sie bedeutend.

Die folgenden Ausführungen beschreiben diesen Anfangsteil der Rollen unter besonderer Beachtung des Zürcher Exemplars. Sie machen aber zugleich auf ähnliche Elemente oder zusätzliche Verzierungen auf den beigezogenen Vergleichsstücken aufmerksam. Stark vereinfacht formuliert lassen sich auf dem Zürcher Belegstück und - in zumeist modifizierter Form - auf den Paralleldokumenten fünf grössere Abschnitte mit den folgenden Hauptelementen erkennen: 1. Lanzetten und Zypressen; 2. Siegel (muhr) und Zel-

\footnotetext{
25 Ganz am Schluss dieser Münchner Rolle ein absichtlich verschmierter und jetzt unleserlicher Vermerk.

26 Ungarische Nationalbibliothek, Budapest, Duod. Arab. 5 (Ende).
}

lenvierecke (wafq); 3. Die Schönen Namen Gottes und die Löblichen Eigenschaften des Propheten; 4. Die Figur Šakl-i 'ayn-i 'alı̄ und 5. Gebete. ${ }^{27}$ 6. Ein letzter Teil der folgenden Beschreibung macht auf die Erwähnung der vier rechtgeleiteten Kalifen auf den beiden Belegstücken aus Berlin und Leipzig aufmerksam.

\subsubsection{Lanzetten und Zypressen}

Aus den erhaltenen Teilen lässt sich schliessen, dass das Grundmuster der Belegstücke aus Zürich und Berlin am Anfang grosse Ähnlichkeiten aufwies. Zu Beginn des Zürcher Dokuments lässt sich in der Rollenmitte eine lanzettenförmige Verzierung erkennen (Länge ca. $14.8 \mathrm{~cm}$; АВ B. 136). Auf ihrem silbergrauen Hintergrund steht in goldenen Buchstaben نصر من الله وفتح قريب وبشّر المؤمنين ئما محد 28 Die beiden Spickél, die sich nach einem ca. $0.3 \mathrm{~cm}$ breiten Leerraum gegen den Rollenrand hin anschliessen, sind mit einem floralen Rankenmuster verziert. An der Basis des ersten Zierfelds des Zürcher Dokuments lässt sich ein kuppelförmiges Ornament in den Farben Rot, Gold (bzw. Braun), Blau, Grün und Weiss feststellen, wie es auch von Anfangszierfeldern von Handschriften bekannt ist. Aus der Kuppelspitze heraus geht eine feine goldene Linie hervor, die auf die zuvor erwähnte Lanzette hinweist, damit aber nicht verbunden ist. Der Leerraum zur linken und rechten Seite der Zentralachse wird erneut durch ein florales Rankenmuster ausgefüllt. Unterhalb die-

27 Dieser Abschnitt weist ergänzend auf die Anrufung von Personen aus der islamischen Heilsgeschichte hin.

28 Auszug aus Q 61:13: „Nașr min al-Allāh wa-fath qarīb wabaššir al-mu'minīn yā Muhammad“ („Hilfe von Gott und naher Sieg. Verkünde frohe Botschaft den Gläubigen, o Muhammad!“). Auf dem Belegstück aus Berlin fehlt diese erste Lanzette jetzt. Auf dem Dokument aus dem Historischen Museum Budapest ist die Lanzette zwar vorhanden. Ob auch darauf Text stand, lässt sich aufgrund der schlechten Erhaltung nicht mit Sicherheit feststellen. Auf dem Karlsruher Exemplar lässt sich dieses Zitat in einem ersten Zierelement ebenso nachweisen (vgl. ausführlicher bei Anm. 30-33). Bain, The late Ottoman En'am-1 şerif 15 o (Anm. 87), macht darauf aufmerksam, dass sich Q 61:13 in der gesamten islamischen Welt häufig auf Waffen belegen lässt. 
ses ersten Abschnitts mit der Lanzette mit dem Auszug aus Q 61:13, schliesst sich ein Zierfeld (Höhe: ca. $10 \mathrm{~cm}$ ) an, auf dem sich auf neutralem Hintergrund zwei weitere, hier goldbraun ausgefüllte, Lanzetten erkennen lassen. Darauf sind in grüner Schrift Teile der šahāda notiert. ${ }^{29} \mathrm{Die}$ Zürcher Rolle wird gegen aussen im gesamten ersten Teil durch ein Zierband (Breite ca. $5 \mathrm{~mm}$ ) eingefasst, auf dem ein goldbraunes Zickzackband auf blauem Hintergrund hin- und herläuft. ${ }^{30}$

Auf dem Karlsruher Exemplar fällt die geringere Abstraktion der Zierelemente auf dem hier diskutierten Abschnitt auf (АВB. 148). Die darauf enthaltene erste Verzierung mit Teilen aus Q 61:13 ist nicht als Lanzette ausgeführt worden, sondern wird gemeinhin als Krone einer Zypresse interpretiert. ${ }^{31}$ In dieser Krone sind zusätzliche Textelemente enthalten: Dem Rand der Krone entlang ist Q 2:255 (Thronvers) notiert worden. ${ }^{32}$ Der Vers

29 Auf den beiden Lanzetten steht je der folgende Text: „Lā ilāha illā Allāh, Muhammad rasūl Allāh". An dieser Stelle setzt auch das am Rollenanfang fragmentarisch erhaltene Dokument aus Berlin ein. Die beiden Lanzetten stehen auf dem Berliner Parallelstück auf einem Hintergrund, der mit Text ausgefüllt ist. Auf der rechten Lanzette steht „Lā ilāha illā Allāh“; auf der linken Lanzette lässt sich noch entziffern „Yā hafiyyya l-alțāf [...]“, also: „O jener, dessen Wohltaten verborgen sind.“

Rolle aus Karlsruhe wird im ersten Teil ebenso von einer schmalen goldenen Zierleiste eingefasst, die $\mathrm{zu}$ beiden Seiten von zwei haarfeinen schwarzen Linien eingerahmt wird. Das Berliner Dokument weist hier eine abweichende Gestaltung auf, lassen sich in diesem Fall auf der Randleiste doch bereits am Rollenanfang Textstellen erkennen; dieselbe Beobachtung trifft auf Cod. or. $8^{\circ} 83$ (Stuttgart) und Cod. arab. 206 (München) zu. Auf den Belegstücken aus Zürich, Karlsruhe und Leipzig setzt der Text auf den beiden Randleisten jedoch erst im zweiten Rollenteil mit dem Beginn der Qașidat alBurda ein (vgl. dazu bereits bei Anm. 13 ff.).

31 Für die Identifikation dieser Verzierung mit einer Zypresse vgl. Petrasch, Die Karlsruher Türkenbeute 382 (Nr. 319). Siehe ausserdem: http://www.tuerkenbeute.de/ sam/sam_sch/RA204_O2_de.php. Die Gleichsetzung dieser Verzierung mit einer Zypresse ergibt sich ausserdem anhand der beiden Paralleldokumente Cod. or. $8^{\circ} 83$ (Stuttgart) und Cod. arab. 206 (München).

32 Zur häufigen Verwendung von Q 2:255 auf Schutzmitteln vgl. Canaan, Decipherment 131. beginnt nach einer hinzugefügten basmala an der linken Basis der Krone. Die letzten Wörter des Verses wurden aus Platzgründen im Innern der Krone notiert. Auf dem Stamm der Zypresse selbst steht die basmala. ${ }^{33}$

Auf dem Dokument aus Karlsruhe ruht die Krone der Zypresse auf einem Stamm, auf dessen mehrgliedrigen Aufbau im folgenden auf zwei Ebenen hingewiesen wird. In einem ersten Schritt wird die Gestaltung des Stamms von unten nach oben beschrieben. Anschliessend werden die auf dem Stamm enthaltenen Textstellen von oben nach unten erläutert.

Der eigentliche Stamm der Zypresse geht aus einer mehrgliedrigen, gelb-braunen Verzierung hervor. Ganz zuunterst lässt sich ein hügelförmiges Element erkennen. Darin steht die Überschrift zu einem Gitterviereck direkt darunter, das die 99 Schönen Namen Gottes enthält (АВв. 149). Nach oben schliessen sich zwei übereinander stehende, ineinander verschlungene Kreise an; der obere Kreis ist rot ausgefüllt. Nach einer vierteiligen, achsialsymmetrisch angeordneten Verzierung schliesst sich gegen oben eine Gruppe von drei sich überschneidenden Kreisen an. Der mittlere Kreis ist am grössten und rot ausgefüllt. Aus dieser Kreisgruppe wiederum geht die bereits erwähnte Zypresse mit Stamm und Krone hervor. ${ }^{34}$ Gemäss A. Fodor dürfte sie den Träger des Dokuments

33 Eine ganz ähnliche Gestaltung lässt sich auf den beiden Belegstücken aus Stuttgart (Cod. or. $8^{\circ} 83$ ) und München (Cod. arab. 206) feststellen. Auf dem Münchner Belegstück wurde der Thronvers dabei auf der rechten und linken Seite der Spitze der Zypresse ganz am Rollenanfang notiert.

34 Auf dem Karlsruher Belegstück wachsen aus dem Stamm der Zypresse rechts und links goldene tulpenartige Blüten hervor, die an das stilisierte Allāh im Emblem der Islamischen Republik Iran erinnern. Die goldenen Kelchblätter umrahmen den roten Stempel der Blüte. Über den Blüten ein freistehender goldener Strich, der sich als šadda interpretieren lässt. Zwei identisch gestaltete Tulpenblüten bereits links und rechts der Spitze der Zypresse. Sie wachsen aus einem länglichen Ornament heraus, in dem sich buchstabenähnliche Elemente erkennen lassen. $\mathrm{Ob}$ es sich um eine mehrfache Abfolge des Ausdrucks huwa („Er“, Gott) handelt, lässt sich nicht 
an eine Moschee erinnern. Neben Moscheebauten wächst häufig ein markanter Baum, bei dem es sich um eine Zypresse handeln kann. Sie ist immergrün ${ }^{35}$ und kann als Lebensbaum verstanden werden. ${ }^{36}$ Später soll auf eine alternative Interpretation dieses Baums hingewiesen werden, der sich einfacher ausgeführt ebenso auf den Paralleldokumenten nachweisen lässt. ${ }^{37}$

Auf dem Karlsruher Exemplar verläuft dem Rand der einander überschneidenden Kreise entlang ein Schriftband (АВв. 148). Der Text darin ist derart angeordnet, dass er beim Übergang vom oberen zum unteren Kreis die Seite wechselt. Eine identische Textanordnung lässt sich bereits auf deutlich früher entstandenen Rollen aus vermutlich mamlukischen Kontexten nachweisen, ist darauf allerdings komplexer ausgeführt worden. Das Gestaltungselement dieser sich überschneidenden Kreise lässt sich als Anspielung auf bzw. Reminiszenz an diese älteren Belegstücke verstehen. Es weist indirekt auch darauf hin, dass die hier untersuchten Rollen in ähnlichen sozio-religiösen Umfeldern entstanden sind wie diese früheren Parallelstücke. ${ }^{38}$

mit Sicherheit entscheiden. Ganz ähnliche Tulpenblüten auch am Anfang von Cod. or. $8^{\circ} 83$ (Stuttgart).

Auf Cod. arab. 206 (München) ist diese Zypresse in der Tat grün.

36 Hinweis von Prof. A. Fodor; mündliche Diskussion, Budapest, 11. Juni 2014 (Prof. A. Fodor ist leider am 4. August 2014 verstorben). A. Fodor stellt dieselben Überlegungen auch an in seinem Artikel „Types of Shīite amulets from Iraq" 198 (mit Abb. 11).

Dieselben Elemente (Hügel-Stamm-Krone) lassen sich in deutlich einfacherer Ausführung ebenso auf dem Belegstück aus dem Historischen Museum Budapest nachweisen. Darauf ist an dieser Stelle ein silberner Kreis zu erkennen, dessen unterstes Viertel abgeschnitten ist. Aus diesem Kreis heraus geht ein Stamm hervor, der die Krone der Zypresse trägt. Der Stamm ist sehr einfach gestaltet. Im silbernen Kreis lassen sich noch verblasste Konturen erkennen; ob es sich um Textelemente oder Verzierungen handelt, lässt sich aufgrund des schlechten Erhaltungszustands des Dokuments nicht entscheiden.

37 Vgl. dazu unten bei Anm. 175-19o.

38 Für weitere Belegstücke mit sich überschneidenden Kreisen wird verwiesen auf Universitätsbibliothek Basel, M III 173 (beschrieben in Schubert und Würsch, Hand-
Nach diesen Bemerkungen zur Gestaltung des Anfangsteils der Karlsruher Rolle ist auf die darin enthaltenen Textelemente hinzuweisen (АВB. 148): In der ersten Gruppe von drei Kreisen steht Q 1 (al-Fätiha). ${ }^{39}$ Das den Kreisrändern entlang verlaufende Schriftband enthält Q 1:1-5 und wechselt beim Übergang vom einen zum andern Kreis, wie erwähnt, die Seite. Die Schlussverse der Fātiḥa sind in der Mitte des zweiten bzw. dritten Kreises (Q 1:6-7a) und auf der rechten und linken Seite des darunter unmittelbar anschliessenden Zierelements eingefügt worden (Q 1:7b)..0 Auf dem nach unten anschliessenden Abschnitt, der zur nächsten Gruppe mit zwei Kreisen überleitet, lassen sich auf der Zentralachse die folgenden Anrufungen Gottes und Muhammads erkennen: Yā Allāh,

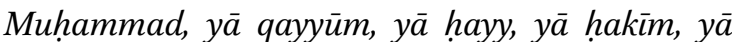
'alìm. ${ }^{41}$ Auf einem Textband steht in den beiden Kreisen darunter dem Rand entlang Q 112 (alIhlāss);42 auch hier wechselt das Schriftband beim Übergang vom einen zum andern Kreis die Seite. Im Mittelteil der beiden Kreise mit Q 112 und auf der hügelförmigen Verzierung an der Basis ist weiterer Text enthalten. Er dient - wie schon angetönt - als Überschrift zum nächsten Teil des Dokuments aus Karlsruhe und weist auf die 99 Schönen Namen Gottes hin. Diese Namen bzw. Eigenschaften Gottes werden in einem direkt anschliessenden Gitter-Viereck auch tatsächlich aufgeführt (АВB. 149). ${ }^{43}$

schriften 243-246 (Nr. 101) und hier Kapitel 4.8). Siehe ausserdem: Staatsbibliothek Berlin, Ms. or. oct. 218 (hier Kapitel 4.3; vgl. Ahlwardt, Verzeichniss I, Nr. 369; datiert 775/1373), 3. Paris, BNF, Arabe 6o88, um 1400 (hier Kapitel 4.5).

39 Vgl. dazu, Canaan, Decipherment 13 o.

40 Zur Linken und Rechten der Anrufung Yā Allāh, Muhammad; siehe gerade anschliessend.

41 Diese beiden zuletzt erwähnten Begriffe rechts bzw. links der Zentralachse. Die Ausdrücke qayyūm (der Beständige), hayy (der Lebendige), hakim (der Weise) und 'alīm (der Wissende) zählen zu den Schönen Namen Gottes. Mit Auslassung von yalid in Q 112:3 (Kopistenfehler).

Dieser Abschnitt mit den Schönen Namen Gottes und die Überleitung dazu werden erst später beschrieben (vgl. unten bei Anm. 9o-93). Auch Cod. arab. 206 (München) führt in zu einer einzigen Gruppe zusammengefassten 
Unmittelbar unterhalb der ersten Lanzette folgt auf dem Zürcher Exemplar ein weiterer Abschnitt mit einer Doppellanzette. ${ }^{44}$ Eine vergleichbare Verzierung lässt sich ebenso auf den Parallelstücken aus Karlsruhe und München erkennen, folgt darauf aber erst deutlich später kurz vor dem Beginn der Qașīdat al-Burda. Diese Verzierung ist auf dem Karlsruher Belegstück erneut in der Form von zwei Zypressen - hier mit goldenem Stamm und goldener Krone - ausgeführt worden. Sie werden von einem schmalen Streifen mit goldenem und braunem, im Mittelteil rot-silbrig-rotem, Hintergrund auseinandergehalten. Auf diesen beiden Zypressen und dem Mittelstreifen ist ein Gebet notiert worden. ${ }^{45}$

Während die beiden Dokumente aus Zürich und Karlsruhe ${ }^{46}$ unterhalb dieses ersten Zierelements mit der Inschrift von Q 61:13 bis zum Beginn der Qașidat al-Burda deutlich voneinander abweichen, lassen sich auf den zwei Belegstücken aus Zürich und Berlin erneut zahlreiche identische Elemente erkennen.

\subsubsection{Siegel (muhr) und Zellenvierecke (wafq)} Unmittelbar unterhalb des Rollenanfangs mit den lanzettenförmigen Verzierungen (Einzellanzette und Doppellanzette) schliesst sich auf dem Zürcher Dokument ein Abschnitt mit sechs Quadraten an; die Länge dieses Abschnitts misst insgesamt $32.0 \mathrm{~cm}$. Beim ersten Quadrat fehlt eine Überschrift; vier weitere Vierecke werden in einem Titelfeld jeweils als muhr (Siegel) bezeichnet. $^{47}$ Die ersten fünf Quadrate enthalten einen

fünf Kreisen Q 1 (al-Fātiḥa) und Q 112 (al-Ihlāṣs) auf. Die zur Fātiha gehörende basmala (mit vorangestelltem Lā ilāha illā Allāh, Muhammadun rasūl Allāh) steht auf dem Münchner Exemplar bereits im grünen Stamm der Zypresse.

44 Mit dieser Doppellanzette beginnt auch Ms. or. oct. 403 (Berlin), dessen eigentlicher Anfang verloren ist. Vgl. die Ausführungen zu diesem Gebet auf Cod. arab. 206 (München) in Anm. 111.

46 Mit seinem Parallelstück in München: Cod. arab. 206.

47 Auch das Belegstück aus dem Historischen Museum Budapest weist solche Titelfelder auf; der darin ursprünglich enthaltene Text ist aber nicht mehr zu erkennen.
Kreis als bedeutendstes Gestaltungsmerkmal. ${ }^{48}$ Die folgenden Ausführungen stellen die einzelnen Abschnitte näher vor (AB B. 138):49

a. Der erste Kreis (Durchmesser ca. $3.5 \mathrm{~cm}$ ) ist in ein goldenes Quadrat eingepasst worden. In der Mitte des Kreises lässt sich eine Blüte mit sechs mandelförmigen roten Blättern erkennen; sie sind goldbraun umrandet. ${ }^{50}$ In den Leerräumen zwischen den sechs Blättern wurde der Ausdruck Allāh abwechselnd in roter und blaugrüner Tinte notiert. Dem Kreisrand entlang verläuft ein Band,

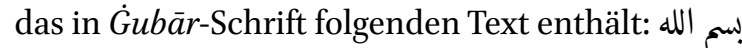
الرحمن الرحيم يا محمد لولاك لولاك لما خلقت الافلاكُ إنك على على

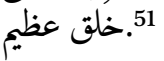

48 Eine Abfolge von fünf Kreisen lässt sich ebenso auf dem Belegstück aus Berlin nachweisen. Bain, The late Ottoman En`am-1 şerif 108f. (auch 232), weist auf die von Mystikern vertretene Auffassung hin, dass die Quadrate die Erde symbolisieren, während der Kreis den Himmel darstelle (mit Verweis auf Ardalan und Bakhtiar, Sense of unity 29).

49 Ergänzend wird auf die Darstellung von Siegeln (muhr) in En'am-ı şerif-Handschriften hingewiesen; siehe dazu Bain, The late Ottoman En'am-ı şerif 99-114.

5 ○ Für ähnlich gestaltete Blüten vgl. München вsв, Cod. arab. 207. Es könnte sein, dass diese hier als Blüte beschriebene Figur eine von oben betrachtete Derwischmütze darstellen soll; dazu sind allerdings weitere Abklärungen anzustellen.

51 Also: „Im Namen Gottes, des barmherzigen Erbarmers. O Muhammad, wenn du nicht gewesen wärst, hätte ich [Gott] die Himmelssphären nicht erschaffen; du hast wahrlich einen erhabenen Charakter." Bei dieser Aussage handelt es sich um einen hadīt qudsī; siehe dazu u.a. van Ess, Theologie und Gesellschaft IV, 456 (mit Anm. 103). J. van Ess bezeichnet diese Aussage als berühmtes, aber offensichtlich spätes Prophetenwort (hadīt qudsī) und verweist auf Furūzānfar, 172 (Nr. 546), und Schimmel, Prophet 114. Weitere Hinweise zu diesem hadīt finden sich unter: http://vb.tafsir.net/forumı/thread 31924 -print.html.

Dieser hadīt qudsī lässt sich ebenso auf dem äussersten Schriftband des ersten Kreises auf der Rolle aus Berlin erkennen (Bl. 4 auf dem Mikrofilm zur Rolle). Die Inschrift endet in diesem Fall nach al-aflāka aber abweichend mit Là ilāha illā Allāh Muhammad rasūl Al[lāh] (šahāda); die šahāda auch auf dem nächsten Schriftband nach innen. Auf dem Berliner Exemplar folgt im Zentrum ein Kreis mit dem Text: Wa-nunazzilu min al-Qur'āni mā huwa šifäun wa-rahmatun li-l-mu'minīn (Q 17:82); zum Gebrauch dieses Koranverses als Schutz gegen körperli- 
b. Auf der Zürcher Rolle folgt ein querliegendes, weinrot umrandetes Rechteck, das in einer Kartusche die Überschrift Muhr-i rasūl („Siegel des Gesandten“) enthält; das Siegel selbst schliesst sich darauf unmittelbar an (Länge dieses Abschnitts: $5.5 \mathrm{~cm})$. Im darin enthaltenen Kreis lassen sich zwei konzentrisch angeordnete Schriftbänder und in deren Zentrum Text auf drei waagrechten Zeilen erkennen. Der Text auf dem äussersten Schriftband lautet: لا اله الا الله محمد رسول الله لا اله الله الله الله الله الله

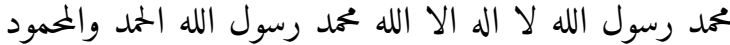
52 Auf dem inneren Schriftband steht:

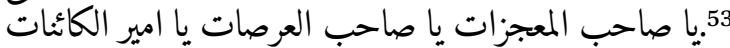
Im Kreis in der Mitte wurde auf drei horizontalen Linien (1. Linie rot, 2. blaugrün, 3. rot) der folgende يا سيد الاولين | يا :Text zum Lob Muhammads notiert 54.سيد الآخرين ا يا خاتم النبيين

c. Besondere Beachtung verdient der nächste Abschnitt auf dem Zürcher Dokument (Länge: $5.6 \mathrm{~cm}$ ). Er enthält in einem querliegenden, grün umrandeten Rechteck in einer Kartusche die Überschrift Muhr-i Sulaymān („Siegel Salomons“). Auf dem goldenen Hintergrund des Quadrats lässt sich ein Kreis erkennen, in den ein Hexagramm (sechsstrahliger Stern bzw. Salomonssiegel) eingefügt

che Krankheiten siehe Bain, The late Ottoman En'am-1 şerif ${ }_{103}$ f. Siehe ausserdem Canaan, Decipherment 131, der auf die Āyāt aš-šifä’ im Koran hinweist. Sie enthalten jeweils einen Ausdruck, der sich vom Verb šafā („heilen“) ableitet. Es sind dies gemäss T. Canaan: Q 9:15, 10:57, 16:69, 17:82, 26:8o, 41:44. Auf dem Berliner Belegstück ist dieses erste Kreiselement mit der Überschrift Muhrī (sic) hātim an-nubuwwat versehen. Zum Hätim an-nubuwwa (Siegel der Prophetschaft) siehe auch Bain, The late Ottoman En`am-ı şerif 94-96. Während die von ihr beschriebenen Hātim an-nubuwwa tränenförmig sind, sind sie auf den vorliegend untersuchten Rollen rund.

handelt sich um eine Wiederholung der šahāda (drei Mal) und ein Lob auf Muhammad am Schluss.

53 Also: „O Herr der Machtwunder, o Herr der Schlachtfelder, o Befehlshaber der Geschöpfe." Kazimirski, Dictionnaire, gibt für den Begriff 'arașa u.a. die Bedeutung an: [4.] „Champ de bataille, arène, et toute place où se donne quelque spectacle." Taeschner, Zünfte und Bruderschaften 466, übersetzt den Ausdruck ehl-i 'arșāt mit „die auf dem Gerichtsfeld Versammelten“.

54 Also: „O Herr der Ersten, o Herr der Letzten, o Siegel der Propheten." worden ist. Während die sechs Strahlen des Sterns rot sind, sind das Zentrum des Sterns und die Zwischenräume zwischen den Strahlen neutral belassen worden. Im Zentrum steht auf drei Zeilen (rot-

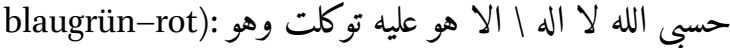

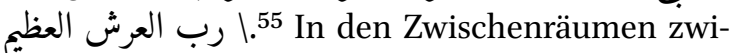
schen den sechs Strahlen des Sterns sind Stellen aus dem Koran kopiert worden, die auf Salomon und besonders auf seine Begegnung mit der Königin von Saba anspielen. Die Einleitung kennzeichnet den Text als Zitat aus dem Koran und hält fest: قال الله سبحانه تبارك وتعالى Der Text fährt im nächsten

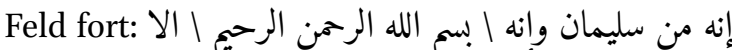
年 ${ }^{56}$ Es schliesst sich im fünften und sechsten Zwischenraum der folgende Text an: 57. وبه نستعين لا حول ولا قوت \الا بالله العلى العظيم

Das soeben geschilderte Hexagramm lässt sich ebenso auf dem Dokument aus dem Historischen Museum Budapest belegen (АВ В. 157). Die sechs Strahlen des Sterns sind hier golden. Der im Stern und darum herum enthaltene Text ist allerdings derart stark verblasst, dass er sich kaum mehr entziffern lässt. Ein Hexagramm ist ausserdem auf zwei hier nicht näher berücksichtigten Belegstücken aus München nachweisbar (АВB. 16o). ${ }^{58}$

55 Q 9:129 (Schlussvers von Q 9): „Allāh, ausser dem es keinen Gott gibt, ist mir Genüge. Auf ihn baue ich mein Vertrauen. Er ist der Herr des gewaltigen Throns." Auf Rollen wird die aus der islamischen Mystik bekannte Vorstellung des bedingungslosen Vertrauens auf Gott (tawakkul) wiederholt thematisiert: vgl. so auch auf Ms. or. oct. 146 (Staatsbibliothek Berlin; hier Kapitel 5.1), das aus einem safawidischen Kontext stammt. Zum Konzept des tawakkul siehe Reinert, Die Lehre vom tawakkul. Auch En'am-ı şerif-Handschriften machen auf den tawakkul aufmerksam; vgl. Bain, The late Ottoman En‘am-1 şerif 121 (Anm. 71), 245 (Anm. 92), 294 (Anm. 175). Zur Frage siehe ebenso bei Anm. 130 und 245

56 Q 27:30-31: „Wahrlich, der [Brief] ist von Salomon und beginnt: ,Im Namen Gottes, des barmherzigen Erbarmers!' Erhebt euch nicht gegen mich, und kommt als Gottergebene zu mir!“

57 „Und [Gott] ersuchen wir um Hilfe (vgl. Q 1:5). Es gibt keine Macht und keine Kraft ausser bei Gott, dem Erhabenen, dem Gewaltigen."

$5^{8}$ 1. Cod. arab. 205 (Anfang der Rolle), und 2. Cod. arab. 207, rechte Spalte, gegen Schluss der Rolle. Auf diesem zweiten Münchner Dokument ist im Innern des Hexagramms 
Überdies ist dieses Element auf der Rolle aus Berlin enthalten; die Überschrift lautet in diesem Fall Muhrī (sic) Sulțān Sulaymān. ${ }^{59}$ Während die Achse des Sterns auf dem Zürcher Dokument genau vertikal ausgerichtet ist, ist sie auf dem Belegstück aus Berlin leicht nach rechts geneigt.

Wenn dieser Stern auf der Karlsruher Rolle auch fehlt, ist Salomon darauf doch zumindest implizit präsent, wie sich aus einem in ein goldenes Quadrat eingefügtes Medaillon ergibt. Darin ist in goldener Schrift der bereits auf dem Zürcher Vergleichsstück belegbare Auszug aus Q 27:30 notiert. ${ }^{60}$ Ein Hexagramm oder eine explizite Erwähnung Salomons fehlt zwar auf B. or. 328 (Leipzig). Es fällt jedoch auf, dass sich auf diesem Belegstück eine Figur mit der Unterschrift Muhr$i$ Bilqīs nachweisen lässt. ${ }^{61}$ Bilqīs ist der arabische Name der Königin von Saba, auf deren Begegnung mit Salomon die auf den Rollen aus Karlsruhe und Zürich kopierten Koranverse anspielen. ${ }^{62}$

Diese Anspielungen auf Salomon und seine Begegnung mit der Königin von Saba sind auf den untersuchten Dokumenten wohl nicht zufällig eingefügt worden. Denn der bereits aus der Bibel bekannte Salomon gilt in der islamischen

auf sechs Zeilen eine Abfolge von Ziffern in roter Tinte angebracht worden. Derartige Folgen von Ziffern haben oft eine tiefere Bedeutung; vgl. dazu Canaan, Decipherment $162 \mathrm{f}$.

59 Auch auf dem Dokument aus Berlin lässt sich verteilt auf vier Zwischenräume zwischen den Strahlen des Sterns Q 27:30-31 erkennen (leicht fehlerhaft kopiert). Es schliesst sich in den beiden verbleibenden Zwischenräumen und im Zentrum Q 112 (al-Ihlās) an. Bain, The late Ottoman En'am-ı şerif 114-117, macht auf Abbildungen von Hexagrammen (auch Pentagrammen und Heptagrammen) in En'am-ı şerif-Handschriften aufmerksam (siehe auch op. cit. 241).

6o Also: إنه من سليمان وانه بسم الله الرحمن الرحيم. Unmittelbar darunter lässt sich auf dem Karlsruher Exemplar ein mit Wafq-i Ihlās (allenfalls irrtümlich falsch kopiert) überschriebenes Zellenquadrat erkennen, in dem die ebenso auf dem Berliner Dokument enthaltene Q 112 notiert worden ist (siehe zu diesem Quadrat unten bei Anm. 81-83).

61 Dieses Siegel (muhr) enthält in einem Kreis eine Abfolge von Ziffern (schwarz) auf fünf Zeilen (silbern).

62 Vgl. oben bei Anm. 56 und 6 o.
Welt nicht nur als ausserordentlich mächtiger Herrscher über die Menschen, sondern er wird im gesamten islamischen Kulturraum auch als Bezwinger der Dämonen geschätzt. ${ }^{63}$ Es lässt sich aufzeigen, dass auch Bilqīs einen dämonischen Charakter hat. ${ }^{64}$

Wenn die untersuchten Rollen mehrfach Hinweise auf Salomon enthalten, appellieren sie damit auch an ihn als Beschützer vor Widrigkeiten aller Art, mit denen sich der Mensch im Alltag konfrontiert sieht. Diesem Machthaber ist es gelungen, die Dämonen (ğinn) zu unterjochen, die als Urheber von allerhand Übel ebenso bekannt wie gefürchtet sind. Wenn die Dämonen auch grundsätzlich als moralisch neutral gelten, sind sie dem Menschen zumeist eben doch eher unangenehm. Sie sind gemäss einem traditionalistischen Verständnis die Verursacher von Krankheiten ganz allgemein. Sie lassen den Menschen einerseits an ğinnitis erkranken, worunter in erster Linie Geisteskrankheiten zu verstehen sind. Anderseits finden sich vielfach Hinweise darauf, dass sie für Seuchen und Epidemien, ganz speziell Pestzüge ( $t \bar{a} \bar{u} n)$, verantwortlich sind. 65

d. Auf dem Zürcher Dokument folgt nach dem Hexagramm in der Tat ein Abschnitt (Länge: $5.6 \mathrm{~cm}$ ) mit der Überschrift Barāy-i țā ūn (Gegen die Pest). ${ }^{66}$ Ein Abschnitt mit dieser Überschrift lässt sich ebenso auf dem Berliner Dokument nachweisen, folgt dort aber später und ist gänzlich anders gestaltet. ${ }^{67}$ Diese beiden Belegstücke schützen ihren Träger damit explizit gegen die Pest. Auf

63 Die Prophetenlegenden (Qișaș al-anbiy $\bar{a}$ ) und weitere textliche Quellen thematisieren Salomons Rolle als Beschützer gegen allerhand Übel vielfach; vgl. dazu Nünlist, Dämonenglaube, Kapitel 10: „Salomon: Kämpfer wider alles Dämonische“.

64 Vgl. Nünlist, Dämonenglaube, Kapitel 10.5 „Bilqīs, die Königin von Saba, in nachkoranischen Quellen“ 464-48o.

65 Nünlist, Dämonenglaube 27of.

66 Diese Überschrift in einem querliegenden, orange umrandeten Rechteck in einer Kartusche mit floralem Rankenmuster auf blauem Hintergrund. Obwohl es sich auch hier um eine Kreisfigur handelt, wird dieses Element nicht explizit als muhr (Siegel) bezeichnet.

67 Vgl. Mikrofilm zur Berliner Rolle: Bl. 11-12. 
dem Zürcher Exemplar ist an dieser Stelle der folgende Text in $\dot{G} u b \bar{a} r$-Schrift auf zwei konzentrischen Bändern und einem Kreis im Zentrum ent-

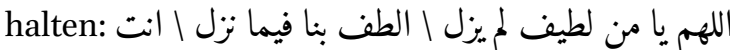

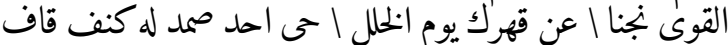

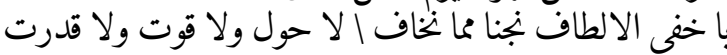
68. الا بالله العلى العظيم ولات

e. Es schliesst sich auf dem Zürcher Belegstück ein nächster Abschnitt mit der Überschrift Muhr-i 'azizz an (Länge: $5.7 \mathrm{~cm}$ ). ${ }^{69}$ Darunter befindet sich in einem goldenen Quadrat ein Kreis mit silbernem Hintergrund. Darin lässt sich ein Quadrat mit $5 \times 5$ Zellen erkennen, in die Textelemente eingefügt worden sind. Der Text ist auf den Horizontalen des Quadrats abwechselnd rot und blaugrün geschrieben (1., 3. und 5. Horizontale: rot; 2. und 4. Horizontale: blaugrün). In den einzelnen Zellen sind Anrufungen Gottes notiert, die je durch ein Bismi [A]llāh eingeleitet werden. ${ }^{70}$ Es schliesst sich auf dem Zürcher Dokument ein weiterer, ähnlich gestalteter Abschnitt an (Länge: $5.8 \mathrm{~cm}$ ), dessen Titel muhr-i šarîf lautet. ${ }^{71}$ Bei diesem Siegel (muhr) handelt es sich erneut um ein Zellenquadrat mit $5 \times 5$ Zellen, das identisch gestaltet ist wie

68 In nicht ganz korrektem Arabisch: „O Gott, o Gütiger, der nicht aufhört. Sei gütig gegenüber uns in dem, was vom Himmel herabkommt! Du bist der Kräftige. Errette uns vor deiner Gewalt am Tag der Störung (? yawm al-halal)! Lebendiger, Einziger, Ewiger. Dem die Flanke des Bergs Qāf gehört (?). O jener, dessen Wohltaten verborgen sind. Errette uns vor dem, was wir fürchten! Es gibt keine Macht und keine Kraft ausser bei Gott, dem Erhabenen, dem Gewaltigen."

69 Diese Überschrift in einem querliegenden, orange umrandeten Rechteck in einer Kartusche mit floralem Rankenmuster auf blauem Hintergrund. Ein Muhr-i 'azizz auch auf dem Berliner Dokument; dort handelt es sich aber um eine kreisförmige Figur.

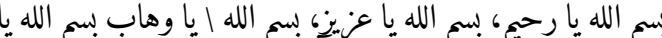

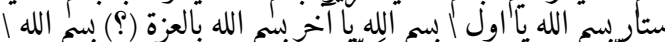

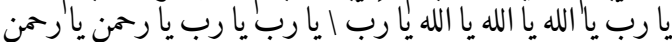
يا رحمن Es handelt sich um Ánrufungen Gottes, dié auf einzelne seiner Qualitäten aufmerksam machen.

Diese Überschrift in einem querliegenden, grün umrandeten Rechteck in einer Kartusche mit floralem Rankenmuster auf blauem Hintergrund. Ein Muhr-i šarif auch auf dem Belegstück aus Berlin; es handelt sich dort aber um ein kreisförmiges Element. das soeben beschriebene. Auch es enthält mehrere Anrufungen Gottes.

Zellenquadrate von der Art der beiden soeben angeführten Beispiele lassen sich auch auf dem Vergleichsstück aus Berlin nachweisen. Auch dort handelt es sich um Quadrate mit $5 \times 5$ Zellen; sie enthalten ähnliche Anrufungen Gottes wie das Zürcher Dokument. Diese Figuren mit Zellenquadraten sind dort den als Muhr-i šarîf bzw. Muhr-i 'aziz bezeichneten Siegeln als selbständige Elemente unmittelbar nachgestellt und mit den Überschriften Muhr-i lațîf bzw. Yavuzluqdan emin olmaq-icün ${ }^{72}$ versehen. Auf dem Belegstück aus Leipzig (B. or. 328) folgt unterhalb einer als Šakl-i 'ayn-i 'alī bekannten Figur ${ }^{73}$ eine Serie von drei Kreisen. In den ersten Kreis (Durchmesser ca. $2.1 \mathrm{~cm}$ ) wurde ein Quadrat mit $4 \times 4$ Zellen eingepasst, in welchen sich einzelne Anrufungen Gottes erkennen lassen. ${ }^{74}$

Auf den beiden Belegstücken aus Karlsruhe und München lassen sich zwar keine Zellenquadrate feststellen, allerdings enthalten beide Dokumente zwei Rechtecke mit Zellen. Auf Cod. arab. 206 (München) lässt sich zuerst ein Rechteck mit der Überschrift Wafq Hayy Qayyūm in roter Tinte erkennen. Darunter folgt ein Rechteck mit $3 \times 8$ Zellen (АВв. 152). ${ }^{75}$ In jede Zelle wurde in roter

72 „Um sich der Strenge [des Muts, der Tapferkeit] sicher zu sein.“ Die Entzifferung der Überschrift ist nicht gänzlich gesichert. Der Verfasser dankt PD Dr. Tobias Heinzelmann, Asien-Orient-Institut, Universität Zürich, für diesen Lesevorschlag.

73 Vgl. dazu unten 6.2.2.4 (bei Anm. 103), und 6.3.1 „Die Figur Šakl-i 'ayn-i 'alı̈', bei Anm. 118-163.

74 In den einzelnen Zellen stehen die folgenden Begriffe (häufig unpunktiert): 1. Zeile: Yā Allāh, al-Fattāh, arRazzāq, al-Fattāh. 2. Zeile: al-Qahhār, ar-Rāziq, al-Miftāh (?), yā Allāh; 3. Zeile: al-Fattāh, ar-Rāziq, al-Qahhār, alFattāh; 4. Zeile: al-Qahhār, ar-Razzāq, al-Fattāh (?), yā Allāh. Diese Ausdrücke zählen zu den Schönen Namen Gottes: al-Fattāh (der den Sieg verleiht), ar-Rāziq und $a r-R a z z \bar{a} q$ (der den Lebensunterhalt verleiht), al-Qahhār (der Bezwinger). In den Kreissegmenten ausserhalb dieses Zellenquadrats stehen die Namen der vier rechtgeleiteten Kalifen mit ihren Beinamen (vgl. unten 6.2.2.6, bei Anm. 112-117).

75 Horizontal $\times$ vertikal. 
Tinte auf neutralem Hintergrund ein einzelner Buchstaben der beiden Begriffe hayy und qayyūm notiert, die zu den Schönen Namen Gottes zählen. ${ }^{76}$ Die einzelnen Buchstaben der beiden Gottesnamen sind verstellt worden und folgen somit nicht direkt aufeinander. Unmittelbar darunter schliesst sich auf dem Münchner Belegstück ein identisch gestaltetes zweites Rechteck an, das $3 \times 7$ Zellen zählt und mit Wafq hafız überschrieben ist. Auch der Ausdruck hafız, („der Bewahrende“) zählt zu den Schönen Namen Gottes. ${ }^{77}$

Ein Wafq Hafız lässt sich ebenso auf dem Karlsruher Dokument nachweisen und folgt dort in Anschluss an den Abschnitt mit der Doppelzypresse. ${ }^{78}$ Dieses Wafq-Rechteck liegt hier quer und zählt $6 \times 3$ Zellen. ${ }^{79}$ Die einzelnen Buchstaben des Ausdrucks hafiz sind in Zellen mit rotem, goldenem und silbernem (jetzt oxydiert) Hintergrund geschrieben worden. ${ }^{80}$ Das zweite ZellenRechteck folgt unmittelbar auf das Medaillon mit Q 27:30. Es enthält in Übereinstimmung mit seiner Überschrift Wafq-i Ihlāṣ eine Abschrift von Q 112 (al-Ihlās ); die einzelnen Begriffe der Sure sind in die $6 \times 3$ Zellen $^{81}$ dieses Rechtecks verteilt. ${ }^{82}$ Die angeschnittenen Zellen einer zusätzlichen obersten Zeile sind leer. Ein Abschnitt mit der Überschrift Wafq-i Ihlāṣ lässt sich in modifizierter Ausführung auch auf Cod. or. $8^{\circ} 83$ (Stuttgart) feststel-

76 Der Ausdruck hayy bedeutet „der Lebendige“, qayyūm "der Beständige“.

Horizontal $\times$ vertikal. Canaan, Decipherment 131, macht auf die Āyāt al-hifž im Koran aufmerksam, die jeweils einen Begriffen enthalten, der sich vom Verb hafaza („bewahren“) ableitet.

78 Vgl. vor Anm. 110.

79 Horizontal $\times$ vertikal.

8o Darunter steht in senkrecht zur Rolle angebrachten Begriffen Q 112 (al-Ihlāṣ, mit Kopistenfehler). Q 112 ist damit auf dem Karlsruher Dokument insgesamt drei Mal enthalten; für die beiden andern Stellen siehe bei Anm. 42 und 82. Bain, The late Ottoman En'am-1 şerif 54, weist darauf hin, dass die Rezitation von Sure 112 allein jenes Verdienst verleiht, das man durch das Lesen eines Drittels des Korans erlangt.

81 Horizontal $\times$ vertikal.

82 Der Hintergrund der einzelnen Zellen ist rot, gelb, braun und silbern (oxydiert). len, wo der Text in auf der Spitze stehende quadratische Zellen eingefügt worden ist (АВ В. 155). ${ }^{83}$

Ein Rechteck mit $3 \times 10$ Zellen (Breite $\times$ Höhe) lässt sich überdies direkt unterhalb der Zypresse am Anfang des Dokuments aus dem Historischen Museum Budapest erkennen. Um das Rechteck herum selbst läuft ein schmales Schriftband. Über diesem Rechteck lässt sich eine rot umrandete Kartusche feststellen, in der vermutlich eine Überschrift enthalten war; sie lässt sich jetzt allerdings nicht mehr entziffern. Auch die restlichen Textelemente auf diesem Abschnitt sind derart stark verblasst, dass sich ihr Inhalt nicht mehr mit Sicherheit erkennen lässt.

Derartige Zellenvierecke sind als wafq (auch wifq) bekannt. ${ }^{84}$ Diese Figuren sind zumeist als Quadrate angeordnet, wie dies auf dem Zürcher Exemplar ${ }^{85}$ und auf dem Belegstück aus Leipzig auch tatsächlich der Fall ist. Sie lassen sich häufig in Dokumenten magischen Inhalts nachweisen. Man unterscheidet dabei zwischen wafq 'adadī und wafq harfi, Zahlen- und Buchstabenquadraten. Auf den vorliegenden Dokumenten lassen sich allerdings nur Zellenvierecke mit Textelementen feststellen. Magische Quadrate stricto sensu fehlen darauf gänzlich. ${ }^{86}$

\subsubsection{Die Schönen Namen Gottes und die} Löblichen Eigenschaften des Propheten

Auf dem Zürcher Dokument folgen darauf zwei weitgehend identisch gestaltete längere $\mathrm{Ab}$ schnitte, die mit den Überschriften Asmäà al-husnā (sic, Länge: $14.9 \mathrm{~cm}$; 3a) bzw. Hilya-i rasūl (Länge: $17.0 \mathrm{~cm} ; 3 \mathrm{~b})$ versehen sind.

83 Diese Figur geht auf der Rolle aus Stuttgart dem Abschnitt mit den Löblichen Eigenschaften Muhammads (Hilya-i šarīf) unmittelbar voraus; vgl. zu diesen Eigenschaften hier anschliessend 6.2.2.3 (bei Anm. 94-101).

84 Vgl. Sesianao, Wafk, in $E I^{2}$.

85 Vgl. bei Anm. 69-71.

86 Magische Quadrate zeichnen sich dadurch aus, dass die Summe der auf jeder Horizontalen, Vertikalen und auf den beiden Hauptdiagonalen des Quadrats aufgeführten Zahlen identisch ist (vgl. Anm. 84, Artikel von J. Sesiano). 
3a. Der erste Abschnitt mit der Überschrift Asmā' al-husnā (sic) enthält die Schönen Namen Gottes, ${ }^{87}$ die wegen ihrer apotropäischen Wirkung geschätzt werden (ABB. 139). ${ }^{88}$ Darunter schliesst sich ein Rechteck mit kleinen, auf der Spitze stehenden Quadraten an. Beim Betrachten erinnert diese Gestaltung an ein Gitter. Das Rechteck enthält auf je zwei Zeilen abwechselnd 3 bzw. 4 ganze Quadrate, in die auf neutralem Hintergrund jeweils einer der Schönen Namen Gottes eingefügt wurde (insgesamt 108 Quadrate mit je einem Begriff in feiner schwarzer Schrift). ${ }^{89}$ Die angeschnittenen, auf der Spitze stehenden halben Quadrate dem Rand des Rechtecks entlang haben einen goldbraunen Hintergrund. Der Schreiber hat beim Kopieren der Begriffe in den einzelnen Quadraten jeweils die Schriftrichtung geändert. Während die Schrift im ersten Quadrat von rechts unten nach links oben verläuft, wurde das nächste Wort von rechts oben nach links unten notiert. Durch diese Anordnung sind die einzelnen Aus-

87 Diese Überschrift selbst ist in einer Kartusche mit floralem Rankenmuster auf blauem Hintergrund in einem querliegenden, orange umrandeten Rechteck enthalten.

88 Der Koran hält fest (Q 7:180): „Die Schönsten Namen sind Gottes, Ruft ihn dabei an!“ولله الاسماء الحسنى فادعوه بها. Zum Konzept der Schönen Namen Gottes siehe: Canaan, Decipherment 135f.; Bain, The late Ottoman En`am-1 şerif 59-61; Anawati, Nom suprême de Dieu. Die Schönen Namen Gottes spielen auch bei Būnī (gest. 1225 oder 1232) eine wichtige Rolle; vgl. El-Gawhary, Die Gottesnamen. Siehe auch Hamès, al-Būnī, in $E I^{3}$.

89 Üblicherweise sind Listen mit 99 Schönen Namen im Umlauf. In den ersten 5 Quadraten steht vorliegend als Einleitung Huwa Allāh / allad̄ī / lā ilāha / illā /huwa. Darauf beginnt die eigentliche Aufzählung der Schönen Namen. Es ist nicht unüblich, dass diese Aufzählungen mehr als die zu erwartenden 99 Schönen Namen enthalten (vorliegend also 103). Die Abweichung dürfte sich damit begründen lassen, dass beim Anfertigen der Rollen ein befriedigender ästhetischer Eindruck höher gewichtet wurde als inhaltliche Aspekte. Dies lässt sich selbst auf Koranrollen beobachten, auf denen häufig Versteile wiederholt werden, um freien Raum auszufüllen. Auch Bain, The late Ottoman En'am-1 şerif 61, macht darauf aufmerksam, dass oft mehr als 99 Schöne Namen Gottes aufgezählt werden (mit Hinweis auf Padwick, Muslim devotions 104-106). drücke in den Diagonalen in jeweils derselben Schriftrichtung enthalten. ${ }^{90}$

Die Schönen Namen Gottes sind auf der Rolle aus Karlsruhe in einem ähnlich gestalteten Gitterfeld aufgeführt (АВВ. 149). Es steht auf diesem Belegstück allerdings bereits deutlich näher am Rollenanfang. Die Schönen Namen folgen hier nach einer halbkreisförmigen Überleitung an der Basis der Zypresse am Beginn des Dokuments. In diesen Halbkreis ist als Überschrift zum anschliessenden Gitterviereck mit den Schönen Namen Gottes der folgende Text eingefügt worden:

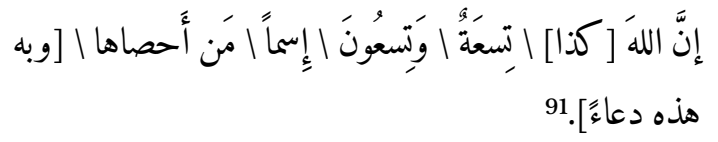

90 Zur Änderung der Schriftrichtung vgl. auch nach Anm. 98: Oft sind Textstellen auch schräg bzw. geneigt kopiert worden, wie dies vorliegend bei der Burda der Fall ist (vgl. bei Anm. 24-26).

91 Derselbe Text ist als Überleitung zum Abschnitt mit den Schönen Namen Gottes auch auf Cod. arab. 206 (München) nachweisbar. Die drei Ausdrücke in eckigen Klammern nur auf dem Karlsruher Dokument; dies in fehlerhaftem Arabisch. Dieser Text spielt auf folgendes Prophetenwort an, das auf einem hier nicht näher untersuchten Parallelstück aus Stuttgart vollständig aufgeführt wird (Cod. or. $\left.8^{\circ} 34\right)$ :

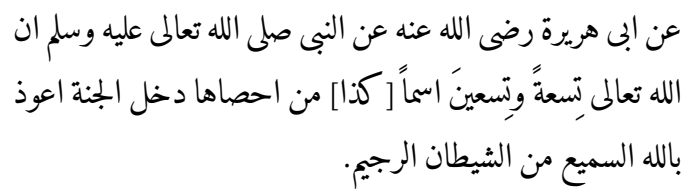

Also: „Von Abū Hurayra - vom Propheten: ,Gott hat 99 Namen. Wer sie aufzählt, wird ins Paradies eingehen. Ich suche Zuflucht bei Gott, dem Hörenden, vor Satan, dem Gesteinigten'“ Zu diesem Prophetenwort siehe auch Bain, The late Ottoman En'am-ı şerif, 59 (mit Anm. 54, und S. 206). Das Prophetenwort lässt sich nachweisen bei Buhārī, Șaḥịh, Kitāb aš-šurūț, Bāb 18, Nr. 2585. Es lautet hier:

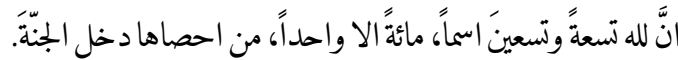

Vgl. auch Buhārī, Șaḥịh, Kitāb at-tawhīd, Bāb 12, Nr. 2957 (al-Buhārī, Șahịḥ; Hg.: Muṣțafā Dīb al-Bugàā. Bayrūt, 1410 h.q./1990). Siehe Tirmid̄ī, Sunan, 44 Kitāb ad-da'wāt, Bāb 86, Hadīt 3847 (Liechtenstein, Thesaurus Islamicus Foundation, 2000). 
Die Beinamen Gottes sind danach in auf der Spitze stehenden Quadraten notiert. Auch hier weisen die meisten Felder einen neutralen Hintergrund auf; es lassen sich aber auch Quadrate erkennen, die rot, golden und silbern (jetzt oxydiert) ausgefüllt sind. Dieser Abschnitt enthält insgesamt 344 Quadrate. ${ }^{92}$ Neben den eigentlichen Schönen Namen sind auch Anrufungen Gottes notiert (z.B. $y \bar{a}$ rabbi). Überdies enthalten mehrere Quadrate bloss einen einzelnen Buchstaben. Dies erklärt, dass die Anzahl der Quadrate (344) in diesem Fall die 99 Schönen Namen Gottes deutlich übersteigt. Es fällt ausserdem auf, dass die Schrift hier in sämtlichen Feldern von rechts unten nach links oben verläuft.

Besonders aufwendig ist der Abschnitt mit den Schönen Namen Gottes auf B. or. 328 (Leipzig) gestaltet (АВ В. 144). ${ }^{93}$ Darauf sind die Namen Gottes in 118 Kästchen (auf der Spitze stehende Parallelogramme) festgehalten worden. Die Kästchen sind farbig ausgefüllt (grün, blau, silbern, gelbbraun, golden) und werden durch die goldenen Einfassungen der einzelnen Parallelogramme voneinander getrennt. Ein ähnlich gestaltetes Gitter mit den Schönen Namen Gottes ist ebenso auf dem Vergleichsstück aus Berlin enthalten, folgt dort allerdings etwas später. Die beschriebenen Quadrate mit neutralem Hintergrund und die farbigen Felder sind auf dem Berliner Exemplar abweichend angeordnet; dies verändert auch den optischen Eindruck. Die Ausführung dieser Vierecke in Form von Gittern dürfte ein bewusst eingesetztes gestalterisches Mittel zur Erhöhung des Schutzcharakters der Rollen darstellen. Gitter können symbolisch zum Ausgrenzen von Störenfrieden und negativen Einflüssen dienen.

3b. Das anschliessende Rechteck auf dem Zürcher Dokument ist mit der Überschrift Hilya-irasūl

92 Diese Zahl wurde übernommen aus der Beschreibung der Rolle in Petrasch, Die Karlsruher Türkenbeute 382b (Nr. 319). Gemäss Ahlwardt, Verzeichniss der arabischen Handschriften III, Nr. 3688, enthält Ms. or. oct. 403146 Kästchen mit Gottesnamen.

93 Überschrift in weisser Tinte auf goldenem Hintergrund: Hādāal-asmā al-husnā. Länge dieses Abschnitts $34.5 \mathrm{~cm}$. versehen (АВ в. 140). ${ }^{94}$ Dieses Rechteck zählt die löblichen Eigenschaften des Propheten Muhammad auf, die dem Träger der Rolle ähnlich wie die Gottesnamen Sicherheit und Schutz bieten sollen. ${ }^{95}$ Die Eigenschaften sind sowohl auf Arabisch (schwarze Tinte) als auch auf Türkisch (rote Tinte) aufgeführt. Die einzelnen Begriffe wurden in kleine, auf der Spitze stehende Quadrate notiert. Auch hier sind abwechselnd 3 bzw. 4 Quadrate pro Linie zu erkennen. Im Gegensatz zum vorangehenden Rechteck mit den Schönen Namen Gottes ist hier zwischen den beschriebenen Zeilen jeweils eine Zeile mit goldenen bzw. silbernen Quadraten ohne Text enthalten.

Die Karlsruher Rolle und ihr Parallelstück in München (Cod. arab. 206) enthalten ebenso einen Abschnitt mit den Löblichen Eigenschaften $\mathrm{Mu}-$ hammads (АВВ. 150). ${ }^{96}$ Sie sind auf dem Belegstück aus Karslruhe allerdings nicht gitterförmig aufgeführt, sondern im Mittelfeld von 18 Medaillons enthalten, die ihrerseits in drei Spalten angeordnet sind. Die sechs Kreise in der Mittelspalte sind vollständig. Die je sechs Kreise in den beiden Seitenspalten sind rechts bzw. links leicht angeschnitten. Diese Medaillons werden durch ein farbiges Schriftband ${ }^{97}$ und ein zumeist goldenes oder gelbes Mittelfeld ${ }^{98}$ gebildet. Während die Eigenschaften Muhammads in den Mittelfeldern in schwarzer Schrift auf Arabisch notiert sind, sind sie im Schriftband dem Kreisrand entlang auf Tür-

94 Diese Überschrift ist in einer Kartusche mit floralem Rankenmuster auf blauem Hintergrund in einem querliegenden, weinrot umrandeten Rechteck enthalten.

95 Vgl. dazu Bain, The late Ottoman En'am-1 şerif 70-78. A. Bain untersucht hauptsächlich hilyas aus dem 18. und 19. Jh. Sie macht aber auch auf die einfacheren hilyas aus dem 17. Jh. aufmerksam, die nur in Textform auf die inneren und äusseren Qualitäten des Propheten hinweisen. Siehe zur Frage ausserdem Zakariya, The Hilye of the Prophet Muhammad.

96 Die Überschrift dieses Abschnitts lautet auf dem Dokument aus Karlsruhe: Hādā mubārak Hilya-i šarîf (in goldener Tinte). Er schliesst sich an das Medaillon mit dem Auszug aus Q 27:30 und an ein Zellenquadrat mit der Überschrift Wafq-i Ihlāṣ an.

97 Es ist bei neun Kreisen rot.

98 Bei vier Kreisen ist das Mittelfeld silbern (oxydiert). 
kisch aufgeführt. Die Schriftrichtung in den einzelnen Spalten ändert sich dabei: Sie verläuft in der rechten Spalte vertikal von oben nach unten. Die Ausdrücke in der Mittelspalte sind horizontal ausgerichtet, stehen aber auf dem Kopf. Die Begriffe in der linken Spalte sind vertikal von unten nach oben zu lesen. Das unterste Medaillon in der rechten Spalte ist als Sichel ausgeführt worden. In die Zwischenräumen zwischen den Kreisen sind dem Rand entlang Begriffe eingefügt worden, die zu den Schönen Namen Gottes zählen. ${ }^{99}$ Auf dem Münchner Belegstück sind diese löblichen Eigenschaften des Propheten ebenso in Kreisen notiert worden. ${ }^{100}$ Auf dem Dokument aus Leipzig (B. or. 328) wiederum stehen diese Merkmale des Propheten bereits ganz am Anfang des Dokuments und sind hier ähnlich wie die Verse der Qașïdat al-Burda in Kästchen notiert worden. ${ }^{101}$ Das Belegstücke aus Berlin (Ms. or. oct. 4O3) seinerseits führt diese Merkmale wie das Zürcher Dokument in Quadrätchen auf. ${ }^{102}$ Auf dem Exemplar aus Stuttgart (Cod. or. $8^{\circ} 83$ ) jedoch wurde eine Gestaltung gewählt, die sich an den Abschnitt mit der Burda anlehnt, damit aber nicht gänzlich identisch ist.

\subsubsection{Die Figur Šakl-i 'ayn-i 'alı̀}

Das Zürcher Dokument enthält in Anschluss an die beiden soeben erwähnten Gitter mit den Schönen Namen Gottes und den Löblichen Eigenschaften Muhammads einen Abschnitt, der in einem Titelfeld mit Šakl-i 'ayn-i 'alı̄ überschrieben ist. Dieses Element ist für die kontextuelle Einordnung der Rolle besonders wichtig und wird deshalb später in

99 Es handelt sich um die folgenden Begriffe: „Yā aḥad, yā șamad, yā wahhāb, yā razzāq, wāsi` al-ğabīn, yā qādir, yā muqtadir, yā wālī, yā muta‘̄āli, yā birr." Man beachte die Bezeichnung wasī al-ğabìn (von breiter Stirn), die Gott anthropomorphe Züge zuschreibt. Auf dem Münchner Belegstück (Cod. arab. 206) lautet die Überschrift dieses Abschnitts Hilya-i Hadrat-i Rasūl. Da der Anfang der Leipziger Rolle fehlt, beginnt das Dokument mitten in der Aufzählung dieser Eigenschaften; Text zumeist auf Türkisch; aber auch Elemente auf Arabisch

Vgl. Bl. 14 auf dem Mikrofilm der Rolle. einem speziellen Abschnitt vorgestellt. ${ }^{103}$ Vorerst stehen die beiden unmittelbar daran anschliessenden Abschnitte auf der Zürcher Rolle im Vordergrund; sie enthalten je ein Gebet.

\subsubsection{Gebete}

Die bisherigen Ausführungen zeigen auf, dass die hier untersuchten Dokumente unter Gläubigen beliebt waren. Sie enthalten vielfach Auszüge aus dem Koran, zählen die Schönen Namen Gottes und die Löblichen Eigenschaften des Propheten auf. Fromme schätzen auch die auf sämtlichen untersuchten Dokumenten nachweisbare Qașídat alBurda. Es erstaunt somit nicht, dass die beigezogenen Belegstücke auch eigentliche Gebete enthalten.

5a. Der Titel des ersten Gebets auf der Zürcher Rolle lautet $D u^{\prime} \bar{a}^{\prime}-i$ ism-i a zam (Gebet des grössten Namens [Gottes; Авв. 141]). ${ }^{104}$ An diese Überschrift schliesst sich das Gebet selbst an. Die Länge dieses Abschnitts misst $14.3 \mathrm{~cm}$. Das Gebet wird von einem blauen Rahmen mit einem floralen roten Rankenmuster eingefasst. Der Schriftspiegel misst $2.3 \times 14.3 \mathrm{~cm}$; der Gebetstext ist auf 11 Zeilen verteilt. Die verhältnismässig breiten goldenen Buchstaben werden beidseits von einer haarfeinen schwarzen Linie eingefasst. Die Sinneseinheiten des Gebets sind durch einen roten Punkt voneinander getrennt. Der vokalisierte Text lautet: بسم الله

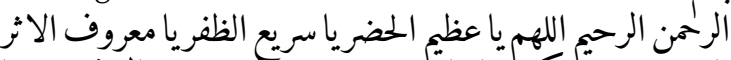

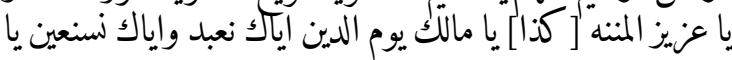

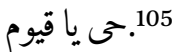

103 Vgl. unten Abschnitt 6.3.1 Šakl-i 'ayn-i 'alī, bei Anm. 118163 .

104 Diese Überschrift ist in einem querliegenden, orange umrandeten Rechteck mit einer Kartusche mit floralem Rankenmuster auf blauem Hintergrund enthalten.

105 Also: „Im Namen Gottes, des barmherzigen Erbarmers. O Gott von gewaltiger Anwesenheit, der schnellen Sieg verleiht, der in seinem Wirken erkannt wird, der edel ist in den [gewährten] Wohltaten. O König des Jüngsten Gerichts. Dich verehren wir, und zu Dir nehmen wir Zuflucht. O Lebendiger, o Beständiger!"Weitgehend derselbe Text ohne einleitende basmala auch im Mittelband von Cod. arab. 206 (München) unmittelbar vor dem Beginn der Qașīdat al-Burda. Die Überschrift 
5b. Die Länge des nächsten Abschnitts auf dem Zürcher Belegstück misst $6.0 \mathrm{~cm}$. Er enthält ein Gebet mit dem Titel $D u^{\prime} \bar{a}^{\prime}-i$ mubārak (Gesegnetes Gebet). Darunter folgt das eigentliche Gebet. Es wurde in einem Quadrat mit $5 \times 5$ Zellen notiert, das von einem blauen Rahmen mit einem roten floralen Rankenmuster eingefasst wird. Der Gebetstext wurde in diesen Zellen mit feiner roter Tinte notiert; zumeist handelt es sich um einen einzelnen horizontal geschriebenen Ausdruck pro Zelle. ${ }^{106}$

Es fällt auf, dass auf dem Dokument aus dem Historischen Museum Budapest eigentliche Gebete $\mathrm{zu}$ fehlen scheinen.107 Auf allen andern Belegstücken lassen sich jedoch Texte mit Gebetscharakter nachweisen. Auf dem Dokument aus Berlin sind zwischen dem Abschnitt mit den Löblichen Eigenschaften Muhammads und dem Beginn der Qașīdat al-Burda zwei längere Gebete enthalten. Unterhalb eines Zierfelds lässt sich die Überschrift Hād $[\bar{a}]$ Du'a $\bar{a}^{\prime}-i$ Qadah (Gebet der Tasse) erkennen. Darauf wurde das lange Gebet auf horizontal angeordneten Zeilen in kleiner Schrift notiert. ${ }^{108}$ Darunter schliesst sich ein

dieses Abschnitts lautet auf dem Münchner Exemplar $D u^{\prime} \bar{a}\left[{ }^{\prime}-i\right]$ ism-i a'zam. Der Text in schwarzem nash ist in zwei von einem grünen Mittelband (darauf šahāda) voneinander getrennten Streifen notiert worden. Der Abschluss auf dem Münchner Exemplar lautet nach iyyāka nastainn لا حول ولا قوة إلا بالله العلى العظيم تم تمام Der Text lautet:

$$
\begin{aligned}
& \text { لسم الله الرحمن الرحيم يا دايعيا قايم ا يا باسط يا حافظ يا رافعيا } \\
& \text { معين يا (؟) ايا حى يا قيوم يا ديان يا برهان يا احد | يا فرديا ذو } \\
& \text { [ كذا] الجلال والاكرام ا برحتك يا ارحم الراحمين. }
\end{aligned}
$$

Das Gebet appelliert also hauptsächlich an Eigenschaften Gottes, die von seinen Schönen Namen bekannt sind.

107 Die Textstellen auf diesem Belegstück sind allerdings stark verblasst und lassen sich kaum mehr entziffern; somit könnte auch auf diesem Dokument Gebetstext vorhanden gewesen sein.

108 Vgl. Bl. 13-11 (sic) auf dem Mikrofilm zur Rolle. Texte und Tonaufnahmen eines Gebets namens Du'ä' alQadah lassen sich im Internet vielfach nachweisen; siehe z. B. http://www.shiavoice.com/play-ks8od.html.
Abschnitt an, der Teile des ebenso auf der Zürcher Rolle nachweisbaren Gebets $D u^{\prime} \bar{a}^{\prime}-i$ Ism-i a'zam enthält. Der Text ist hier allerdings mehrfach unvollständig bzw. verderbt; er weist ausserdem wiederholt Kopistenfehler auf. Das Gebet ist in verhältnismässig grossen Buchstaben auf horizontalen Zeilen auf einem Hintergrund mit Text in kleiner Schrift notiert worden. Zudem lässt sich auf dem Berliner Belegstück der Anfang des Nādi'Alī-Gebets nachweisen, das sich besonders unter Schiiten grosser Beliebtheit erfreut. Es ist um die 'Ayn-i 'alì-Figur herum angeordnet. ${ }^{109}$

Gebetstexte lassen sich überdies auf dem Belegstück aus Karlsruhe feststellen. Ein Gebet ist in diesem Fall in die Doppelzypresse integriert worden. ${ }^{110}$ Cod. arab. 206 (München) wiederum appelliert an die Schutzmächtigkeit Hiḍrs (Überschrift Du'a $\bar{a}^{-}-i$ Hadrat-i Hidr). Dieses Gebet ist ebenso in

109 Der Gebetstext lautet:

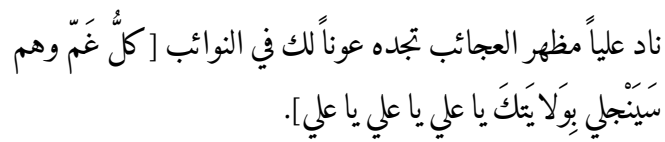

Sehr oft werden nur die beiden ersten Wörter des Gebets notiert; sie sollen das Gebet als Ganzes in Erinnerung rufen. Dieses Gebet wird aufgeführt bei Mağlisī, Bihār al-anwār (Bayrūt, ğild 2, șafha 73, hatț 11). Es lässt sich aber bereits im Korankommentar Maybudīs (aktiv 1126) nachweisen, der unter dem Titel Kašf ul-asrār wa 'uddat ul-abrār bekannt ist. Ein unsichtbarer Rufer (hātif) oder Gabriel soll das Gebet Muhammad bei der Schlacht von Uhud zugerufen haben. Dieses Gebet wurde auch auf Is 1623 (Chester Beatty Library, Dublin) kopiert (siehe Kapitel 5.3 nach Anm. 36; bei Anm. 9194; Abschnitt vor Anm. 97 und bei Anm. 107). Es steht ausserdem auf Arabe 5102 (BNF, Paris; vgl. Kapitel 5.4, vor Anm. 74 und bei Anm. 114-115).

110 Vgl. Karlsruhe, BLB, RA 204 (keine Überschrift vor diesem Abschnitt):

بسم الله الرحمن الرحيم يا ودود يا ودود، يا ذا العرش المجيد يا

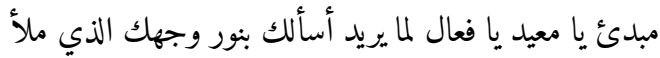

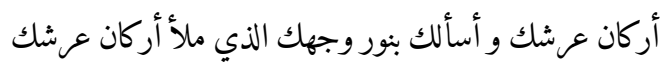
وأسألك بقدرتك التي قدرت بها على جميع خلقك، و[أسألك] برحمتك التي وسعت كل شيء لا إله إلا أنت يا مغيث أغثني برحمتك يا ارحم الراحمين والحمد لله رب العابل لإلمين. 
einen Abschnitt mit einer Doppelzypresse integriert $^{111}$ Auf der besonders aufwendig gestalteten Rolle aus Leipzig (B. or. 328) ist am Anfang des linken Seitenbands entlang der Burda rückwärtslaufend ein Gebet mit dem Titel Du'ā' Habīb Allāh enthalten (ABB. 143).

Die beiden zuletzt angeführten Gebete appellieren also auch an Muhammad und Hidr. Diese beiden Personen aus der islamischen Heilsgeschichte werden hier dem Gläubigen als Vorbild vorgestellt. Dies zeigt auf, dass derartigen Dokumenten neben ihrer Schutzwirkung auch eine erbauliche Funktion zukommt. ${ }^{112}$ Auf den untersuchten Rollen finden sich auch regelmässig Hinweise auf wei-

111 Dieses Gebet bildet das vorletzte Element vor der Qașidat al-Burda auf Cod. arab. 206 (München). Dieser Abschnitt enthält zwei Zypressen, deren Kronen (silbern; Stämme: grün) durch einen Mittelstreifen voneinander getrennt werden. Der Abschnitt ist mit der Überschrift Du'a $\bar{a}^{\prime}-i$ Hadrat-i Hidr versehen (auf der Rolle: Hidr mit unpunktiertem $h \bar{a}^{\prime}$ ). Der Text lautet: 1. absteigend: a. Zypresse rechts (zuerst rote, dann

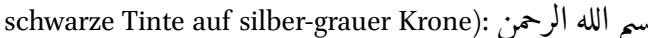

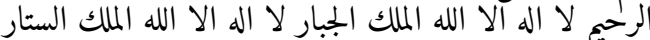

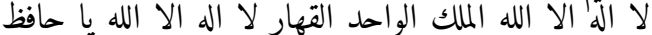

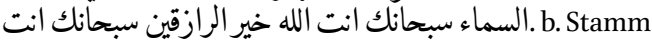
der Zypresse (schwarze Tinte auf grünem Grund): الن [ Eذا] الله خير الوارثين سبحانك انت الله gang zwischen den beiden Stämmen (rote Tinte auf neutralem Hintergrund): خير الغافين سبحانك انت الله Und dann 3. aufsteigend: a. Stamm der Zypresse links (rote Tinte auf grünem Grund): خير الفاطرين سبحانك انت الله b. Krone der Zypresse (rote Tinte auf silber-

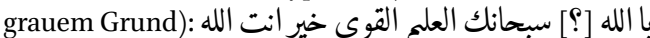

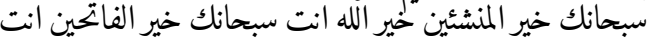

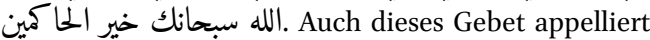
damit an Gott hauptsächlich Kraft der von seinen Schönen Namen bekannten Eigenschaften. Die Wörter und Wortteile folgen gerade im Schlussteil (3b) mehrfach nicht direkt aufeinander. Die Aussage bleibt jedoch klar ersichtlich: Subhānaka anta Allāh; es schliesst sich ein hayr an, das jeweils durch ein Partizip aktiv im Plural präzisiert wird.

112 Auf den vorliegend untersuchten Dokumenten werden folgende Personen aus der islamischen Heilsgeschichte erwähnt und dem Gläubigen damit implizit als Vorbild präsentiert: 1. Muhammad: Zürich, Berlin, Karlsruhe, München, Budapest, Leipzig; 2. Salomon: Zürich, Berlin, Karlsruhe, München, Budapest; 3. 'Alī: Zürich, Berlin, Karlsruhe, München; 4. Hidr: München. tere Personen aus der islamischen Heilsgeschichte; dazu zählen die vier rechtgeleiteten Kalifen.

\subsubsection{Hinweise auf die vier rechtgeleiteten} Kalifen

Nach den zuvor erwähnten Auszügen aus dem Gebet Du'ä-i ism-i azam schliesst sich auf dem Berliner Belegstück ein rechteckiger Abschnitt an, in dem sich eine Unterteilung in fünf Hauptfelder erkennen lässt. Ihr Hintergrund wird durch Text in kleiner Schrift gebildet (oft Anrufungen Gottes). Als Haupttext lassen sich in vier vertikal angeordneten Feldern jedoch die Namen Allāh und Muhammad (1. Feld) und daran anschliessend jene der vier rechtgeleiteten Kalifen erkennen (2. Feld: Abū Bakr, 'Umar; 3. Feld: 'Uțmān; 4. Feld: 'Alī). Diese vier Rechtecke mit den vertikal notierten Namen werden durch ein querliegendes Rechteck voneinander getrennt, in dem steht. „ba-umīdi rabb al-'izz".113

Es ist nicht unüblich, dass die Namen der vier rechtgeleiteten Kalifen auf Dokumenten in Rollenform erwähnt werden, wie dies vorliegend auf Ms. or. oct. 403 (Berlin) der Fall ist. ${ }^{114}$ Soweit ersichtlich lassen sich diese vier rechtgeleiteten Kalifen unter den beigezogenen Belegstücken ausserdem auf B. or. 328 (Leipzig) nachweisen. Sie werden darauf mit ihren Beinamen einerseits in den Segmenten am Rand des Kreises mit dem Muhr-i Bilqīs erwähnt. ${ }^{115}$ Überdies werden ihre Namen auf dem Leipziger Belegstück zwischen den beiden Klingen des Dū l-faqār-Schwerts aufgeführt (А BB. 145). An dieser zweiten Stelle schliessen sich nach der Nennung 'Alīs ausserdem die Namen seiner beiden Söhne Hasan und Husayn an. ${ }^{116}$ Die vier rechtgeleiteten Kalifen werden zusätzlich auf Cod. or. oct. 146 (Berlin) erwähnt, das allerdings aus einem safawidischen Kontext stammt. ${ }^{117}$

\footnotetext{
113 Also: „In Hoffnung auf den Herrn der Erhabenheit“.

114 Siehe Canaan, Decipherment 143.

115 Vgl. bei Anm. 61 und 172.

116 Vgl. bei Anm. 172.

117 Vgl. hier Kapitel 5.1, zwischen Anm. 6 und 7.
} 


\subsection{Bemerkungen zur ideologischen Einordnung der Dokumente}

Die untersuchten Rollen enthalten unterschiedliche Elemente, die bei der Interpretation ihrer Funktion und ihrer ideologischen Einordnung zu beachten sind. Sie sind im vorangehenden deskriptiven Teil teilweise bereits kurz erwähnt worden, sollen aber in den folgenden Ausführungen besondere Aufmerksamkeit erhalten. Es handelt sich um die folgenden Aspekte:

1. die Figur mit der Überschrift Šakl-i 'ayn-i 'alī

2. das Schwert $\underline{D} \bar{u}$ l-faqār, die Anrufung der vier rechtgeleiteten Kalifen und der Baum am Rollenanfang

3. die prominente Erwähnung von Q 61:13, der Begriff šakl, die Siegel (muhr) und das Gebet der Tasse

4. die Erwähnung Hiḍrs

5. die Abbildung von Sonne und Mond

6.3.1 Šakl-i 'ayn-i alī: 'Alī spielt bei der Interpretation der mit der Überschrift Šakl-i 'ayn-i 'alı̄ versehenen Figur eine wichtige Rolle. ${ }^{118}$ Diese komplex gestaltete Figur lässt sich sowohl auf dem Dokument aus Berlin ${ }^{119}$ als auch auf den Belegstücken aus Zürich (АВB. 142) und Leipzig (АВB. 146) nachweisen. Sie ist in modifizierter Form überdies auf dem Exemplar aus dem Historischen Museum Budapest enthalten (ABB. 159). Zusätzlich lässt sie sich auf einem Dokument aus München feststellen, das allerdings nicht zu den hier näher diskutierten Rollen zählt (АВв. 16о). ${ }^{120}$ Sie fehlt jedoch auf dem Belegstück aus Karlsruhe, Cod. arab. 206

118 Die weiteren Ausführungen kommen hier eingehender auf die zuvor erst im Vorbeigehen erwähnte Figur $\breve{S} a k l-i$ 'ayn-i 'alı̄ zurück (vgl. oben, 6.2.2.4, bei Anm. 103).

119 Auf dem Berliner Dokument ist ihr ein Rechteck mit Text in $\dot{G} u b \bar{a} r$-Schrift vorangestellt. Es enthält sechs horizontale Reihen. Die Reihen 1-2 und 4-6 sind in vier senkrechte Zellen unterteilt. Die 3. Reihe weist keine Unterteilung auf.

120 München, Bayerische Staatsbibliothek, Cod. arab. 207 (gegen Schluss der Rolle); vgl. Aumer, Die arabischen Handschriften 62.
(München) ${ }^{121}$ und Cod. or. $8^{\circ} 83$ (Stuttgart). Sie ist allerdings in ganz ähnlicher Ausführung von als Talismanhemden (tılsımlı gömlekler) bezeichneten Kleidungsstücken bekannt, die u. a. aus dem Topkapi-Museum stammen. ${ }^{122}$ Sie lässt sich ausserdem mehrfach in En'am-ı şerif-Handschriften nachweisen. ${ }^{123}$

Die folgenden Ausführungen beschreiben diese Figur anhand des Zürcher Dokuments, auf dem sie besonders sorgfältig gestaltet worden ist (АВв. 142):124 Unterhalb des Titelfelds mit der

121 Die Figur fehlt ebenso auf Cod. arab. 205 (München), das sich zum Vergleich zusätzlich beiziehen lässt.

122 Tezcan, Tilıslımlı gömlekler: Katalog Nr. 11 (S. 76-79, von Naqqāš Ḥasan Pāša, gest. 1622); Katalog 98f. (Nr. 17, ins 19. Jh. datiert); Katalog 100-103 (Nr. 18, ins 19. Jh. datiert); Katalog 142-145 (Nr. 33, ins 16. Jh. datiert); Katalog 166 f. (Nr. 43, ins 17.Jh. datiert); Katalog 188f. (Nr. 56, ins 16.-17. Jh. datiert); Katalog 193 (Nr 6o, aus Koranhandschrift, datiert 1072/1661-1662, vgl. dies auch S. 18, Figur 4). Die diskutierte Figur lässt sich ausserdem nachweisen bei Habīb b. Mūsā arRiḍā Afšāī Urūmīya'ī an-Nağāfì, Ğāmi ul-Fawā’id fi Asrār ul-maqāṣid (Persisch) 386. Qum, ohne Jahr (?). Ch. Gruber, A pious cure-all 139f., liest die Figur auf der von ihr untersuchten Handschrift, wohl in Anschluss an A. Bain (vgl. folgende Anm.) 'ayn 'alā Allāh („an eye upon God“). Siehe ausserdem Schimmel, Mystische Dimensionen 117 (nur Abbildung, ohne Erklärung).

Es sei darauf aufmerksam gemacht, dass Joseph von Hammer-Purgstall die auf einem derartigen Talismanhemd enthaltenen Textstellen ins Deutsche übertragen hat: „Über die gefeyten talismanischen Hemden der Moslimen“.

Bain, The late Ottoman En'am-ı şerif 118-121. A. Bain interpretiert die Figur primär als 'Ayn 'alä Allāh (Auge auf Gott, so auch 165, 249, 306, 327, 344), macht aber zusätzlich auf einen allfälligen Bezug zu 'Alī aufmerksam [so 263, ganz deutlich 279: „This is the likeness of 'Alì's eye ('ayn), may God ennoble his face."; 293 f.; 334 f.: Hinweis auf eine Figur „The Eye of 'Alī": „Hād̄ā šakl 'ayn-i 'Alī, karrama Allāh wağha-hū"]. Leider liess sich A. Bains Arbeit nur als Internet-Download beschaffen, in dem das umfangreiche Abbildungsmaterial bloss in bescheidener Qualität zugänglich ist. Anhand dieses Materials liess sich die von A. Bain primär vorgeschlagene Lesung 'ayn 'alā Allāh nicht überprüfen.

124 Auch auf B. or. 328 (Leipzig) ist diese Figur sehr aufwendig ausgeführt worden. 
Überschrift Šakl-i 'ayn-i 'alı̄ steht in einer längli-

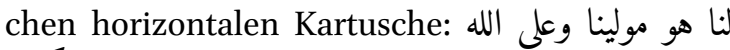
25 Darunter folgt ein Kreis, der von einem goldenen Rahmen eingefasst wird. Auf dem neutralen Hintergrund des Kreises steht auf vier horizontalen Zeilen: كهيعص احم عسق ان والق القل 年 126 Zur Rechten und Linken dieses kleinen Kreises lassen sich zwei senkrecht stehende Rechtecke erkennen, die vertikal geschrieben den folgenden Text enthalten: a. (rechts, Schriftrichtung aufsteigend): وله 127 b.

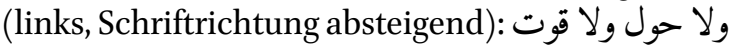
Unmittelbar unterhalb dieses kleinen Kreises lässt sich ein deutlich grösseres Kreiselement erkennen. In den Winkeln ausserhalb dieses Kreises lassen sich die folgenden Textstellen nachweisen: a. (oben rechts, rot und blaugrün, von unten nach oben gelesen): اللهم يا مفتح الابواب افتح النح

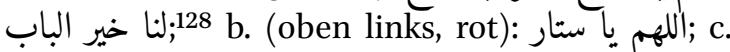
(unten rechts, rot): اللهم يا رفيع الدرجات :d. (unten

125 Q 9:51 (Schluss); der Anfang dieses Verses folgt später (vgl. vor Anm. 127). Q 9:51 lautet vollständig: قل لن يصيبنا الا ما كتب الله لنا هو مولانا وعلى الله فاليتوكل المؤمنون. Also: „Sprich: ,Nur das wird uns treffen, was uns Gott bestimmt hat.' Er ist der Schutzherr, und auf ihn sollen die Gläubigen vertrauen." (Übersetzung H. Bobzin). Zur häufigen Verwendung dieses Verses auf Amuletten vgl. Bain, The late Ottoman En'am-ı şerif 64, die die Stelle zu den āyāt šarīfa zählt.

126 Es handelt sich um die rätselhaften Buchstaben aus Q 19:1 (grünblaue Schrift), und Q 42:1-2 (rote Schrift). Auf den beiden nächsten Zeilen steht in grünblauer bzw. schwarzer Schrift Q 68:1. Vgl. dazu Canaan, Decipherment 15of. Auf B. or. 328 (Leipzig) sind die rätselhaften Buchstaben aus Q 19:1 und Q 42:1-2 ebenso vorhanden; dann aber folgt als Ersatz für Q 68:1 wa-l-kitāb al-mubin (Wendung im Koran mehrfach nachweisbar, u.a. Q 12:1).

127 In schwarzer Schrift. Q 9:51 (Anfang). Der Schluss dieses Verses bereits zuvor; vgl. Anm. 125 .

128 Also: „Gott, o Öffner der Türen, öffne uns die beste Tür!“ Auf B. or. 328 (Leipzig) direkt unterhalb der Ayn-Figur senkrecht und Schriftrichtung aufsteigend: Yā mufattiha al-abwāb (rechts) bzw. Yā musabbiba alasbāb (links); also: „[O Gott, der] die Türen öffnet und die Ursachen bewirkt.“ links, blaugrün): اللهم يا دافع البليات ${ }^{29}$ In den soeben erwähnten Hauptkreis ist auf der rechten Seite ein kleinerer Kreis eingefügt, in dem in blaugrüner, roter und wieder blaugrüner Schrift geschrieben steht: الله يتوكل المتوكلون In der oberen Kreishälfte steht in fünf senkrechten stabähnlichen Elemen-

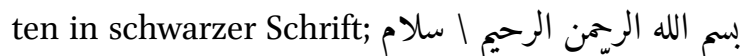

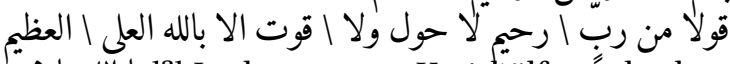

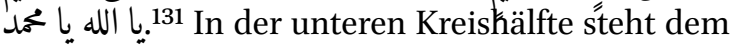

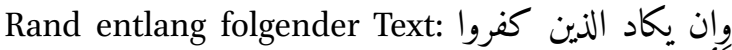

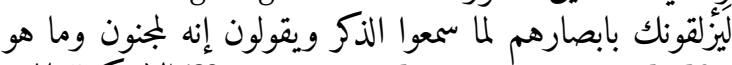
132 Im Innern der unteren Kreishälfte

129 Übersetzungen der drei soeben angeführten arabischen Wendungen lauten: „Gott, o Verhüller [der Sünden].“ - „O Gott, der die Plätze [der Gläubigen im Paradies] erhöht.“ - „Gott, o Abwehrer der Menschen, die Unheil verursachen!“ (siehe Kazimirski, Dictionnaire, s.v. baliyya, Pl. baliyyāt, 2). Auf B. or. 328 (Leipzig) lassen sich ganz ähnliche Anrufungen nachweisen, die an Gottes Schutz und Hilfe appellieren: Über dem 'ayn steht

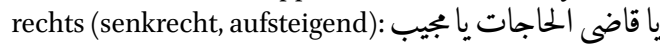

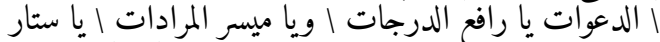

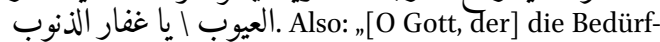
nisse erfüllt, der die Gebete erhört, der die Plätze [der Gläubigen im Paradies] erhöht, der das Erwünschte erleichtert, der die Fehler verhüllt und die Sünden vergibt."

130 Mit fehlendem 'alā am Anfang: „Auf Gott vertrauen die Vertrauenden." Die Wendung kommt im Koran mehrfach vor, u.a. Q 3:122. Zum Gottvertrauen (tawakkul) siehe Anm. 55 und 245 .

131 Also etwa: „Im Namen Gottes, des barmherzigen Erbarmers. Der Gruss ergeht von einem barmherzigen Herrn. Es gibt keine Macht und keine Kraft ausser bei Gott, dem Erhabenen, dem Gewaltigen. O Gott, o Muhammad." Auf B. or. 328 (Leipzig) fehlt Text in diesen Stäben. Inhaltlich teilweise ähnliche Anrufungen Gottes finden يا حي يا قيوم : sich hier im kleinen Kreis rechts, wo steht

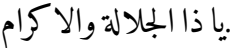

132 Q 68:51-52. H. Bobzin übersetzt: „[51] Ja, die ungläubig sind, die brächten dich fast zum Straucheln mit ihren Blicken, wenn sie die Mahnung hören. Und sie sagen: ,Siehe, er ist fürwahr besessen!' [52] Doch er ist nichts als eine Mahnung für die Weltenbewohner." Die Zeilen sind dabei von rechts nach links, also von unten nach oben zu lesen. Dieselbe Koranstelle auch auf B. or. 328 (Leipzig), hier verteilt auf die beiden Bögen in der unteren Hälfte des grossen 'ayn. Gemäss Bain, The late Ottoman En`am-1 şerif 102 (auch 112), schützt Q 68:51-52 v.a. gegen den Bösen Blick. 


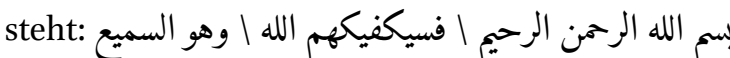

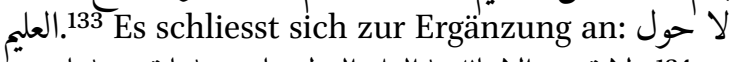
134.ولا قوت :الا بالله \العلى العظيم يا حى ايا قيوم \يا معين

Die vorangehende Beschreibung hat sich bewusst auf die in dieser als Šakl-i 'ayn-i 'ali bezeichneten Figur enthaltenen textlichen Elemente konzentriert. ${ }^{135} \mathrm{Im}$ folgenden soll jedoch auf die Gestaltung dieser Figur als Ganzes eingegangen werden. Die in den weiteren Ausführungen vorgeschlagene Interpretation dürfte massgeblich zur Einordnung der Rollen aus Zürich, Berlin, Leipzig und Budapest, beitragen. Es sei jedoch festgehalten, dass die hier vertretenen Interpretationen nicht abschliessend sind und weiterer Überprüfungen bedürfen. ${ }^{136}$

Bei der Beschreibung der in dieser Figur enthaltenen Textelemente wurde mehrfach auf darauf erkennbare Kreiselemente hingewiesen. Auf dem Belegstück aus Berlin lässt sich als Hauptelement deutlich der Buchstaben 'ayn aus dem arabischen Alphabet erkennen. In modifizierter Form ist ein goldenes 'ayn ebenso in einem Abschnitt unmittelbar vor der Qașidat al-Burda auch auf dem Dokument aus dem Historischen Museum Budapest enthalten. In gegenüber dem Berliner Exemplar abgeänderter Form ist dieser Buchstaben überdies auf dem Zürcher Belegstück festzustellen. Dieses ‘ayn lässt sich ausserdem auf der Rolle aus Leipzig nachweisen.

In dieses grosse 'ayn hinein sind auf der Berliner, Leipziger und Zürcher Rolle zwei Ausdrücke geschrieben worden. Es handelt sich einerseits um den Begriff 'alì. Er wird durch einen kleineren Kreis

133 Ende von Q 2:137: „Doch Gott wird dich gegen sie beschützen. Er ist der Hörende, der Wissende." Dieser Koranvers ist auf Rollen von der hier untersuchten Art vielfach enthalten.

134 „Es gibt keine Macht und keine Kraft ausser bei Allāh, dem Erhabenen, Gewaltigen. O Lebendiger, o Beständiger, o Helfender!“

135 Auch auf Ms. or. oct. 403 (Berlin) sind in die Ayn-Figur textliche Elemente integriert, vgl. Mikrofilm zur Rolle Bl. 17 .

136 Man beachte auch die ergänzenden Hinweise zum Begriff šakl in der Überschrift zu dieser Figur hier unten bei Anm. 193-208. gebildet, der auf der rechten Seite in den grossen Kreis der Hauptfigur eingefügt wurde; auch dieser kleine Kreis steht für den Buchstaben 'ayn. Links davon folgen mehrere senkrecht angeordnete Stäbe bzw. Striche. Der erste davon steht für den Buchstaben lām. Der den Kreis nach unten abschliessende, nach links geschwungene Bogen stellt gemäss dieser Interpretation den Buchstaben $y \bar{a}^{\prime}(\bar{\imath})$ im Begriff 'al̄ dar. In der oberen Hälfte des Hauptkreises fallen in erster Linie die bereits erwähnten senkrechten Stäbe oder Striche auf. Ganz am linken Rand lässt sich auf der Zürcher Rolle ein kleines Viereck erkennen; auf dem Berliner Belegstück handelt es sich um ein Dreieck mit nach links weisender Spitze. Diese einzelnen Elemente bilden zusammen den Ausdruck Allāh. ${ }^{137}$

Aus der hier vorgeschlagenen Entschlüsselung ergibt sich, dass diese Figur die drei folgenden arabischen Begriffe enthält: 'ayn, 'alī und Allāh. Mit dem Begriff Allāh ist eindeutig Gott gemeint. Der Ausdruck 'alì hingegen lässt sich unterschiedlich interpretieren. Er lässt sich einerseits als Adjektiv mit der Bedeutung „hoch, erhaben“ verstehen; dieser Ausdruck zählt zu den 99 Schönen Namen Gottes. Anderseits kann damit auch 'Alī, der Milchbruder und Schwiegersohn des Propheten Muhammad gemeint sein. 'Alī (regierte 656-661) war nicht nur der vierte rechtgeleitete Kalif der Muslime, sondern zugleich auch der erste Imam der Schii-

137 Nicht ganz überzeugend scheint A. Bains Versuch (u.a. S. 121, in ihrer Dissertation The late Ottoman En'am1 şerif), den im Buchstaben 'ayn enthaltenen Begriff Allāh als Pupille eines Auges zu deuten. Es ist nicht ersichtlich, warum die in Natur runde Pupille in Form von mehreren senkrechten Strichen dargestellt werden soll. Es drängt sich die Frage auf, ob die Lesung der diskutierten Figur als 'ayn 'alä Allāh durch A. Bain und ihre Informanten aus dem Umfeld der Naqšbandiyya nicht als taqiyya $z u$ verstehen ist. Jedenfalls scheint diese Interpretation den Kern der Sache zu verhüllen. Die Überschriften zur Figur auf den in diesem Beitrag untersuchten Rollen sind ganz klar als Šakl-i 'ayn$i$ 'alī (bzw. ähnlich) zu lesen; eine Lesung 'ayn 'alā Allāh, ist nicht möglich. Auch Dr. I. Afs̃ār las die Überschrift zur Figur auf dem Zürcher Belegstück ganz selbstverständlich als šakl-i 'ayn-i 'alı̄ (Diskussion mit I. Afšār, Teheran, Januar 2005). 
ten. Der übergeordnete Buchstaben 'ayn dieser Figur, in den die beiden Begriffe Allāh und 'alī/'Alì eingefügt worden sind, kann aber ebenso als Wort verstanden werden. Seine Grundbedeutung lautet im Arabischen „Wesen“ ('ayn). Der Ausdruck 'ayn kann überdies „Auge“ und "Quelle“ bedeuten. ${ }^{138}$ Gerne wird der Buchstaben 'ayn in unterschiedlichen Kreisen ${ }^{139}$ auch als Abkürzung für den Namen 'Alī benutzt. Es fällt auf, dass sich dieses 'ayn deutlich erkennbar auch auf dem Dokument aus Budapest nachweisen lässt (АВ B. 159). ${ }^{140}$ Darauf fehlen allerdings die meisten der auf den Belegstücken aus Berlin und Zürich soeben aufgezählten zusätzlichen Elemente. ${ }^{141}$

138 Im Sinn eines Exkurses sei hier auf 'Alīs Abstieg in einen Brunnen hingewiesen. Ob die fragliche Episode für die Interpretation der vorliegenden Figur auch tatsächlich relevant ist, soll offen bleiben. Es ist bekannt, dass sich 'Alī nicht nur bei Muhammads Schlachten gegen menschliche Gegner als Kämpfer hervortat. Es lässt sich vielmehr belegen, dass er auch nicht davor zurückschreckte, die gefährlichen ğinn in ihre Schranken zu weisen. Mehrere Quellen wissen jedenfalls davon, dass 'Alī in den Brunnen Bìr Dāt al-'alam (etwa: „der Brunnen mit der Flagge“) hinabstieg, als die ğinn die Menschen daran hinderten, ungestört Wasser zu schöpfen. Dabei hat 'Alī eine bedeutende Zahl der gefürchteten Dämonen vernichtet. Es kann nicht a priori ausgeschlossen werden, dass das 'ayn - es bedeutet im Arabischen ja auch „Quelle“ - in der diskutierten Figur implizit nicht auch auf diese Episode anspielt. Beim Šakl- $i$ 'ayn-i 'alı̄ handelt es sich um ein Symbol. Seine Hersteller dürften es begrüsst haben, wenn damit ganz unterschiedliche Assoziationen verbunden wurden. Vgl. zu 'Alīs Abstieg in den Brunnen Bìr Dāt al-'́alam: Nünlist, Dämonenglaube 196, Anm. 19.

139 Diese Kreise werden im vorliegenden Beitrag noch näher vorgestellt.

140 Auf dem Belegstück aus Budapest lässt sich ein goldenes 'ayn erkennen, in dessen grossen unteren Bogen ein Viereck mit $4 \times 3$ Zellen eingepasst ist. Sechs Zellen sind golden, die andern sechs enthalten Begriffe; sie sind derart stark verblasst, dass sie sich - ebenso wie die weiteren Textelemente - auf dem zur Verfügung stehenden Abbildungsmaterial nicht mehr entziffern liessen. Im oberen kleinen Kreis des 'ayn meint man, unter einem $b \bar{a}$ ' die Buchstabenfolge كهيعص zu erkennen (Buchstabenfolge am Anfang von Q 19:1; vgl. Anm. 126).

141 Aufgrund der deutlich einfacheren Gestaltung dieser Figur auf dem Belegstück aus Budapest wird vermutet,
Bei der Entschlüsselung der geschilderten Figur bieten sich somit mindestens zwei Interpretationen an. a. Einerseits lässt sie sich dahingehend verstehen, dass Allāh kraft seines Wesens ('ayn) „hoch, erhaben" ('alī) ist. Auch traditionalistisch orientierte Theologen können dieser Lesart problemlos zustimmen. b. Anderseits spricht vieles dafür, dass der Begriff 'alı̄ in dieser Figur für den Milchbruder und Schwiegersohn des Propheten steht. Eine solche Lesart liefe darauf hinaus, dass die geschilderte Figur 'Alī in seinem innersten Wesen ('ayn) göttliche Natur zuschreibt bzw. ihn mit Allāh gleichsetzt. Diese Interpretation ist für die traditionalistisch orientierte Theologie selbstredend inakzeptabel.

Allerdings legt gerade die im vorliegenden Beitrag nicht detailliert untersuchte Rolle Cod. arab. 207 (München) diese zweite Erklärung nahe (АвВ. 16o). Auf diesem Belegstück lässt sich die 'Ayn$i$ 'alī-Figur am Schluss ebenso nachweisen. ${ }^{142} \mathrm{Die}$ Figur ist auf diesem Dokument mit der Überschrift Hādā muhr-i Hadrat-i 'Alī radiya Allāh 'an-hū versehen. Die Wendung Hadrat-i 'Alī zeigt auf, dass dieses Siegel (muhr) an die Schutzkraft 'Alīs appelliert. Die Formel radiya Allāh 'an-hū unterstreicht zusätzlich, dass hier von 'Alī, Muhammads Milchbruder und Schwiegersohn, als Menschen die Rede ist. Allfällige Zweifel an dieser Sichtweise werden durch einen türkischen Kommentar zerstreut, der der diskutierten Figur unmittelbar vorangestellt und mit der Überschrift Hādā šarh-i muhr-i Šāh$i$ mardān Hadrat-i 'Alī radiya Allāh 'an-hū versehen ist. Der Ausdruck Šăh-i mardān, König der Menschen, ist als Beiname zur Bezeichnung 'Alīs gut belegt. ${ }^{143}$ Der erwähnte türkische Kommentar macht auch auf die ausserordentlichen Eigenschaften dieser Figur aufmerksam. ${ }^{144}$ Auf diesem

dass es früher entstanden ist als seine Parallelen aus Zürich, Leipzig und Berlin. Vgl. bereits oben, Anm. 120.

Vgl. z.B. Dihhudā, Luġat-nāma, s.v. Siehe ausserdem Mélikoff, Hadji Bektach: Un mythe et ses avatars $23 \mathrm{f}$., 142, 176, 205f., 23 o.

Dieser Kommentar in teils verderbtem Türkisch hält fest: Wer dieses Siegel (muhr) anschaue, sei vor dem 
Parallelstück aus München (Cod. arab. 207) sind in die Figur hinein selbst mehrfach Anrufungen 'Alīs $(y \bar{a}$ 'Alī $)$ und der Name Gottes (Allāh) eingefügt worden. Ausserdem lassen sich darin Attribute erkennen, die auch von Listen mit den Schönen Namen Gottes bekannt sind. Sie dürften vorliegend allerdings auf 'Alī zu beziehen sein. ${ }^{145}$ In den Winkeln des Vierecks sind ausserhalb der Buchstabenkombination erneut vier Anrufungen 'Alīs in roter Tinte notiert worden. Zusätzlich lassen sich in schwarzer Tinte weitere Anrufungen 'Alīs, Allāhs und zwei Mal die šahāda feststellen.

Die Gestaltung dieser Figur auf Cod. arab. 207 (München), aber auch ihre Ausführung auf den hier näher untersuchten Belegstücken legt eine Annäherung 'Alīs an bzw. Gleichsetzung mit Allāh nahe. Diese Interpretation ist aus der Perspektive der traditionalistisch orientierten islamischen Theologie selbstredend höchst problematisch. Ein indirekter Hinweis, dass die hier vertretene Erklärung dieser Figur zutrifft, dürfte sich jedoch aus dem Belegstück aus Leipzig ableiten lassen (АВB. 146). Darauf ist die diskutierte Figur mit ausserordentlicher Sorgfalt ausgeführt worden. ${ }^{146}$ Die Buchstaben der drei Ausdrücke 'ayn, 'al̄ und Allāh sind golden und werden von feinen

Höllenfeuer gefeit. Die dem Siegel inhärente Segenskraft (baraka) erfülle jeden diesseitigen und jenseitigen Wunsch. Gott verleihe jenem die Kraft von sieben Männern, der es mit reiner Gesinnung betrachte. Er besiege dann im Krieg die Feinde wie dies 'Alī mit dem $D \bar{u} l$ faqār-Schwert getan habe. Es seien jene verflucht, die Unrecht tun, heuchlerisch oder ungläubig sind und das Siegel nicht mit Überzeugung anschauen. Wer an diesem Siegel zweifle, wird mit jenem verglichen, der mit seiner eigenen Mutter in der Ka'ba (Bayt al-Harām) siebzig Mal Unzucht (zanā $)$ treibe. Ausserdem feie das Siegel vor Schussverletzungen (tūfang/țüfang) und Schwerthieben. Und man behalte dank ihm bei Auseinandersetzungen die Oberhand.

145 Ergänzend sei darauf hingewiesen, dass in dieser Figur auf Cod. arab. 207 (München) auch zwei Abfolgen von Ziffern in roter Tinte enthalten sind.

146 Höhe der 'Ayn-Figur: $4.0 \mathrm{~cm}$. Es ist bereits darauf hingewiesen worden, dass sich mehrere auf dem Zürcher Dokument nachweisbare Textelemente ebenso auf dem Belegstück aus Leipzig feststellen lassen; vgl. dazu Anm. 128. schwarzen Linien umrandet. ${ }^{147}$ Ausserdem ist der Abschnitt mit einem Titelfeld versehen, auf dem in weisser Schrift Šaklal-'ayn al-mubārak („das gesegnete šakl des 'ayn") ${ }^{148}$ steht. Zwischen dem Titelfeld und der goldenen Figur allerdings ist fein säuberlich ein Rechteck herausgeschnitten worden, das $1.6 \times 3.6 \mathrm{~cm}$ misst. Wenn sich der diesbezügliche Beweis auch nicht schlüssig führen lässt, wird hier dennoch die Vermutung geäussert, dass auf dem jetzt fehlenden Ausschnitt - ähnlich wie auf Cod. arab. 207 (München) - explizite Hinweise auf die göttliche Natur 'Alīs enthalten gewesen sein mussten. Dies wiederum dürfte einem späteren Besitzer des Dokuments nicht mehr opportun erschienen sein. Eine solche Auffassung legt nicht zuletzt der Umstand nahe, dass das Belegstück aus Leipzig zusätzlich eine sorgfältig ausgeführte Abbildung von 'Alīs Schwert Dū l-faqār enthält. ${ }^{149}$

Es ist bei dieser Gelegenheit festzuhalten, dass die Vergöttlichung 'Alīs unter heterodoxen Gruppierungen weit verbreitet ist. Es kann beispielsweise auf die 'Alī-Ilāhīs in Iran verwiesen werden, denen eine Kombination der beiden Begriffe 'Alī und Allāh (bzw. ilāh) den Namen gegeben hat. ${ }^{150}$ M. Moosa weist aber auch auf 'Alīs göttliche Stellung bei den Nuṣayriern in Südost-Anatolien bzw. Nordwest-Syrien hin. ${ }^{151}$ Auch die Bektāšīs schreiben 'Alī göttliche Natur zu. ${ }^{152}$ Das Feiern dieser Einheit (tawhìd) von 'Alī und Allāh stellt übrigens den Höhepunkt der Ayin-i Cem-Zeremonie bei den Bektāšīs und den Nuṣayriern dar. ${ }^{153}$ Dabei wird 'Alī als Šāh oder Šāh-i mardān gepriesen und als Gottheit verehrt.

\footnotetext{
147 Zwischen den Stäben des Allāh: dunkelgrün; jetzt Kupferfrass, vereinzelt ging Papier verloren.

148 Vgl. zum Begriff šakl unten bei Anm. 193-208.

149 Vgl. dazu bei Anm. 169-173.

150 Es handelt sich dabei um eine alternative Bezeichnung der Ahl-i Ḥaqq in Iran; vgl. Moosa, Extremist Shiites 117.

$15^{1}$ Moosa, op. cit. 27; 324-336: „The Nusayri religious system: The apotheosis of Ali“.

152 Mélikoff, Hadji Bektach: un mythe et ses avatars 20-24. Eine Bektāšī-Hymne hält u.a. fest: „Men Ali'den gayrı Tanrı bilmezem.“ - „Ich kenne keinen andern Gott als 'Alī." (23).

153 Loc. cit. 204-206.
} 
In dieselbe Richtung weisen die im deskriptiven Teil bereits erwähnten Buchstabenkombinationen, die am Anfang von ausgewählten Suren stehen. ${ }^{154}$ Ausgewählte Kombinationen sind auf den Belegstücken aus Zürich, Leipzig und Berlin mit Abweichungen im Detail jeweils in den oberen Bogen des Buchstabens 'ayn eingefügt worden. ${ }^{155}$ M.A. Amir-Moëzzi macht nun darauf aufmerksam, dass 'Alī in der unter dem Titel Huṭbat al-bayān bekannten und ihm selbst zugeschriebenen Schrift u. a. festhält: „Ich bin das Geheimnis der Buchstaben, ich bin die Bedeutung des tāāwāsin, ich bin der innere Sinn (bāṭin) des hâawāmìm, ich bin der Herr (șāhib) des alif-lām-mìm, ich bin das Nūn wal-qalam."156

Wenn die Buchstabenfolgen in der von M.A. Amir-Moëzzi beigezogenen Fassung der Hut bat al-bayān auch nicht gänzlich mit jenen auf den beigezogenen Rollen übereinstimmen, ${ }^{157}$ wird hier doch die Annahme vertreten, dass die ihnen zugrundeliegenden Auffassungen weitgehend identisch sind. Es fällt auch auf, dass sich 'Alī in der Hutbat al-bayān mehrfach mit Ausdrücken bezeichnet, die zu den Schönen Namen Gottes zählen. Er meint in dieser Schrift ausserdem, dass er selbst die Schönen Namen sei, bei denen man Gott anrufe (anā l-asmā' al-husnā allatì yud'ā bi-hā). Es sei überdies festgehalten, dass sich 'Alī in dieser Predigt als das "Auge Gottes" (anā 'ayn Allāh) bezeichnet. Diese Aussage ruft unwillkürlich die Figur des 'ayn-i 'ali in Erinnerung, kann der arabische Begriff 'ayn doch auch "Auge“ bedeuten. Es ist dies nicht der Ort, M.A. Amir-Moëzzis Überlegungen im Detail aufzugreifen. Bei dieser Gelegenheit ist einfach festzuhalten, dass sich anhand der von

\footnotetext{
154 Vgl. dazu oben bei Anm. 126.

155 Auf dem Zürcher Exemplar handelt es sich um die كهيعص ا حم اعسق انون والقلم | وما Buchstabenfolgen

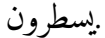

156 Vgl. Amir-Moëzzi, Aspects de l'imāmologie duodécimaine I: Remarques sur la divinité de l'Imām, hier zitiert 213 (mit Anm. 93, S. 214).

157 M.A. Amir-Moëzzi zitiert die Huṭbat al-Bayān in der Fassung Gađfar al-Kašfiss (vgl. loc. cit. 209, mit Anm. 61 und 62).
}

ihm beigezogenen Belegen aufzeigen lässt, dass die Imame und ganz besonders 'Alī auch in Quellen aus der gemässigten Schia vergöttlicht werden.

Die Vergöttlichung 'Alīs ist aber - wie bereits angetönt - unter Gruppierungen aus dem Umfeld der Gulāt-Schia besonders klar ausgebildet. Dazu zählt u.a. die Bektāšiyya. Die göttliche Verehrung 'Alīs lässt sich u.a. anhand einer Hymne Wīrānīs (Vīrānī) aufzeigen. ${ }^{158}$ Wīrānī sieht im Allāh umschreibenden Begriff al-'alī ganz am Ende des Thronverses (Q 2:255: وهو العلى العظيم) einen Hinweis auf 'Alī, den ersten Imām der Schiiten. Wīrānī dürfte im 16. Jh. gelebt haben. Es ist bekannt, dass er der Hurūfiyya angehörte und sich als 'Alīilāhī verstand. ${ }^{159}$ I. Mélikoff macht übrigens darauf aufmerksam, dass sich der in der Bektāšiyya feststellbare Pantheismus in der Hurūfiyya als Vergöttlichung des Menschen äussert. Der Name Gottes manifestiert sich gemäss diesen Auffassungen im menschlichen Gesicht. Man erkennt darin den Namen 'Alīs, der sich für Wīrānī mit Faḍl Allāh Astarābādī, dem Begründer der Hurūfiyya, vermischt. Im Gesicht eines Bektāšīs oder eines 'Alawīs lassen sich die Buchstaben 'ayn, lām und $y \bar{a}^{2}$ erkennen. Sie stehen für den Bogen der Augenbrauen, die Nase und den Schnurrbart. ${ }^{160}$

Abgesehen von den von M.A. Amir-Moëzzi beigebrachten Quellen oder Wīrānīs Hymne lassen sich Vorstellungen von einer göttlichen Natur 'Alīs im islamischen Kulturraum auch bei Ibn Bābawayh feststellen. Ibn Bābawayh ${ }^{161}$ macht jedenfalls

$15^{8}$ Vgl. Moosa, Extremist Shiites 42 mit Anm. 42 (S. 462); mit Verweis auf Jacob, Die Bektāšiyya 39. Amir-Moëzzi, Icon and meditation 28, macht in einem andern Kontext ebenso darauf aufmerksam, dass Gläubige unablässig den Namen des ersten Imams wiederholten, der zugleich der Name Gottes sei.
159

160

161
Zu Wīrānī siehe Mélikoff, Hadji Bektach: un mythe et ses avatars 125, 236-240.

Melikoff, La divinisation d'Ali chez les Bektachis-Alévis 101.

Zu Ibn Bābawayh (gest. 381/991), auch Šayh Ṣadūq genannt, vgl. McDermott, Ebn Bābawayh (2), in EIr. Ibn Bābawayh zählt zu den bedeutendsten Gelehrten und Überlieferern der Zwölferschiiten und ist u.a. der 
ebenso darauf aufmerksam, dass der Begriff al-'ali ganz am Schluss des Thronverses nicht als Attribut zur Umschreibung einer Eigenschaft Gottes zu verstehen ist, sondern dass sich der Begriff al'Alī eben auf 'Alī, Muhammads Milchbruder und Schwiegersohn, bezieht. Er tut dies trotz des im Korantext enthaltenen Artikels. ${ }^{162}$

Vor dem Hintergrund der hier angestellten Überlegungen spricht vieles dafür, dass die diskutierten Dokumente aus Zürich, Leipzig, Berlin und Budapest im unmittelbaren Umfeld des Derwischordens der Bektāšiyya entstanden sind. Da auf den Paralleldokumenten aus Karlsruhe, Stuttgart und München die 'Ayn-i 'alī-Figur selbst fehlt, sind sie mutmasslich mit Kreisen in Verbindung zu bringen, in denen eine explizite Vergöttlichung 'Alīs weniger opportun schien. Die folgenden Ausführungen schenken ausgewählten weiteren Elementen auf den untersuchten Dokumenten Beachtung, die Hinweise auf die in Frage kommenden Gruppierungen enthalten.

6.3.2 Das Schwert Dō l-faqār, die Anrufung der vier rechtgeleiteten Kalifen und der Baum am Rollenanfang: Abgesehen von seiner göttlichen Natur gilt 'Alī im islamischen Kulturraum als Vorbild des mutigen, auf seine Ehre bedach-

Verfasser des Werks Man lā yahḍuru-hū al-faqīh. Siehe zu Ibn Bābawayh ausserdem: Fyzee, Ibn Bābawayh I, in $E I^{2}$.

Ibn Bābawayh, Macān̄ al-ahbār, Tihrān, Maktabat aṣȘadūq, 1959: Ibn Bābawayh hält fest $(55$, 3. Abschnitt; Kapitel „Macānī asmā’ Muḥammad wa-'Alī wa-Fāṭima wa-l-Ḥasan wa-l-Ḥusayn wa-l-a’imma 'alay-him assalām“):

كان رسول الله (ص) ذات يوم جالساً وعنده على وفاطمة

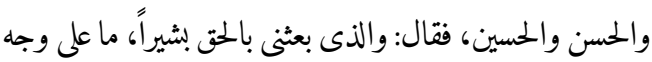
الارض خلق احبّ إلى الله عزّ وجلّ ولا اكَّم عليه منّا، إنّ الله

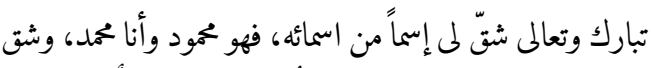

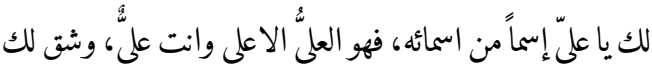

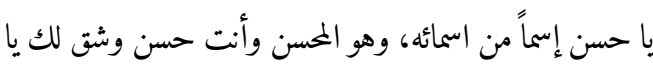

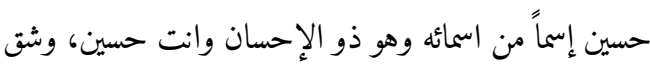
لك يا فاطمة إسماً من اسمائه فهو الفاطر وأنت الفاطمة. ten Jünglings und Kämpfers (arabisch: fatā; persisch: ğawān-mard; vgl. lateinisch: iuventus). Es kann dabei auf das Prophetenwort „Lā fatā illā 'Alī, wa-lā sayfa illā Dū l-faqār" verwiesen werden. ${ }^{163}$ Diese Aussage wird gemeinhin als Hinweis auf 'Alīs ausserordentliche Qualitäten im Kampf interpretiert. Vorliegend kann auf die weitreichenden Implikationen dieses Prophetenworts nicht ausführlich eingegangen werden. Es sei aber darauf hingewiesen, dass die Verehrung 'Alīs nicht allein in der Gulät-Schia selbst bedeutenden Raum einnimmt, sondern auch in den Futuwwa- und AhīBünden eine zentrale Rolle spielte. ${ }^{164}$

Während sich Futuwwa-Gruppierungen bereits früh nachweisen lassen und mit der vom Abbasiden-Kalifen an-Nāṣir li-Dīn Allāh initiierten Reform (1207) an Bedeutung gewinnen, gelten die $A h \bar{\imath}$-Bünde gewissermassen als ihre Nachfolgeorganisation. Die Ahi-Bünde entwickeln sich in Anschluss an den Mongolensturm (Fall der Festung Alamut: 1256; Fall Bagdads: 1258) und bilden in der zweiten Hälfte des 13. Jh. und der ersten Hälfte des 14. Jh. eine wichtige politische und soziale Kraft. Der maghrebinische Gelehrte Ibn Bațūța (1304-1377) beschreibt derartige Bünde im Bericht über seine Reise durch Ostanatolien. ${ }^{165}$ Diese Gruppierungen weisen ihrerseits enge Beziehungen zur islamischen Mystik und den Derwischorden auf und lassen sich davon häufig nur schwer abgrenzen. ${ }^{166}$ S.E. Wolper geht dabei so

163 Calmard, D̄ū 'l-Faqār, in EIr, weist diese Aussage nach bei Ṭabarī, I.3, S. 1359, 1402; Bal'amī, (Ausgabe Rowšan), III, 169; Dihhudā, s.v. Dū l-faqār; cf. Dozy, II, s.v. faqara. Bei den Sunniten geht der Satzteil Là sayfa illā d̄ū lfaqār voraus.

164 Vgl. zu den Futuwwa- und Ahī-Bünden Kapitel 3.2.1-2.

165 Ibn Baț̣ūța, Voyages d'Ibn Batoutah (Defrémery et Sanguinetti). II, 26o-352.

Thorning, Beiträge 214; Taeschner, Zünfte und Bruderschaften 282 und 288-298; Arnakis, Futuwwa traditions in the Ottoman Empire 232; Irwin, Futuwwa 161b; Lewisohn, 'Ali ibn Abi Talib's ethics of mercy 119; Wolper, Cities and Saints 3ob, 77b; Netton, Islam, Christianity and the mystic journey $48 \mathrm{f}$.

166 Vgl. z.B. Taeschner, Der Anteil des Sufismus z.B. $43 \mathrm{f}$ und passim; Wolper, op. cit. 77 . 
weit, die Begriffe $A h \grave{\imath}$, Derwisch und Șūfī gewissermassen als Synonyme zu verwenden. ${ }^{167}$

In späterer Zeit lässt sich das in den FutuwwaGruppierungen und den $A h \bar{\imath}$-Bünden gelebte Ideal in abgeflachter Form in den als șinf (Pl. așnāf) bekannten Handwerksgilden beobachten. ${ }^{168}$ Den folgenden Ausführungen ist der Hinweis vorauszuschicken, dass die Blütezeit der FutuwwaGruppierungen und Ahī-Bünde stricto sensu im Osmanischen Reich im 17.Jh., der Entstehungszeit der meisten hier untersuchten Dokumente, längst vorbei war. Es zeigt sich allerdings, dass Vorstellungen aus diesen Kreisen auch im 17.Jh. weiter nachweisbar sind. Dabei dürfte ihre eigentliche Bedeutung nicht mehr immer wirklich verstanden worden sein.

Für eine Einordnung der hier untersuchten Dokumente ins Umfeld der Futuwwa und damit verwandten Gruppierungen spricht, dass sich jenes Prophetenwort, in dem Muhammad 'Alī als wahren fatā lobt, ganz am Anfang einer hier nicht näher vorgestellten Rolle aus München auch tatsächlich belegen lässt. ${ }^{169}$ Ausserdem enthält B. or. 328 (Leipzig) unmittelbar vor dem Beginn der Qașïdat al-Burda eine Abbildung des D̄u l-faqārSchwerts, dessen Höhe ca. $12.8 \mathrm{~cm}$ misst (АВB. 145). Dieses Schwert wird allgemein mit 'Alī in Verbindung gebracht und fungiert als sein persönliches Erkennungszeichen. ${ }^{170}$ Auf dem Leipziger Exemplar lässt sich im Schwertgriff ein Kreis erkennen, in dem auf fünf Zeilen angeordnete Einzelbuchstaben eingefügt worden sind. Diese Einzelbuchstaben könnten einen Text bilden, der sich allerdings nicht sinnvoll erschliessen liess. ${ }^{171}$ Zwischen

167 Wolper, op. cit., z. B. $77 \mathrm{f}$.

168 Kafadar, Yeniçeri-esnaf relations 57-6o, skizziert wichtige Aspekte dieser Fragestellung.

169 Cod. turc. 42 (München): Zuerst Q 61:13 (Auszug): نصر

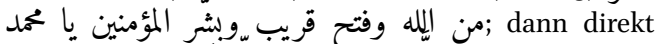

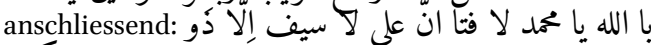
الفقار [كذا].

Gemäss Calmard, Dū 'l-Faqār, in EIr, soll der Prophet dieses doppelklingige Schwert bei der Schlacht von Badr erbeutet und bei der Schlacht von Uhud an 'Alī überreicht haben.

Die vier oberen Zeilen sind golden unterstrichen. Ganz den beiden Klingen des Schwerts stehen in weissen Buchstaben auf goldenem Hintergrund die Namen „Allāh Muḥammad Abū Bakr / 'Umar 'Uțāān 'Alī wa-l-Ḥasan al-Ḥusayn". ${ }^{172}$ Abbildungen von 'Alīs Dū l-faqār-Schwert sind auch auf weiteren Dokumenten in Rollenform nachweisbar, die hier allerdings nicht analysiert werden. ${ }^{173}$

Diese gemeinsame Anrufung der drei ersten Imame der Schiiten ('Alī, Ḥasan und Ḥusayn) mit den drei ersten rechtgeleiteten Kalifen der Sunniten (Abū Bakr, 'Umar, 'Uțānn) ist problematisch, wenn man die Dokumente aus einer ausschliesslich schiitischen Perspektive zu erklären versucht. Diese Feststellung trifft unabhängig davon zu, ob man aus dem Blickwinkel einer moderaten Form der Schia (Zwölferschia) oder einer ihrer GulätAusbildungen argumentiert. Unter den Schiiten ist nämlich das Verfluchen (sabb wa la'nat) der Kalifen Abū Bakr, 'Umar, 'Uțmān weit verbreitet, gelten ihnen diese doch als Usurpatoren, die nach Muhammads Tod die eigentlich 'Alī zustehende Macht an sich gerissen haben. ${ }^{174}$ Allerdings lässt

am Schluss lässt sich die Anrufung yā Allāh erkennen. Allenfalls stehen die Buchstaben für Ziffern.

172 Die Namen der vier rechtgeleiteten Kalifen sind auf der Rolle aus Leipzig zusätzlich bereits in den Randsegmenten des Muhr-i Bilqūs nachweisbar und dort um ihre Beinamen ergänzt (vgl. Anm. 61 und 115): 1. Abū Bakr aṣȘiddīq, 2. 'Umar al-Fārūq, 3. 'Uțmān Dīi (sic) an-Nūrayn, 4. 'Alī al-Murtaḍā. Zur Erwähnung der vier rechtgeleiteten Kalifen auf Dokumenten in Rollenform vgl. 6.2.2.6 (bei Anm. 113-117). Diese vier Namen (Abū Bakr, 'Umar, 'Uțmān, 'Alī) und jene Allāhs und Muhammads werden überdies auf dem Berliner Belegstück gemeinsam erwähnt (vgl. Abb. 10 auf dem Mikrofilm der Rolle).

173 Alīs Schwert $D \bar{u}$ l-faqār lässt sich ebenso nachweisen auf der Rolle Cod. arab. 204 (München), die aus einem osmanischen Umfeld stammt. Für weitere Abbildung des Schwerts vgl. ausserdem Cod. turc. 41 (München) und Ms. or. oct. 146 (Staatsbibliothek Berlin). Das zuletzt angeführte Belegstück lässt sich in die Zeit zwischen 1570 und 1580 datieren (vgl. dazu hier Kapitel 5.1 und Nünlist, Devotion and protection: Four amuletic scrolls from Safavid Persia 86-9o). Bain, The late Ottoman En'am-1 şerif 148-150, weist ausserdem auf Abbildungen von 'Alīs Schwert in En'am-ı şerifHandschriften hin.

Vgl. Calmard, Tabarru', in $E I^{2}$. 
sich die gemeinsame Erwähnung 'Alīs mit den drei ersten rechtgeleiteten Kalifen gerade im Umfeld der Futuwwa-Gruppierungen und der Ahī-Bünde belegen. ${ }^{175}$

Auch die Darstellung eines Baums am Anfang der hier untersuchten Rollen dürfte sich als Reminiszenz an bereits aus dem Umfeld der Futuwwa bekanntes Gedankengut erklären lassen. Er ist auf dem Karlsruher Belegstück besonders detailliert ausgebildet (АВВ. 148), lässt sich in einfacherer teils stilisierter - Ausführung aber auch am Anfang der andern diskutierten Belegstücke nachweisen. F. Taeschner jedenfalls ist in seinen Untersuchungen zum Bundeswesen im Islam mehrfach auf den Ausdruck Šağarat al-futuwwa (Futuwwa-Baum) gestossen. ${ }^{176}$ Der Ausdruck lässt sich bereits am Anfang des 13. Jh. in der von Šihāb ad-Dīn 'Umar as-Suhrawardī verfassten Risālat al-Futuwwa nachweisen. ${ }^{177}$ Beschreibungen dieses Baums lassen sich aber auch in andern Quellen belegen.

Hartabirtī - ein sonst unbekannter Autor, der am Anfang des 13. Jh. aktiv war ${ }^{178}$ - geht in seiner Abhandlung Tuhfat al-wașāya auch auf die Reform der Futuwwa unter dem Kalifen an-Nāșir li-Dīn Allāh ein. Er erwähnt dabei den Baum der Futuwwa und nennt diese einen „Zweig von jenem prophetischen, reinen, sauberen Baum [der Futuwwa] des an-Nāṣir li-Dīn Allāh". ${ }^{179}$ Hartabirtī widmet diesem Baum ein eigenes Kapitel seiner Abhandlung (Kapitel 2) und nennt ihn einleitend den „Baum des Erfolgs“ (šăgarat al-fawz). Er sieht in der šağara țayyiba (Q 14:24) eine Anspie-

175 Vgl. z. B. Yildirim, Shīitisation 58; I.R. Netton weist auf Sulamī (936-1021) hin, der in seinem Kitāb al-Futuwwa Abū Bakr, 'Umar und 'Alī als Wächter der Futuwwa bezeichnet (Netton Islam, christianity and the mystic journey 45, mit Anm. 525). A. Hartmann, an-Nāșir liDìn Allāh (1180-1225) 210, macht auf die hohe 'AlīVerehrung im Zusammenhang mit der Reorganisation der Futuwwwa unter an-Nāṣir li-Dīn Allāh aufmerksam. Taeschner, Zünfte und Bruderschaften. Op. cit. 242. Suhrawardī galt als Hoftheologe des Kalifen an-Nāṣir li-Dīn Allāh; er soll enge Beziehungen zu Derwischkreisen unterhalten haben (vgl. op. cit. 229).

178 Taeschner, Zünfte und Bruderschaften 84.

179 Taeschner, op. cit. 191. lung auf diesen Baum. Die Wurzeln dieses Baums würden fest ruhen auf „Wahrhaftigkeit, Zuverlässigkeit, Frömmigkeit, Enthaltung von Hurerei und Verrichtung des pflichtmässigen Gebets". ${ }^{180}$ Hartabirtī beschreibt den Baum der futuwwa dabei als einen in einer Vase stehenden siebenblättrigen Strauss. Die Blätter des Baums enthalten Beschriftungen mit Erklärungen zu ihren jeweiligen Bedeutungen. Dieser Baum sei ein Hinweis auf den Ritus der futuwwa; jeder Ast sei geschmückt mit einer Frucht; sie deutet jeweils eine der Stationen der fityān an. ${ }^{181}$

Hinweise auf den Baum der futuwwa finden sich ausserdem in einem persischen Futuwwat-nāma des Mawlānā Nāṣirī, das im Jahr 689/129o beendet wurde und zum Schrifttum der Ahī-Bünde zählt. ${ }^{182}$ Auch das von Yahyaā b. Hualīl al-Burgàāī mutmasslich 1365 auf Türkisch verfasste Fütüvvetnāme gehört zur $A h \bar{\imath}$-Literatur. ${ }^{183}$ Burḡāzī äussert sich in Kapitel 4 seiner Schrift zum Baum der futuwwa. ${ }^{184}$ Es handle sich um einen Baum mit Ästen. Der Stamm dieses Baums bedeute, auf dem Weg Gottes Gutes zu tun. Seine Zweige stünden für Rechtschaffenheit und Lauterkeit, seine Blätter für Anstand und Zurückhaltung. Seine Wurzel wiederum stelle Einheitsglaube und Einheitsbekenntnis dar. Während seine Früchte mit der Gotteskenntnis (márifat) und der Gesellschaft der Heiligen in Verbindung gebracht werden, symbolisiert sein Saft das Erbarmen Gottes. Dieser Baum gedeihe unter dem Herz des yiğits ${ }^{185}$. Seine Zweige wüchsen hoch empor und gelangten mit Licht zur

180 Loc. cit. 198 und 199; dabei handelt es sich gemäss F. Taeschner um die fünf Gebote der futuwwa (vgl. 6o9, Anm. 32). Siehe dazu allgemein F. Taeschners Übersetzung von Kapitel 2 aus Hartabirtīs Abhandlung, 198-203.

181 Op. cit. $201 \mathrm{f}$.

182 Op. cit. 301 und 312 (Hinweis auf Kapitel IV über den Baum der futuwwa).

183 Zur Einordnung von Autor und Werk vgl. op. cit. 302 f.

184 Vgl. op. cit. 321 und 346-348.

185 Beim Ausdruck yiğit handelt es sich um eine türkische Lehnübersetzung des arabischen Ausdrucks fatā; siehe dazu Taeschner, Zünfte und Bruderschaften 13, und sein Index s.v. yiğit. 
Majestät Gottes. Der yiğit habe seinen Wohnsitz unter diesem Baum.

Die aus der futuwwa bekannten Ideale lassen sich später - wie bereits angetönt - auch als Ordnungsprinzipien der Zünfte bzw. Handwerksgilden (șinf, Pl. aṣnāf ) nachweisen und beeinflussten deren Ethik massgeblich. Im vorliegenden Kontext relevant sind Äusserungen des Ibn 'Alä' udDīn in seinem Grossen Fütüvvetnāme. Das Werk hat einen eindeutig schiitischen Hintergrund und ist 1524 entstanden. ${ }^{186}$ Ibn 'Alā' ud-Dīn greift in seiner Schrift Aussagen früherer Šayhs auf. Sie hätten die futuwwa mit einem Baum verglichen. Sein Ursprung seien die Eigenschaften Gottes, seine Äste die Qualitäten der Propheten, seine Blätter jene der Heiligen und seine Früchte jene der Gläubigen. Die Wurzel dieses Baums sei das Einheitsbekenntnis und und die reine Gesinnung (tevhīd $u$ ihlāss), seine Äste die Gerechtigkeit und Lauterkeit (sıdq u șafā) und ausserdem die Vertragstreue ('ahd u vefā). Seine Blätter wiederum stünden für Anstand und Schamhaftigkeit (edeb u hayāa), seine Früchte für die Kenntnis Gottes (márifet ullāh). Sein Wohlgeschmack stehe für Edelmut und Freigebigkeit (kerem u sahā); sein Saft stelle das Erbarmen Gottes (rehmet ullāh) dar. ${ }^{187}$ Da 'Alī all diese Eigenschaften in sich vereinigte, sei er als der vorzüglichste fatā gepriesen worden. ${ }^{188}$

Vor dem Hintergrund der hier beigebrachten Belege $^{189}$ kommt man nicht umhin in der Dar-

186 Vgl. Taeschner, op. cit. 407-410. Der vollständige Name des Verfassers lautet Seyyid Mehemmed b. Seyyid 'Alā' ud-Dīn el-Ḥuseynī er-Riżavī; er bezeichnet sich als schafiitischen Qāḍ̄ von Bursa. Seine Schrift ist als Fütüvvetnāme-i kebir und unter dem Paralleltitel Miftāh ud-daqā’iq fi bayān al-futuwwa wa-l-haqā’iq bekannt. F. Taeschner weist auf die eindeutig schiitische Orientierung dieser Schrift hin. Er ruft ausserdem in Erinnerung, dass Bālım Sulțān (gest. 922/1516) zu dieser Zeit die Anhänger Ḥāğǧī Bektāš Velīs (gest. 738/1337) im Derwischorden der Bektāšiyya strikter organisierte.

Man beachte, dass sich die hier aufgezählten Begriffe reimen.

188 Op. cit. $45^{2} \mathrm{f}$.

189 Zusätzlich zu F. Taeschner und den von ihm angeführten Quellen weisen auch die folgenden Wissenschafter auf die Identifikation der futuwwa mit einem Baum stellung des Baums am Anfang der untersuchten Rollen ein Echo dieser Vorstellungen zu vermuten. Es fällt dabei auf, dass Ibn 'Alā' ud-Din explizit festhält, dass dieser Baum in den Eigenschaften Gottes wurzle. Diese Feststellung ruft unmittelbar das Belegstück aus Karlsruhe in Erinnerung (АВB. 149), auf dem der Baum in der Tat aus einem Gitter-Viereck herauswächst, das die Schönen Namen Gottes aufführt. Die Textstelle bei Ibn 'Alā' ud-Dīn macht ausserdem auf die hohe Bedeutung der Einheit Gottes und der reinen Gesinnung (tevhìd u ihlāṣ) in der Futuwwa aufmerksam. Es fällt auf, dass Q 112, al-Ihlāș, das Bekenntnis zum Monotheismus im Koran par excellence, auf den hier untersuchten Dokumenten mehrfach kopiert worden ist. Dies ist wohl nicht zufällig geschehen. 190

6.3.3 Die prominente Erwähnung von Q 61:13, der Begriff šakl, die Siegel (muhr) und das Gebet der Tasse: Es ist davon auszugehen, dass die auf den Rollen zitierten Koranstellen mit Bedacht ausgewählt worden sind. Dies dürfte insbesondere auf Q 61:13 zutreffen. Ein Auszug aus diesem Vers ist unübersehbar in der Krone der Zypresse ganz am Anfang der Dokumente aus Zürich (АВB. 136), Karlsruhe (АВВ. 148), Stuttgart (АВВ. 156) und München (АВB. 153) platziert worden. ${ }^{191}$ Vordergründig verspricht dieses Koranzitat dem Träger der Rolle Hilfe und Sieg im Kampf. Die Platzierung dieser Stelle am Rollenanfang macht durchaus Sinn, wenn man dem Umstand Rechnung

hin: Yildirim, Shi itisation 65 (Anm. 75), und Ohlander, The Futuwwat-nāma of Najm al-Dīn Zarkūb of Tabriz 32.

190 Auch Taeschner, op. cit. 642 (Anm. 30), erkennt im Begriff ihlāṣ bei Ibn 'Alā' ud-Dīn eine Anspielung auf Q 112 .

191 Auf den Belegstücken aus Karlsruhe, München und Stuttgart wurde am Anfang zusätzlich der Thronvers (Q 2:255) kopiert. Da die Belegstücke aus Berlin und Leipzig am Anfang nur unvollständig erhalten sind, fehlen die Zypresse und ein allfälliger Eintrag von Q 61:13 darauf. Im Fall der Rolle aus dem Historischen Museum Budapest lässt sich nicht mehr mit Sicherheit feststellen, ob auf der zwar vorhandenen Zypresse ursprünglich Text enthalten gewesen war. 
trägt, dass derartige Dokumente als Schutzmittel gerade unter Soldaten beliebt gewesen sein dürften. Allerdings dürften noch weitere Aspekte das Einfügen dieses Verses am Anfang der untersuchten Belegstücke beeinflusst haben. Die folgenden Ausführungen machen auf unterschiedliche Aspekte aufmerksam, die dabei zu berücksichtigen sind.

J.K. Birge z.B. weist darauf hin, dass die fragliche Koranstelle (Q 61:13) in der Bektāšiyya auch bei der Initiationszeremonie rezitiert wird. ${ }^{192}$ Initiationszeremonien sind ausserdem von den andern hier bereits mehrfach erwähnten Gruppierungen (Futuwwa- und Ahī-Bünde, Derwischorden, Handwerksgilden) bekannt. Bei diesen Ritualen wird auch die Gürtung ( $\check{s} a d d$ ) des Novizen vollzogen. ${ }^{193}$ Es spricht Verschiedenes dafür, dass sich auch die auf den beigezogenen Dokumenten mehrfach angeführten Begriffe šakl und muhr vor einem solchen Hintergrund erklären lassen. Jedenfalls bringen $\mathrm{H}$. Thorning und F. Taeschner diese beiden Ausdrücke in ihren Untersuchungen zur futuwwa mit den erwähnten Initiationszeremonien in Verbindung.

Der soeben erwähnte Begriff šakl ist aus den Überschriften $\mathrm{zu}$ der schon zuvor analysierten 'Ayn-i 'alī-Figur bekannt. ${ }^{194}$ Auf den ersten Blick ergibt die übliche Bedeutung des Begriffs šakl („Form, Gestalt, Figur“) einen hinreichenden Sinn bei der Übersetzung dieser Überschriften (etwa: „die Figur des erhabenen 'ayn" oder „die erhabene Figur des 'ayn"). H. Thorning ist nun allerdings bei seinen Untersuchungen zum islamischen Vereinswesen im Zusammenhang mit der Initiation und Gürtung des Novizen mehrfach auf die Ausdrücke

192 Birge, The Bektashi order of dervishes 185 und 188.

193 F. Taeschner und H. Thorning weisen darauf hin, dass die Gürtung das zentrale Element der Initiation des Novizen in die futuwwa bilde. Vgl. z. B. die Darstellung bei Ibn al-Mi'mār, Kitāb al-Futuwwa (übersetzt bei Taeschner, Zünfte und Bruderschaften 136-141; siehe ausserdem Taeschners Index 665, s.v. šadd).

194 Zürich: „šakl-i 'ayn-i 'alī“; Leipzig: „šakl al-'ayn almubārak“; Berlin: „šakl-i 'ayn-i 'alī būdur“; Budapest: jetzt unleserlich. šakl, šakla und šakala gestossen, die eine andere Interpretation nahelegen. ${ }^{195}$

Bei der Gürtung (šadd) des Novizen werden in der Regel 3, 5, aber auch 7 Knoten gebunden. Nach dem Anbringen dieser Knoten werden dem Gebundenen die Enden des Gurts rechts und links eingesteckt. Die von H. Thorning beigezogenen Quellen benutzen bei der Beschreibung dieses Vorgangs das Verb šakala (I. Stamm). Das Infinitivnomen (mașdar) dazu lautet šakl. Die gängigen Wörterbücher führen als Bedeutung von šakala u. a. „binden, fesseln“ an. ${ }^{196}$ E. Lane macht in seinem Wörterbuch überdies auf die Wendung šakala al-faras bi-š-šikāl aufmerksam. Sie bedeutet: „he bound the legs of [the horse or] the beast with the rope šikăl“. Der Begriff šikāl bezeichnet dabei einen Gurt, ${ }^{197}$ was im vorliegenden Zusammenhang einen durchaus passenden Sinn ergibt. ${ }^{198}$ Diese Hinweise legen es nahe, den Begriff šakl in den Überschriften zur 'Ayn-i 'alı̄-Figur als Infinitivnomen mit der Bedeutung „Binden, Knüpfen“ zu verstehen. Die Wendung wäre damit zu übersetzen mit „das Binden des erhabenen 'ayn" bzw. „das erhabene Binden des 'ayn'.

Gemäss H. Thorning sagt der Meister (ustād), wenn er dem Gebundenen das rechte Ende des šadd zur rechten Seite einsteckt das islamische Glaubensbekenntnis ins Ohr. Beim Einstecken des linken Zipfels spreche er den unter Schiiten ver-

195 Für die folgenden Ausführungen siehe: Thorning, Beiträge 148-151, 153, 156 (mit Anm. 2), 245, 254 (mit Anm. 3).

196 Wehr, Wörterbuch: „fesseln (ein Reittier mit dem šikāl)“; Kazimirski, Dictionnaire: „1. Lier, attacher (un quadrupède ou oiseau) avec le šikāl“; Dozy, Supplément: „Nouer“. Vgl. zum šikāl die Ausführungen bei Lane, Lexicon, gerade anschliessend. Identische Hinweise auch bei Ibn Manzūin, Lisān al-'arab.

197 Man verwendet ihn, um das Tier am Davonlaufen zu hindern.

198 Thorning, op. cit. 148, macht in diesem Zusammenhang auf weitere Einträge bei R. Dozy (I, 778: „mettre un poignard ou les pans de sa robe dans sa ceinture“) und bei E. Lane aufmerksam. Gemäss E. Lane verwendet man das Verb šakala, wenn eine Frau ihre Locken nach links und rechts festknüpft (so auch gemäss Ibn Manẓūr). 
breiteten Zusatz aus, wonach 'Alī der wal̄̄ Allāhs sei. H. Thorning bringt diese Zeremonie des šakl sodann mit dem Einpflanzen der beiden „Setz-

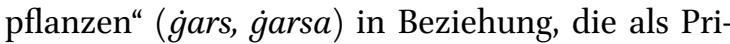
vileg Hasans und Husayns bezeichnet werden. ${ }^{199}$ Die diesbezüglichen Bemerkungen in den von $\mathrm{H}$. Thorning konsultierten Handschriften bringen die Zeremonie des šakl also mit jener der garsa in Verbindung. Sie halten u.a. fest: فاذا عقد الثلاث

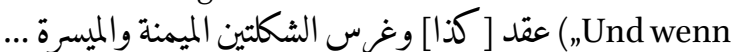
er die drei Knoten geknüpft und die beiden šakla gepflanzt hat, die rechte und die linke usw.“). Diese Quelle erkennt offensichtlich in der Zeremonie des šakl, des Einsteckens der beiden Enden des šadd, eine Beziehung zu Hasan und Husayn. Beim Einstecken der beiden Enden soll man je eine Fätiha an Hasan bzw. Husayn rezitieren. Diese Zeremonie des šakl wird dabei auch muhr aš-šadd genannt.

F. Taeschner ist nun in seinen Untersuchungen zur Initiation des Novizen in Ibn 'Alā' ud-Dīns bereits zuvor beigezogenen grossen Fütüvvetnāme ebenso auf den Begriff muhr aš-šadd gestossen. ${ }^{200}$ Ibn 'Alā' ud-Dīn beschreibt darin, wie Muhammad 'Alī jenen Gürtel umbindet, den ihm der Erzengel Gabriel bei seinem Aufstieg in den Himmel (mi'rāğ) umgelegt hatte. Muhammad bindet dabei 'Alī den Gurt von rechts um die Lenden und rezitiert dazu Lobpreisungen auf Gott. Der Prophet knüpft danach den zweiten Knoten auf den Namen Gabriels und den dritten auf seinen eigenen Namen. Anschliessend habe er, Muhammad, das Siegel darauf gesetzt. F. Taeschner meint, dass dank dieser letzten Geste Gott über die Unverletzlichkeit der einzelnen Knoten wache. Muhammad habe bei dieser Zeremonie die beiden Enden des Gürtels von rechts bzw. links eingesteckt. Die

199 Ein von H. Thorning (S. 149) beigebrachter Kommentar hält zum Bezug der garsa zu Hasan und Husayn fest: „Wie Hasan und Husayn die Geheimnisse 'Alīs sind, so sind in die beiden Garsa alle Geheimnisse des Schedd gelegt, das sind nämlich diejenigen, welche der Ustâdh in das Ohr des Gebundenen sagt. Auf diese Weise ist die ganze Tarîqa erbaut."

200 Die weiteren Ausführungen stützen sich auf Taeschner, Zünfte und Bruderschaften 438.
Futuwwa-Leute würden dies das Siegel der Gürtung (muhr-i šadd) nennen. Diese Beschreibung verdient gerade auch vor dem Hintergrund Beachtung, dass der Begriff muhr auch in der Überschrift zur 'Ayn-i 'alī-Figur auf dem hier nur zur Ergänzung beigezogenen Belegstück Cod. arab. 207 (München) enthalten ist; der Titel lautet darauf Hādā muhr-i Hadrat-i 'Alì radiya Allāh 'an-hū (ABB. 16o). ${ }^{201}$

Es ist nun interessant, dass Ibn 'Alā' ud-Dīn im Grossen Fütüvvetnāme auch die Öffnung des Gürtels als Abschluss der Zeremonie beschreibt. ${ }^{202}$ Drei Tage nach der Gürtung komme der Novize mit einem Geschenk wieder zu seinem Šayh. Er lege dabei seine beiden Hände um die Gürtung und rezitiere Q 48:1-3. ${ }^{203}$ In Hinblick auf die vorliegende Situation ist der Ausdruck fath an dieser Stelle nicht mehr mit „Sieg“, sondern mit „Öffnung“ zu übersetzen, was sich anhand der Grundbedeutung des Begriffs durchaus rechtfertigen lässt. ${ }^{204}$ Bei der Öffnung des ersten Knoten ('uqda) rezitiere der Novize die Sure al-Ihlās.. ${ }^{205}$ Bei der Öffnung des zweiten Knoten sage er Q 61:13, also exakt jene Stelle, die auf den hier beigezogenen Dokumenten am Rollenanfang so prominent kopiert worden ist (ABB. 136, 148, 153, 156). ${ }^{206}$ Er füge dann erneut die Sūrat al-Ihlās an. Beim Öffnen des dritten Siegels,

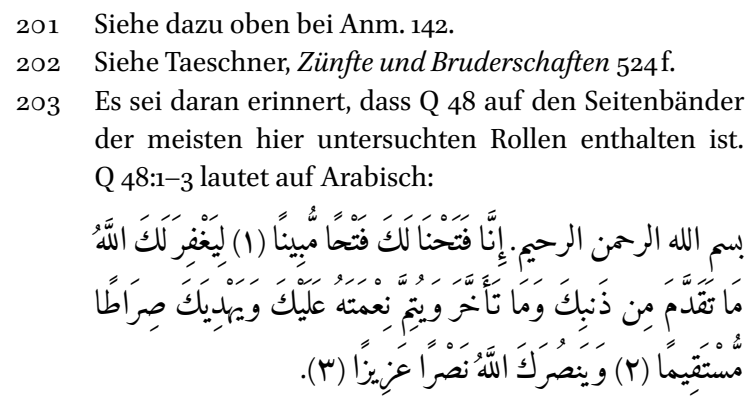

204 F. Taeschner übersetzt: „Siehe, wir haben dir eine offenkundige Öffnung geöffnet, [zum Zeichen,] dass dir Gott deine früheren und späteren Sünden vergibt und seine Huld an dir erfüllt und dich eine gerade Strasse leitet und dass Gott dir mit mächtiger Hilfe beisteht."

205 Also Q 112; sie ist auf den untersuchten Rollen mehrfach aufgeführt.

206 F. Taeschner übersetzt die Stelle in Anbetracht der Situation: „Hilfe von Gott und nahe Öffnung [bzw. Sieg], und verkünde den Gläubigen, o Muhammad!“ 
das als muhr - ganz offensichtlich ein Synonym für 'uqda - bezeichnet wird, rezitiert er Q 7:89b und danach erneut $Q$ 112. Es folgen weitere Koranstellen ${ }^{207}$ und Gebete, die das Lösen der Gürtung abschliessen.

Die Figur Šakl-i 'ayn-i 'alī würde gemäss dieser Darstellung also an das Binden (šakl) jenes Knotens erinnern, der bei der Initiationszeremonie im Namen 'Alīs geknüpft wird. Die fragliche Wendung wäre somit etwa zu übersetzen als „das Binden des 'ayn [im Namen] 'Alīs" (allenfalls: „das Binden des erhabenen 'ayn"). Diesem Aspekt ist bei der Interpretation dieser komplexen Figur zusätzlich zu den bereits oben angestellten Überlegungen Beachtung zu schenken. Ausserdem wird vor dem Hintergrund der beigebrachten Stellen die Auffassung vertreten, dass auch die unterschiedlichen weiteren mit muhr überschriebenen Abschnitte einen unmittelbaren Bezug zu Initiationszeremonien aufweisen. Solche Abschnitte lassen sich gerade auf dem Zürcher Belegstück mehrfach belegen (ABB. 138). ${ }^{208}$

Bis anhin liess sich nicht abschliessend klären, ob allenfalls auch das auf dem Berliner Dokument nachweisbare Gebet der Tasse (Du'ả'-i Qadah) mit Initiationszeremonien in Verbindung zu bringen ist. Es ist aber durchaus möglich, dass dieses Gebet in jenem Moment rezitiert wird, da dem Kandidaten der Becher mit dem Initiationstrunk gereicht wird. 209

Die soeben angestellten Überlegungen laufen darauf hinaus, verschiedene auf den Rollen enthaltene Textstellen und Figuren als Elemente aufzufassen, die bei den religiösen und para-religiösen Zeremonien im Umfeld von Derwischorden und damit verwandten Gruppierungen von Bedeutung

207 Q 110:1-3; Q 3:8; Q 1 (al-Fätiha).

208 Es handelt sich dabei um 1. muhr-i rasül, 2. muhr-i Sulaymān, 3. muhr-i 'azìz und 4. muhr-i šarî́; siehe die Beschreibung oben bei Anm. 52-54 (muhr-i rasül), 5557 (muhr-i Sulaymān), 69 f. (muhr-i aziz) und 71 (muhr-i šariff).

209 Zum Reichen des Bechers mit dem Initiationstrunk siehe z. B. Taeschner, Zünfte und Bruderschaften 17, 59 f., 80,156 f. und 258 . waren. Sie dürften gerade auch mit Initiationszeremonien und den dabei rezitierten Gebeten, Lobpreisungen Gottes oder Muhammads und weiteren Textstellen in Verbindung zu bringen sein. Diese Rollen bauen dabei auf in den „Liturgien“ dieser Kreise relevanten Texten auf. Es sei bei dieser Gelegenheit im Vorbeigehen daran erinnert, dass aus dem byzantinischen Christentum sogenannte Liturgierollen (liturgical scrolls) bekannt sind. Allfällige Bezüge der hier untersuchten Dokumente dazu lassen sich nicht a priori von der Hand weisen. ${ }^{210}$ Aus dieser Perspektive betrachtet können die hier untersuchten Rollen zu einer Reaktualisierung der Initiationszeremonien oder anderer religiöser Zusammenkünfte im Umfeld von Bruderschaften beitragen, aus der ihr Träger gerade in Zeiten der Not Kraft schöpfen kann.

Die untersuchten Dokumente enthalten nicht in jedem Fall ausreichende Hinweise, die eine präzise Zuordnung zu einer bestimmten Gruppierung erlauben. Bei den Belegstücken aus Zürich, Leipzig, Berlin und Budapest steht allerdings - wie bereits aufgezeigt - eine Zuordnung zur Bektāšiyya im Vordergrund. Bei den Rollen aus Karlsruhe, Stuttgart und München (Cod. arab. 206) dürften jedoch in erster Linie Bezüge zu einem andern Derwischorden oder einer Handwerksgilde $(s \inf )$ in Betracht zu ziehen sein. Die Überlegungen zu den historischen Kontexten, in denen diese Dokumente hergestellt und in Gebrauch waren, können allenfalls zur Präzisierung jener Kreise beitragen, die dabei in Frage kommen. ${ }^{211}$ Zuvor sei im Sinn einer Ergänzung allerdings auf zwei weitere auffällige Elemente auf den untersuchten Rollen hingewiesen.

6.3.4 Erwähnung Hiḍrs: Für eine Zuordnung der vorliegenden Dokumente ins Umfeld von $\dot{G}$ ulāt-Gruppierungen spricht allenfalls auch ein zusätzliches Element: Cod. arab. 206 (München) appelliert u.a. an die Schutzwirkung der Schönen Namen Gottes, ${ }^{212}$ die Löblichen Eigenschaften

\footnotetext{
210 Vgl. z.B. Maniaci, The liturgical scroll; Gerstel, Liturgical scrolls.

211 Siehe dazu unten Abschnitt 6.4 (bei Anm. 224-253).

212 Abschnitt Asmā al-ḥusnā (sic), vgl. bei Anm. $87 \mathrm{f}$.
} 
des Propheten, ${ }^{213}$ an die Schutzkraft 'Alīs ${ }^{214}$ und zuletzt an den Propheten Hidrr. ${ }^{215}$ Ein Titelbalken enthält auf diesem Belegstück auf rotem Hintergrund jedenfalls die Überschrift $D u^{c} \bar{a}^{\prime}-i$ Hadrat- $i$ Hidrr („Gebet des erhabenen Hidur“; Ав B. 154). Das Gebet selbst wird direkt anschliessend aufgeführt und ist in eine Doppelzypresse eingefügt worden. ${ }^{216} \mathrm{M}$. Moosa macht in seiner bereits mehrfach zitierten Untersuchung auf die besondere Bedeutung Huiḍrs unter den Qizilbāš in der Türkei aufmerksam. Er betont, dass Hidr aber auch unter

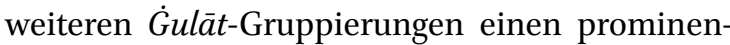
ten Platz einnehme. Er erwähnt in diesem Zusammenhang die Bektāšīs und die Nuṣayrier in Syrien namentlich. ${ }^{217}$

6.3.5 Die Abbildung von Sonne und Mond: Abbildungen von Sonne und Mond, die sich auf einzelnen der hier beigezogenen Dokumente nachweisen lassen, könnten allenfalls ebenso zu ihrer ideologischen Einordnung beitragen. Jedenfalls fallen ganz am Anfang der Karlsruher Rolle an der Spitze der Zypresse zwei goldene Verzierungen auf, die als Mondsichel (unten) bzw. als Sonnenscheibe (oben) interpretiert werden (А B B. 148). ${ }^{218}$ Auch auf der Spitze der Zypresse ganz am Anfang von Cod. arab. 206 (München) lässt sich eine

213 Abschnitt Hilya-i pāk-i Hadrat-i Rasūl.

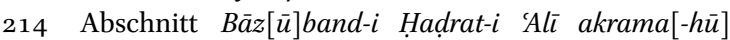
Allāh. Der Begriff $b \bar{a} z[\bar{u}]$ band in der Überschrift zu diesem Abschnitt zeigt allenfalls auf, dass derartige Rollen am Oberarm $(b \bar{a} z \bar{u})$ getragen wurden.

215 Zur Hiḍr-Figur allgemein siehe: Franke, Begegnung mit Khidr; beachte auch Wolper, Khị̂r.

216 Der Text dieses Gebets wurde in Anm. 111 festgehalten.

217 Moosa, Extremist Shiites 445: „The Khadir [= Hiḍr] also had a prominent place among other extremist Shiites, like the Bektashis and the Nusayris of Syria." Vgl. zu Hididr auch op. cit. $106 \mathrm{f}$. M. Moosa verweist im Zusammenhang mit Hiḍrs Stellung zusätzlich auf die beiden folgenden Quellen (534, Anm. 74): a. Hasluck, Christianity and Islam II, 319-336, und b. Dussaud, Nosairis 128-135.

$218 \mathrm{Zu}$ dieser Interpretation vgl. die Beschreibung der Karlsruher Amulettrolle in Petrasch, Die Karlsruher Türkenbeute 382a (Nr. 319). Siehe ausserdem: http://www.tuerkenbeute.de/sam/sam_sch/RA2O4_o2 _de.php. runde Verzierung erkennen (АВ В. 153). Ihre Gestaltung weicht gegenüber dem Belegstück aus Karlsruhe ab. Sie ist auf dem Münchner Exemplar als kreisrunde, goldene Scheibe ausgeführt worden, in deren obersten Teil eine silberne Ellipse eingefügt worden ist. Diese goldene Scheibe auf Cod. arab. 206 liesse sich einerseits als Sonne interpretieren. Anderseits reduziert die eingepasste silberne Ellipse diese Scheibe gewissermassen $\mathrm{zu}$ einer Sichel. Diese Figur würde damit zugleich Sonne und Mond andeuten, die am Anfang des Karlsruher Dokuments auch tatsächlich nachweisbar sind. Wenn diese beiden Elemente auf den weiteren beigezogenen Belegstücken (Zürich, Leipzig, Berlin, Budapest) fehlen, könnte sich dies damit erklären lassen, dass bei ihnen allen der eigentliche Beginn verloren gegangen ist. Die Abbildung von Sonne und Mond am Anfang der beiden Belegstücke aus Karlsruhe und München hat vermutlich eine besondere Bedeutung; sie liess sich bis anhin allerdings nicht mit Sicherheit erschliessen.

Es fällt jedoch auf, dass I. Mélikoff im Zusammenhang mit der Vergöttlichung 'Alīs in der Bektāšiyya auch auf die Bedeutung des Sonnenkults hinweist. ${ }^{219}$ 'Alī wird gern als Sonnengottheit verehrt. Auch der Löwe (haydar) und der Kranich (turna), mit denen 'Alī identifiziert wird, werden mit der Sonne in Beziehung gebracht. ${ }^{220} \mathrm{M}$. Moosa wiederum macht in seiner Untersuchung zur $\dot{G} u l a \bar{t}-$ Schia auf die Bedeutung des Lichts bei den Nușayriern (Alawiten) aufmerksam, die 'Alī ebenso vergöttlichen. ${ }^{221}$ Die Sonne gilt ihnen als Licht des Lichts. Und 'Alī ist im Licht der Sonne verborgen, aus deren Auge ('ayn) er wieder erscheinen wird. ${ }^{222}$

219 Mélikoff, Hadji Bektach: un mythe et ses avatars 22-24. 220 Es kann auch an die Darstellungen des Löwen erinnert werden, hinter dem die Sonne aufgeht (š̈r wa huršld). Beachte für einen Einstieg zur Frage den Beitrag auf Persisch unter: http://fa.wikipedia.org/wiki/_شيروف خورشيد (mit Abbildungen).

221 Moosa, Extremist Shiites 256-257 (Grundzüge des Problems), und 337-341 (v.a. 337-339): „28. The Nusayris concept of light: Shamsis and Qamaris“.

222 Es wird hier an die Figur 'Ayn-i 'alī erinnert; viel- 
Unter den Nuṣayriern gibt es allerdings zwei Gruppierungen, die unterschiedliche Auffassungen zur Rolle der Sonne bei der Verehrung ihres Gottes 'Alī vertreten. Die Qamarīs, die Mondverehrer (von arabisch qamar, Mond) glauben, dass 'Alī im Mond zu Hause ist. Die schwarzen Flecken, die auf dem Mond sichtbar sind, sind gemäss diesem Standpunkt Merkmale des verehrten 'Alī. Er habe einen Körper, Arme, Beine, trage eine Krone und sei mit dem Schwert $\underline{D} \bar{u}$ l-faqār bewaffnet. Die Šamsīs (von arabisch šams, Sonne) stellen sich hingegen auf den Standpunkt, dass 'Alī für die Morgensonne stehe und die Sonne sein Wohnsitz sei. Sie halten 'Alī auch für den Erschaffer des leuchtenden Vollmonds. Für die Šamsīs steht deshalb fest, dass die Sonne als Wohnsitz des Schöpfers der Verehrung würdiger ist als der Mond, der erschaffen worden ist.

Diese Bemerkungen können erst in ganz allgemeiner Form auf eine allenfalls bei der Interpretation der Abbildung von Sonne und Mond auf den diskutierten Dokumenten zu beachtende Problematik hinweisen. M. Moosa macht in seiner Diskussion der Standpunkte der Šamsīs und Qamarīs auf zusätzliche Implikationen aufmerksam, denen bei einer weiteren Auseinandersetzung eingehender Beachtung zu schenken wäre. ${ }^{223}$ Es sei einfach in Erinnerung gerufen, dass die soeben vorgebrachte Erklärung der Abbildung von Sonne und Mond einstweilen nicht gesichert ist.

\subsection{Zum historische Kontext}

Die vorangehenden Ausführungen legen nahe, dass die in diesem Kapitel diskutierten Rollen aus osmanischen Kontexten unter Gläubigen allgemein beliebt waren. Oft dürften sie aus dem Umfeld heterodoxer Kreise stammen. Dabei steht in den vorliegenden Fällen zumeist eine Zuord-

leicht können M. Moosas hier vorgestellte Ausführungen zusätzlich zu ihrer Erklärung beitragen.

223 Auch Moosa, op. cit. 337-339, „28. The Nusayris concept of light: Shamsis and Qamaris“, skizziert diese Implikationen erst grob. nung zur Bektāšiyya im Vordergrund, die im Osmanischen Reich besonders aktiv war. Die Bektāšiyya ist bis heute auf dem Balkan vertreten; sie ist bzw. war aber auch in weiteren Regionen Südosteuropas aktiv (z.B. Bulgarien, Rumänien, Ungarn). Auch Vorstellungen, die sich im Umfeld der aus der Futuwwa-Bewegung und den Ah̆̄-Bünden hervorgegangenen Handwerksgilden (șinf, Pl. aṣnāf) und in bestimmten Derwischorden nachweisen lassen, können aber bei der Erklärung ausgewählter weiterer Elemente von Bedeutung sein, die auf den untersuchten Dokumenten enthalten sind. Dieser Umstand spielt bei der Eingrenzung jener Gebiete eine Rolle, in denen die in diesem Kapitel diskutierten Belegstücke in Gebrauch waren und allenfalls auch hergestellt wurden.

In den folgenden Ausführungen steht in einem ersten Schritt das Dokument aus dem Historischen Museum Budapest im Vordergrund. Es wurde bei archäologischen Grabungen auf dem Palasthügel in Budapest in einem Schacht von $2 \times 2 \mathrm{~m}$ Seitenlänge und einer Tiefe von $14 \mathrm{~m}$ nördlich der königlichen Stallungen entdeckt. ${ }^{224}$ Die Funktion dieses Schachts ist nicht geklärt. ${ }^{225}$ Die Funde aus dem oberen Teil des Schachts $(2-8 \mathrm{~m})$ stammen aus dem 18. und 19. Jh.; es handelt sich zumeist um Keramik. Im Bereich von 7-11 m unter der Oberfläche gehören die Fundstücke zur Osmanischen Zeit. Noch weiter unten wurden Fundstücke aus dem späten Mittelalter (14.-16. Jh.) entdeckt. Dazu zählt auch ein Seidengewebe mit den Wappen der ungarischen Königshäuser.

Da Buda von 1541 bis 1686 Zentrum der von den Osmanen in Ungarn eingerichteten Provinz (vilayet) war, ${ }^{226}$ ist diese Rolle aufgrund der archäo-

224 Die Grabungen begannen 1994, konnten aus technischen Gründen aber erst 1999 fortgesetzt werden. Die hier angeführten Angaben zur Ausgrabung stammen von den Informationstafeln zum diskutierten Objekt im Historischen Museum Budapest.

225 Der Schacht könnte ursprünglich als Brunnen gedient haben; allerdings fehlen Wasserspuren. Später scheint er als Abort und Abfallgrube gebraucht worden zu sein. Géza, Buda, in $E I^{3}$. Süleymān der Prächtige (regierte 1520-1566) war nach der Schlacht von Mohács am 5. Dū l-Hiğğa 932/12. September 1526 in Buda einmarschiert. 
logischen Evidenz mit dieser Zeit in Verbindung zu bringen. Auch ist darauf hinzuweisen, dass die Osmanen die Vorteile des Palasthügels in Buda als Festungsplatz zu schätzen wussten. Aufgrund der gegenüber den Parallelstücken aus Zürich, Leipzig und Berlin deutlich einfacher ausgeführten Gestaltung des Abschnitts mit dem 'ayn wird die Rolle aus Budapest hier eher der 2. Hälfte des 16. Jh. als der 1. Hälfte des 17. Jh. zugeordnet. Ob das Dokument in Budapest selbst angefertigt wurde oder aus Istanbul oder einer andern Gegend des Osmanischen Reichs stammt, lässt sich nicht entscheiden. ${ }^{227}$ Es ist aber bekannt, dass die Bektāšiyya bereits im 16. Jh. in Budapest vertreten war. An ihre Präsenz in Ungarn und in Budapest selbst erinnert noch heute die Türbe, die dort zu Ehren des Bektāšiyya-Heiligen Gül Bābā errichtet wurde. ${ }^{228}$

Eine zeitliche Einordnung der hier diskutierten Rollen ins 17. Jh. wird durch entsprechende Einträge in den Kolophonen einzelner Dokumente klar gestützt. So lässt sich der Abschluss der Abschrift von B. or. 328 (Leipzig) auf den 21. Rağab 1041/12. Februar 1632 datieren. ${ }^{229}$ Ein halbes Jahrhundert später wiederum ist Cod. or. $8^{\circ} 83$ (Stuttgart) entstanden (20. Dū l-Hiğğa 1093/2O. Dezember $\left.{ }_{1682}\right)^{230}$ In dieselbe Richtung weist überdies eine tugra-ähnliche Marke auf dem Behältnis, in dem das Belegstück aus Karlsruhe aufbewahrt wurde (АВВ. 151). Aufgrund dieses Hinweises lässt sich die Büchse in die Zeit Sultān Ibrāhīms (regierte 1640-1648) datieren. Mit an Sicher-

227 Prof. Dr. A. Fodor äusserte diese Vermutungen zur örtlichen und zeitlichen Einordnung in einer Diskussion mit dem Verfasser am 11. Juni 2014 in Budapest.

Vgl. zu Gül Bābā und seiner Tekke bzw. Türbe in Buda: Fekete, Gül-Baba et le Bektāšī Derkāh de Buda. Mehmed Pasha hat diese Tekke zu Beginn der osmanischen Herrschaft in Ungarn zwischen 1543 und 1548 errichtet (loc. cit. 1). L. Fekete äussert ernsthafte Zweifel an der Historizität der Person Gül Bābās (loc. cit. 7-10: „La silhouette du derviche mort se projetait toujours d'une manière plus grandiose dans la perspective des temps et qu' on savait entourer sa personne de contes et de légendes d' autant plus nombreux qu' il s' éloignait d' avantage dans l' histoire." S. 9).

229 Vgl. die Angaben in Anm. 6.

230 Vgl. die Angaben in Anm. 10. heit grenzender Wahrscheinlichkeit stammt auch die Rolle selbst aus dieser Zeit. ${ }^{231}$

Das Karlsruher Dokument ist ausserdem interessant, da es aus der dortigen Türkenbeute stammt. Es dürfte sich wahrscheinlich bereits in einem alten Karlsruher Inventar aus dem Jahr 1688 nachweisen lassen. ${ }^{232}$ Die Zugehörigkeit dieses Belegstücks zur Türkenbeute ruft die kriegerischen Auseinandersetzungen in Erinnerung, die im 16. und 17. Jh. zwischen europäischen Mächten, allen voran Österreich-Ungarn, und den muslimischen Osmanen im Gang waren. Die Europäer dürften Dokumente von der hier diskutierten Art oft bei Schlachten gegen ihre osmanischen Feinde erbeutet haben. ${ }^{233}$

Auch das Zürcher Dokument könnte aus Kriegsbeute stammen. Die Zentralbibliothek Zürich besitzt mehrere Dokumente, die gemäss handschriftlichen Einträgen beim Entsatz von Wien im Jahr 1682 ( sic) in westliche Hände gelangten. ${ }^{234}$ Es handelt sich um einen aufwendig gestalteten Almanach $^{235}$ und mehrere Dokumente adminis-

231 Es ist zwar grundsätzlich problematisch, bei den hier untersuchten Dokumenten aufgrund der Datierung des Behältnisses auf die Entstehungszeit der darin enthaltenen Rolle selbst zu schliessen. Jüngere Rollen können ohne weiteres in ältere Behältnisse gesteckt worden sein oder umgekehrt. Auch könnten später neue oder aufwendiger ausgeführte Behältnisse eine einfachere frühere Schutzhülle ersetzt haben. Im Fall des Karlsruher Belegstücks dürften Behältnis und Rolle aber von Anfang an zusammengehört haben.

Vgl. Inventarium über die fürstliche Rüst Cammer zu Carlsburg, 1688 (GLA 47/696): „Ein Silbern Buchs, worin das Alcoran. Haben Ihr dhlt: Mein Gnädigster Herr, gleich zuhanden genomen." Hinweis aus Petrasch, Die Karlsruher Türkenbeute 382 (Nr. 319, Anfang).

233 Zur mutmasslichen Herkunft der Karlsruher Sammlung vgl. Petrasch, Die Karlsruher Türkenbeute 1-51, v. a. 1-17. Kürzere Darstellung in Petrasch, Türkenbeute: eine Auswahl IX-Xxvir.

234 Die erwähnten Einträgen stammen aus Ms. or. 6 und 24 (siehe folgende Anm.); sie datieren den Entsatz Wiens wohl irrtümlich ins Jahr 1682. Der zweite Entsatz Wiens fand aber in der Tat im Jahr 1683 statt; siehe dazu Kreutel, Beč, in $E I^{2}$.

235 Nünlist, Katalog 28 (Ms.or. 6). Beachte den handschrift- 
trativer Art. ${ }^{236}$ Obwohl auf der Zürcher Rolle ein derartiger Hinweis fehlt, lässt sich nicht ausschliessen, dass auch sie beim Entsatz von Wien in westliche Hände fiel. Das Fehlen eines entsprechenden Vermerks auf dem Dokument selbst liesse sich damit erklären, dass man sich dessen hohen kunsthistorischen Werts bewusst war und es nicht unnötig verunstalten wollte. Ein Begleitzettel mit Angaben zur Herkunft des Dokuments, wie er im Fall von Ms. or. 24 erhalten geblieben ist, könnte seit der Schenkung an die Burgerbibliothek Zürich, eine Vorläuferinstitution der heutigen Zentralbibliothek, im Jahr 1774 abhanden gekommen sein.

Ergänzend sei auf jenen Junker Landvogt Zoller von Baden hingewiesen, der im Fall von Ms. or. 6 und Ms. or. 24 als Schenker aufgeführt wird. ${ }^{237}$ Es dürfte sich um Johann Jacob Zoller, den Besitzer umfangreicher Kollektaneen, handeln, der von 1721-1792 lebte. ${ }^{238}$ Die Zoller waren eine Zürcher Junkerfamilie, die mit Ausnahme einiger Geistlicher v.a. im Militär- und Staatsdienst tätig war. Sie gehörten ab spätestens 1545 bis zum Erlöschen des Zürcher Zweigs 1792 zur Gesellschaft der Schildner zum Schneggen. ${ }^{239}$ Der Hinweis, dass Angehörige dieser Familie Aufgaben im Militärdienst übernahmen, wirft die Frage auf, ob allen-

lichen Eintrag auf der letzten Seite des Dokuments: „Dieses Mscrpt ist bei dem Entsatz von Wien A. 1682 in den türkischen Lager gefunden und A. 1774. von Junker Landvogt Zoller der Burgerbibliothek in Zürich verehrt worden."

Op. cit. Ms.or. 24.0 und 24.1-5 (S. 84). Auf dem Umschlag, in dem diese Dokumente aufbewahrt werden (24.0), steht: „Türkische, mit einem Stämpel bezeichnete Schriften, die in dem Türkischen Lager nach dem Entsatz v: Wien 1682 gefunden worden: 5. Stk. Der Burger Bibliothek in Zürich von Jnkr Landvogt Zoller: von Baden 1774.“

237 Mit bestem Dank an den Historiker Dr. Beat Hodler, Bern, für die folgenden Hinweise.

238 Vgl. Cattani, Zentralbibliothek Zürich: Schätze aus vierzehn Jahrhunderten 15 o.

239 Vgl. Hürlimann, Artikel "Zoller“, in Historisches Lexikon der Schweiz. Siehe: http://www.hls-dhs-dss.ch/textes/ d/D2386o.php?topdf=1. Mit Verweis auf C. KellerEscher, Promptuarium genealogicum, o.J. (Zentralbibliothek Zürich, Handschriftenabteilung). falls ein Vorfahre des Schenkers persönlich am Entsatz von Wien beteiligt gewesen war. Dies liess sich bis anhin nicht klären. Eine Antwort fände sich allenfalls im umfangreichen Nachlass eines andern Angehörigen der Familie in der Zentralbibliothek Zürich, der sich vorliegend allerdings nicht auswerten liess. ${ }^{240}$ Das Geschlecht der Zoller erlosch in Zürich mit dem Tod des mutmasslichen Schenkers.

Aus den hier angestellten Überlegungen geht mit grosser Sicherheit hervor, dass die in diesem Kapitel untersuchten Rollen auf die eine oder andere Art mit kriegerischen Auseinandersetzungen zwischen den muslimischen Osmanen und den christlichen Europäern in Verbindung zu bringen sind. Dies wiederum legt die Vermutung nahe, dass die Osmanen diese Dokumente als Schutzmittel im Kampf auf sich trugen und ihnen damit auch eine Amulettfunktion zukam.

Wenn wir bisherige Erkenntnisse vorübergehend wieder ausblenden, lassen auch verschiedene Elemente auf den einzelnen Rollen eine derartige Funktion der Dokumente als naheliegend erscheinen. So ist der Abschnitt unmittelbar vor der Figur mit dem 'Ayn-i ál̄ auf dem Berliner Belegstück mit der Überschrift Yavuzluqdan emin olmaq-icün ${ }^{241}$ versehen. Aus diesem Titel lässt sich schliessen, dass das Dokument seinem Träger Mut und Tapferkeit verleihen sollte; es sind dies Eigenschaften, die gerade den erfolgreichen Kämpfer auszeichnen. Auch die unmittelbare Bedeutung des ganz am Anfang der Dokumente aus Karlsruhe, Zürich, Stuttgart und München ${ }^{242}$ platzierten Zitats von Q 61:13 stellt ihren Trägern oder Besitzern Erfolg und Sieg im Kampf in Aussicht. ${ }^{243}$

240 Vgl. Nachlass des Hans Wilpert Zoller (Stadtschreiber in Zürich und Historiker, lebte 1673-1757): Zentralbibliothek Zürich, Ms. J 21-434 (sporadisch), Ms. P 64286429, Ms. V 442 (https://www.helveticarchives.ch/detail .aspx? ID =175055).

241 „Um sich der Strenge [des Muts, der Tapferkeit] sicher zu sein." Vgl. bereits oben Anm. 72.

242 Bayerische Staatsbibliothek, München, Cod. arab. 206; auch Cod. turc. 42.

243 Auf all diesen Dokumenten steht am Anfang auf der Krone der Zypresse Q 61:13 (Auszug): نصر من الله وفتح 
Die Abschrift von Q 48, al-Fath (Der Sieg), auf dem Seitenband der untersuchten Rollen, legt eine solche Interpretation ebenso nahe. In dieselbe Richtung deuten sodann, wie bereits aufgezeigt, die Hinweise auf 'Alī und sein Schwert Du l-faqār. ${ }^{244}$ Es fällt ausserdem auf, dass die diskutierten Dokumente mehrfach auf das Konzept des tawakkul, des bedingungslosen Vertrauens des Gläubigen auf Gott, aufmerksam machen. ${ }^{245}$

All diese Beobachtungen legen die Annahme nahe, dass derartige Rollen v.a. bei Angehörigen der Osmanischen Truppen beliebt waren. Überdies dürften sich auch Gläubige ganz allgemein damit gegen allerhand Unbill des Lebens geschützt haben. ${ }^{246}$ Es zeigt sich dabei, dass derartige Dokumente in ganz unterschiedlicher Qualität angefertigt worden sind. Unter den hier näher untersuchten Belegstücken wurde bei der Herstellung der Exemplare aus Zürich, Leipzig, Karlsruhe und Budapest (Historisches Museum) ein auffällig hoher Aufwand betrieben. ${ }^{247}$ Dies lässt sich allein schon anhand des ausgesuchten Beschreibstoffs festhalten, bei dem es sich um äusserst feines, nahezu transparentes, sehr gut geglättetes Papier handelt. Auch die weitere Ausführung die-

Dieser Eintrag dürfte ursprünglich auch am Ánfang der Rollen aus Berlin und Leipzig gestanden haben, der jetzt allerdings in beiden Fällen fehlt. Es fällt auf, dass dieser Auszug aus Q 61:13 auch auf dem hier nicht näher untersuchten Belegstück B. or. 322 (Leipzig) steht; in diesem Fall wird in Anschluss an Muhammad zusätzlich 'Alī angerufen. Būs̄inīs Qașidat al-Burda schliessen, die den Abschluss sämtlicher hier vorgestellter Dokumente bildet. Solche Rollen dienten somit als Breitbandschutzmittel gegen allerhand Widrigkeiten.

247 Das Belegstück aus Berlin ist jedoch von deutlich geringerer Qualität. Dies lässt sich unabhängig von seinem schlechten Erhaltungszustand festhalten. Auch das kurz erwähnte Dokument aus der Ungarischen Nationalbibliothek, Budapest (Duod. Arab. 5), zählt zu den Dokumenten einfacher Machart und dürfte für einen Gläubigen aus der breiten Masse angefertigt worden sein. ser vier Dokumente deutet darauf hin, dass sie für Angehörige der Eliten angefertigt wurden. ${ }^{248}$ Es sei nur an die aufwendig gestalteten Ornamente, die sorgfältige Farbwahl, die Verwendung von goldener Farbe ${ }^{249}$ und die aufmerksam ausgeführten Abschriften der Textstellen auf diesen vier Exemplaren erinnert. ${ }^{250}$

Vieles spricht damit dafür, dass diese Dokumente für Angehörige der osmanischen Elitetruppen, die Janitscharen, angefertigt worden sind. Ein solcher Bezug liegt auch nahe, da die engen Beziehungen zwischen der Bektāšiyya und den Janitscharen allgemein bekannt sind. ${ }^{251}$ Ausser-

248 J. von Hammer-Purgstall äussert zwar die Vermutung, dass sich jene Krieger mit derartigen Rollen schützten, die nicht über ausreichende finanzielle Mittel verfügten, um eine Abschrift des gesamten Korans $\mathrm{zu}$ erstehen. Derart allgemein formuliert dürfte diese Feststellung allerdings kaum zutreffen. Es gilt doch dem Umstand Rechnung zu tragen, dass es auf Reisen oder im Krieg viel praktischer war, kleinere Schutzmittel mitzuführen als grosse Prachtskorane. Vgl. von Hammer-Purgstall, Ueber die gefeyten talismanischen Hemden der Moslimen 28.

249 So auf B. or. 328 , Leipzig.

$25^{\circ}$ Es fällt auf, dass bei der Herstellung von Cod. or. $8^{\circ} 83$ (Stuttgart) ein deutlich geringerer Aufwand betrieben wurde, was u. a. in der Verwendung eines hellen Grüns zum Ausdruck kommt. Dies lässt sich als Hinweis darauf verstehen, dass sich in Hinblick auf die Belagerung Wiens im Jahr 1683 zahlreiche Krieger derartige Schutzmittel beschaffen wollten. Die Kopisten und Miniaturisten könnten dadurch unter Zeitdruck geraten sein. Für eine solche Interpretation spricht die Datierung des Belegstücks aus Stuttgart, dessen Herstellung am 2o. Dū l-Hiğğa 1093/20. Dezember 1682 abgeschlossen wurde. Der zweite Entsatz von Wien fand kurz darauf im Jahr 1683 statt.

251 Zu den Beziehungen zwischen der Bektāšiyya und den Janitscharen siehe Karamustafa, God's unruly friends 83 f. und 95. Darin S. 84: „The reason for the success of the Bektāşis was the firm connection with the Ottoman military system: the Janissaries, by long-standing tradition, paid allegiance to Hāēi Bektāş, the patron saint of the Bektāşī group." A.T. Karamustafa macht in Anm. 71 (S. 133) auf zahlreiche weitere Belege für die engen Beziehungen zwischen den Bektāšīs und den Janitscharen aufmerksam.

Man beachte zusätzlich Mélikoff, Hadji Bektach: Un mythe et ses avatars 101f., 151-153, und ihr Index s.v. "Janissaires“; dieselbe, Un ordre de derviches colonisa- 
dem weiss man, dass Bektāšiyya-Gruppierungen und Angehörige der Janitscharen-Truppen sowohl in Konkurrenz zu, aber auch in engem Austausch mit den Handwerksgilden standen und die in diesen Kreisen vertretenen Auffassungen massgeblich beeinflusst hatten bzw. teilten. Es sei daran erinnert, dass Handwerksgilden dazu verpflichtet werden konnten, Feldzüge des Osmanischen Sultans durch Materiallieferungen oder durch das Stellen von Truppenkontingenten zu unterstützen. ${ }^{252}$

Zwar lässt sich die genaue Herkunft der untersuchten Belegstücke nicht mit letzter Sicherheit beweisen. Es bestehen allerdings doch zahlreiche Hinweise darauf, dass die osmanischen Soldaten derartige Dokumente bei ihren Feldzügen auf sich trugen. Diese Rollen zielten damit also auch auf eine moralische Stärkung ihrer Träger im Kampf ab. J.C. Vadet spricht in einem andern Kontext im Zusammenhang mit Angehörigen von FutuwwaBünden von einem réarmement moral. ${ }^{253}$

teurs: les Bektaşis 118-123. Auch Fekete, Gül-Baba et le Bektāšī Derkāh de Buda; L. Fekete hält u.a. fest (S. 2): „Pečevī raconte que les ghazis de Buda ayant rapporté un grand bouc d'une de leurs entreprises militaires, l'ont remis au Gül-Baba-tekke pour être immolé - ce qui prouve que les tekke de Buda tout comme les bektāš̄-tekke en général étaient en rapport étroit avec les Janissaires.“ S. 3: „En temps de guerre, [les derviches bektāšīs] partaient eux aussi en campagne avec les soldats pour stimuler leur zèle guerrier." Siehe auch S. 7 f.: Gül Bābā selbst soll an zahlreichen Feldzügen, auch an der Eroberung Budas, teilgenommen haben.

Kafadar, Yeniçeri-eșnaf relations 65 : „In a practice that can be dated as far back as the fourteenth century [...] the government required a number of guilds to send their members to military campaigns." Vgl. auch Yi, Guild dynamics $192 \mathrm{f}$.: „It is well known that the guilds had to provide the army with tradesmen who would serve them on the battlefield.“ - „Not only were guildsmen expected to accompany campaigns to remote places such as Poland or Iraq, but also the remaining members of the guild had to provide for the orducu tradesmen during their war service and also for livelihood of their families back to Istanbul.“ - „Given the incessant warfare in the early to mid-seventeenth century, the burden shouldered by the guilds for military recruits must have been considerable."

\subsection{Abschliessende Bemerkungen}

In der bisherigen westlichen Forschung werden Dokumente von der hier vorgestellten Art mit Vorliebe mit der Magie (sihr) und den Debatten über ihr Erlaubtsein in Verbindung gebracht. Zu den Hauptvertretern der islamischen Magie zählen Būnī, Tilimsānī und Pseudo-Mağrìțī. ${ }^{254}$ Es ist auch völlig unbestritten, dass auch die in diesem Abschnitt (Kapitel 6) vorgestellten Belegstücke wiederholt unterschiedliche, aus der Magie bekannte inhaltliche und gestalterische Elemente aufweisen. Sie lassen sich gerade auch in Werken der soeben angeführten Autoren belegen (z.B. geheimnisvolle Buchstaben am Surenanfang, Wahl der kopierten Koranverse und Gebetstexte, Gitter, Netze, Buchstabenquadrate, Hexagramme als Hinweis auf Salomon, besondere Anordnung von Textstellen).

Auch dieses Kapitel (6) machte zwar bei der Beschreibung der Dokumente auf diese Elemente aufmerksam, rückte ihre Bedeutung in der Magie aber bewusst in den Hintergrund. Dies erklärt sich aus der Auffassung, dass einzelne magische Elemente auf einem bestimmten Belegstück nicht auch dem Objekt als Ganzem magische Eigenschaften verleihen. Eine zu starke oder sogar ausschliessliche Interpretation dieser Belegstücke aus der islamischen Magie heraus wird ihrer eigentlichen Bedeutung und der Klärung der konkreten Umstände und Umfelder nicht gerecht, mit denen sie in Verbindung zu bringen sind. Es wird hier der Standpunkt vertreten, dass die in diesem Abschnitt (Kapitel 6) untersuchten Rollen und vergleichbare Dokumente unter Gläubigen allgemein beliebt waren. Oft sind sie im Umfeld heterodox ausgerichteter Gruppierungen entstanden (GंulätSchia, Sufi-Orden (țariqa), Futuwwa- bzw. AhīBünden, unter dem Begriff șinf bekannte gildenartige Korporationen). Bei den im vorliegenden Beitrag vorgestellten Dokumenten liegen zumeist Bezüge zur Bektāšiyya nahe. Im Fall von Beleg-

254 Vgl. dazu Nünlist, Dämonenglaube 389 (mit Anm. 7479). 
stücken aus andern historischen Kontexten dürften Abhängigkeiten von andern Gruppierungen zum Tragen kommen, wie in den Kapiteln 4 und 5 aufgezeigt wurde.

Die Affinität gewisser heterodox orientierter Kreise zur Magie kann dabei nicht in Abrede gestellt werden. Im Fall der Bektāšiyya ist an die Integration von verfolgten Angehörigen der Hurūfiyya zu erinnern. Die in diesen Kreisen vertretenen Auffassungen dürften die Rezeption von aus der Magie bekannten Vorstellungen begünstigt haben. Es bleibt allerdings zu betonen, dass bei der Untersuchung derartiger Dokumente in Rollenform einer Erklärung aus der Magie heraus weniger Raum zugestanden werden sollte, als dies bis anhin gerade in der westlichen Forschung geschehen ist. Anders zu entscheiden, liefe darauf hinaus, den sekundären Zugang, also die Erklärung aus der Magie heraus, als das Primäre darzustellen. 


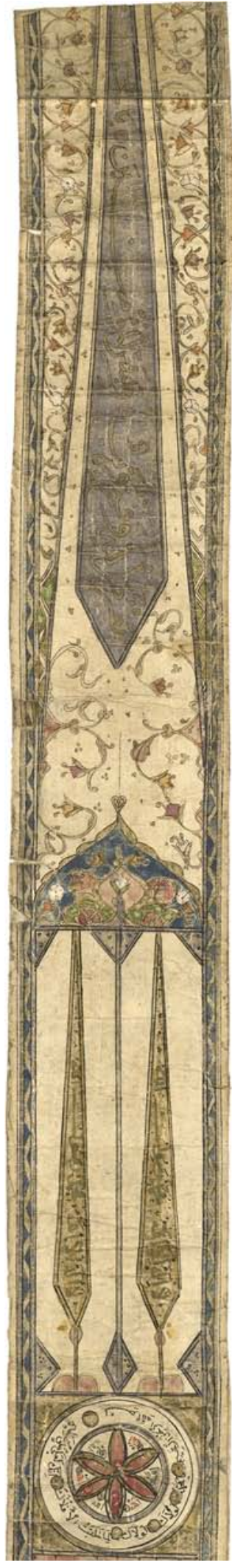

АВв. 136

Zentralbibliothek Zürich, Ms.or. 20 (vgl. bei Anm. 28-3o, bei Anm. 191, bei Anm. 205f.): Am Anfang des erhaltenen Teils der Rolle aus Zürich befinden sich zwei Abschnitte mit Lanzetten. Der Hintergrund der ersten Lanzette ist silbern. In goldener Schrift steht hier aufsteigend ein Auszug aus Q 61:13: „Nașr min Allāh wa-fath qarīb wa-baššir al-mu’minīn yā Muhammad.“ Auf den beiden goldbraun ausgefüllten Lanzetten darunter stehen in grüner Schrift Teile der šahāda. 


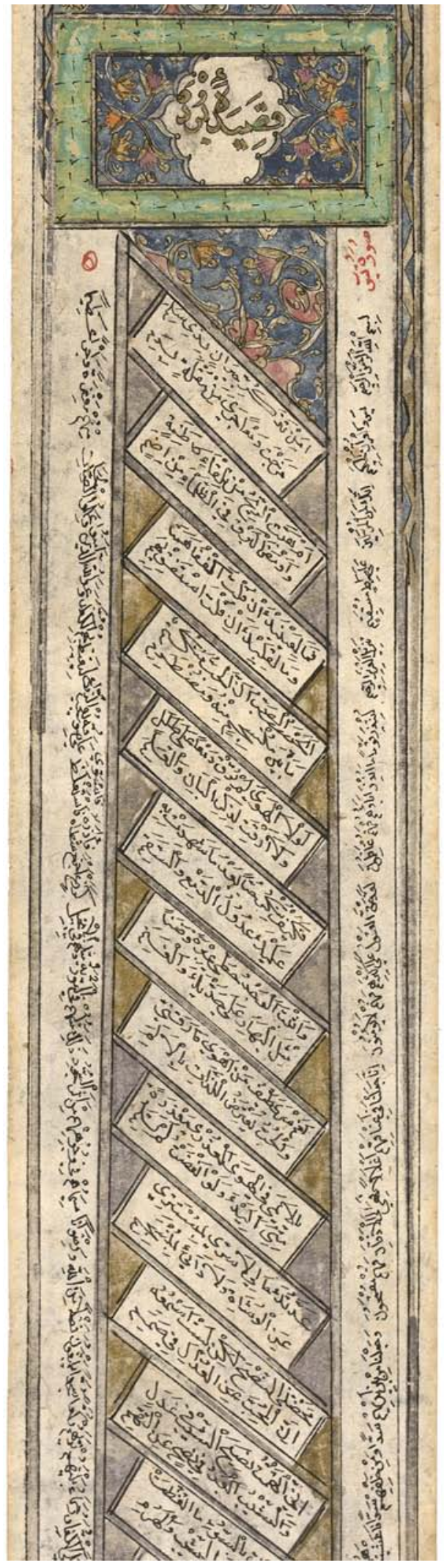

ABB. 137

Zentralbibliothek Zürich, Ms.or. 20 (vgl. Abschnitte mit Anm. 13-20 und Anm. 24-26): Die in Kapitel 6 untersuchten Rollen weisen im zweiten Teil nicht nur eine Kombination derselben Texte auf (Būṣīīis Qașīdat alBurda, Abschriften von Suren 36 und 48 auf den beiden Randleisten). Es fällt vielmehr auf, dass dieser zweite Teil der Rolle darauf auch ganz ähnlich aufgebaut ist (vgl. АB B. 143, 147, 158). 


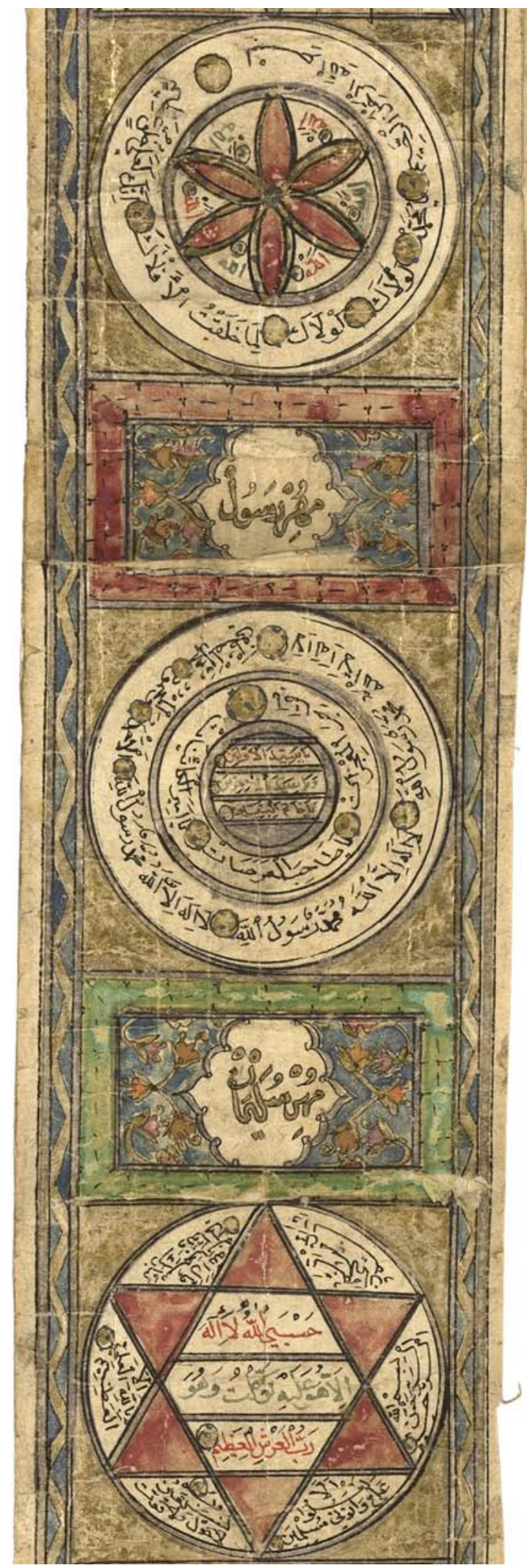

ABв. 138

Zentralbibliothek Zürich, Ms.or. 20 (vgl. Abschnitte mit Anm. 47-57): Nach dem Anfangsteil mit den lanzettenförmigen Verzierungen schliesst sich auf dem Zürcher Dokument ein Abschnitt mit verschiedenen Siegeln (muhr) an. Die Überschrift zum zweiten Abschnitt lautet Muhr-i rasūl (Siegel des Gesandten [Muhammad]); im Titelfeld des dritten Abschnitts steht Muhr-i Sulaymān. Das Hexagramm darunter spielt auf Salomon an. Beim ersten hier gezeigten Abschnitt fehlt eine Überschrift. 


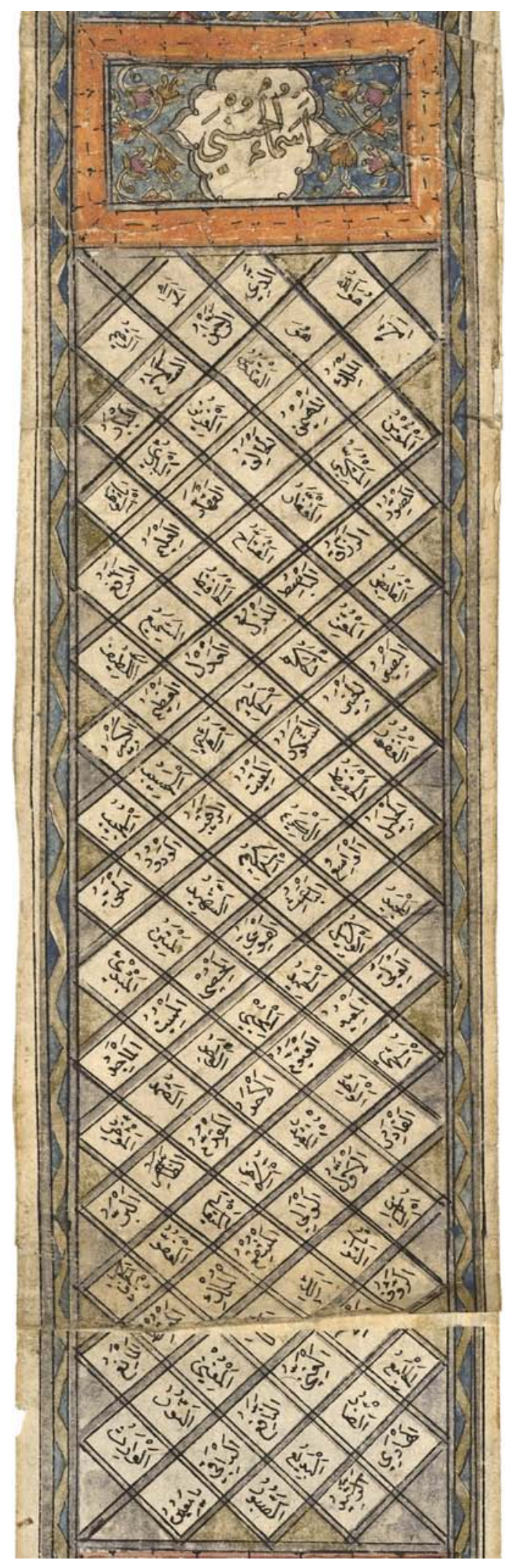

ABB. 139

Zentralbibliothek Zürich, Ms.or. 20 (vgl. bei Anm. 87-9o): Abschnitt mit den Schönen Namen Gottes (Asmā’ al-ḥusnā sic); sie sind auf dem Zürcher Exemplar in auf der Spitze stehenden Quadraten angeordnet. 


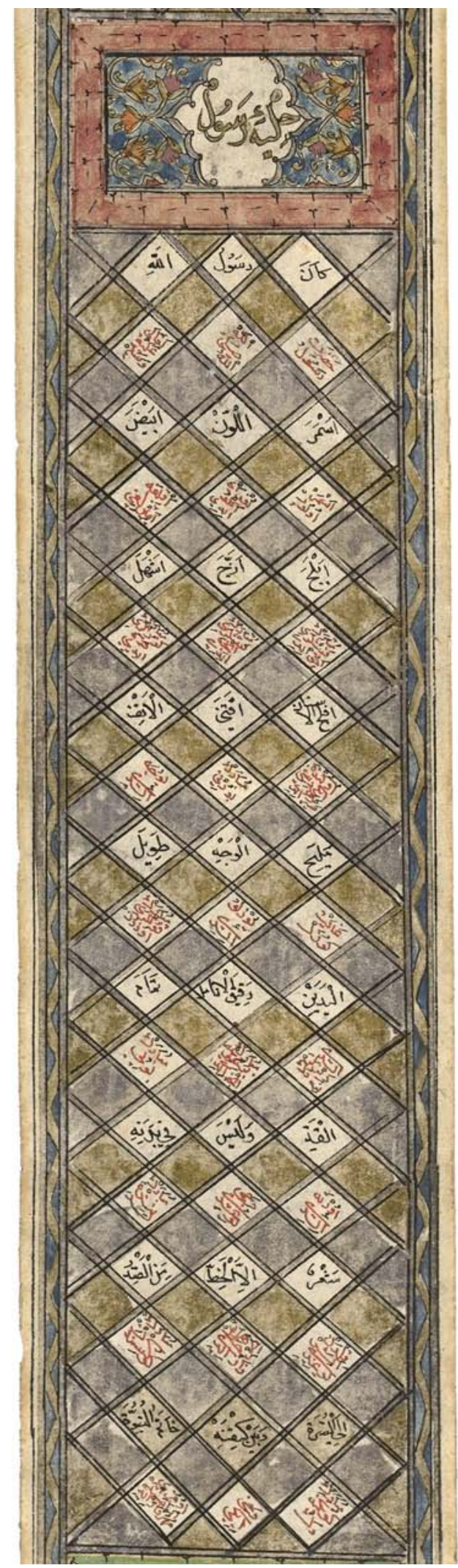

ABB. 140

Zentralbibliothek Zürich, Ms.or. 20 (vgl. Abschnitt mit Anm. 94-95): Das Zürcher Belegstück enthält einen Abschnitt, in dem die Löblichen Eigenschaften des Propheten (Hilya-i rasūl) ähnlich wie die Schönen Namen Gottes in einem Rechteck in Kästchen notiert worden sind. Diese löblichen Eigenschaften entfalten Schutzwirkung. 


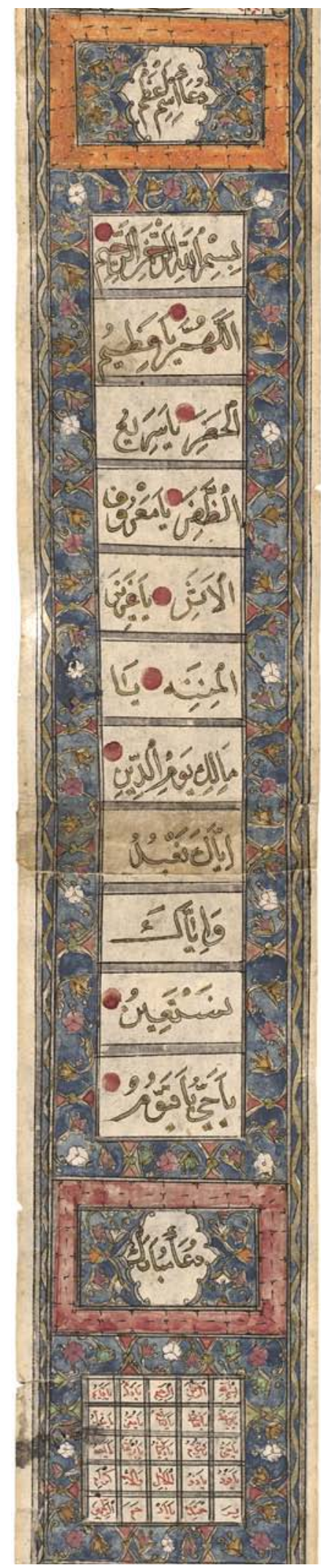

ABB. 141

Zentralbibliothek Zürich, Ms.or. 20 (vgl. bei Anm. 104-106): Die untersuchten Dokumente enthalten vielfach Gebete. Beim ersten Gebet auf dem gezeigten Ausschnitt handelt es sich um eine Anrufung Gottes bei seinem grössten Namen (Du'a ${ }^{\prime}-i$ ism-i $a$ z $\left.z a m\right)$. Es schliesst sich ein Zellenquadrat an ( $5 \times 5$ Zellen); es enthält eine Du' $\bar{a}^{\prime}-i$ mubārak („Gesegnetes Gebet“). Dieses Gebet ist in ein Zellenquadrat eingepasst $(5 \times 5$ Zellen $)$. 


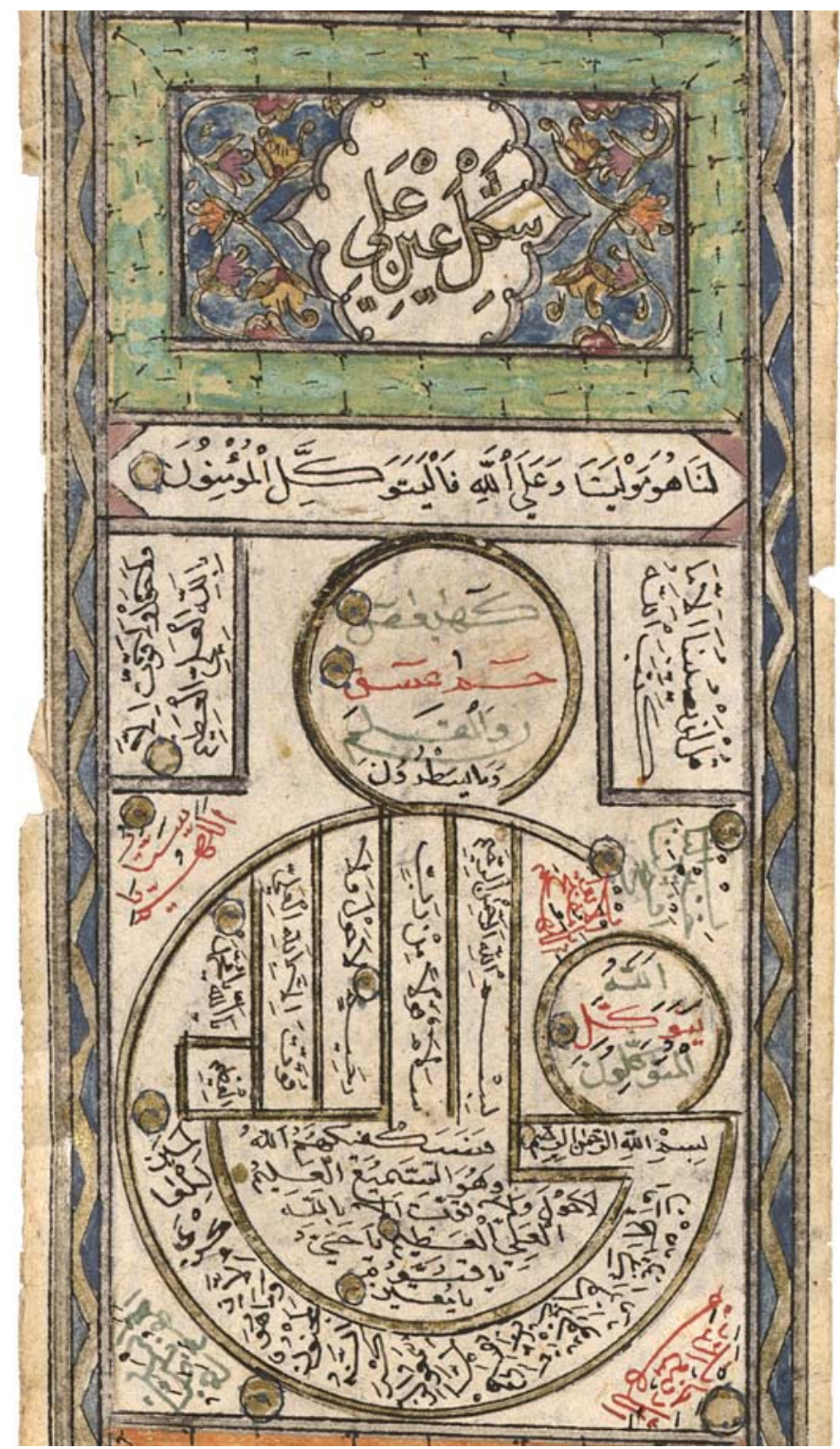

ABB. 142 Zentralbibliothek Zürich, Ms.or. 20 (vgl. nach Anm. 118163): Mehrere Rollen aus osmanischen Kontexten enthalten eine Figur mit der Überschrift Šakl-i 'ayn-i 'alī/'Alī (oder ähnlich). Sie ist für die kontextuelle Einordnung dieser Dokumente von besonderer Bedeutung (vgl. die Авв. 146, $159,160)$. 


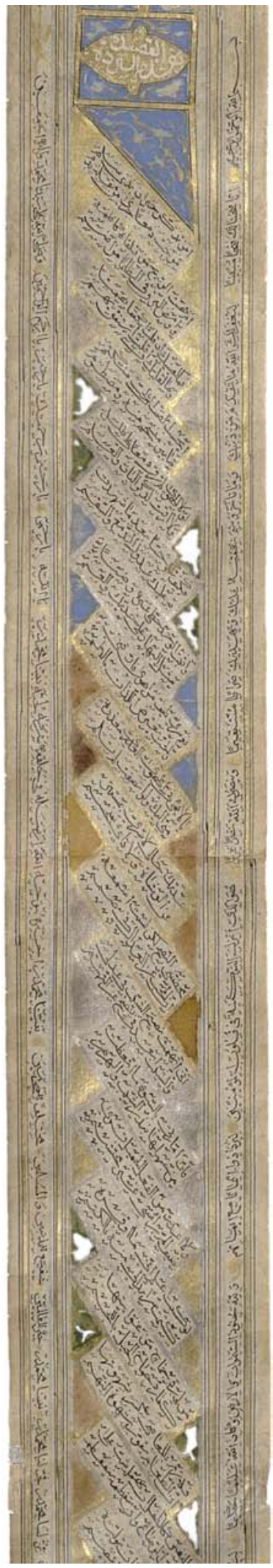

ABB. 143

Universitätsbibliothek Leipzig, B. or. 328 (vgl. Abschnitte mit Anm. 13-2o und Anm. 24-26): Auch im zweiten Teil der Rolle aus Leipzig steht Būṣīīs Qașīdat al-Burda (Mantelode). Ihr Text ist hier ebenso in geneigten Kästchen angeordnet. Auf der rechten Randleiste beginnt eine Abschrift von Q 48. Sie umfährt den Schlussteil der Rolle. Am Ende der Abschrift von Q 48 hängte der Kopist den Text eines Gebets mit der Überschrift Du'ä’ Habīb Allāh an (linke Randleiste, Schluss; vgl. auch Ав B. 137, 147, 158). 


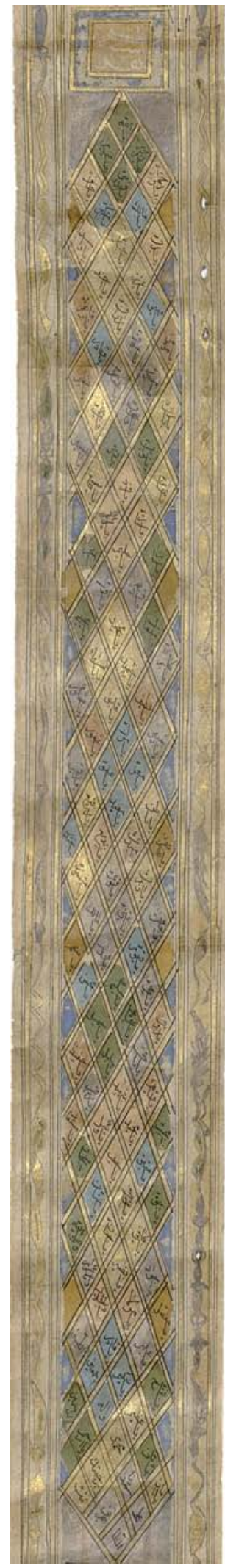

ABB. 144

Universitätsbibliothek Leipzig, B. or. 328 (vgl. Abschnitt mit Anm. 93): Der Abschnitt mit den Schönen Namen Gottes ist auf dem Belegstück aus Leipzig besonders aufwendig ausgeführt worden. Die Namen wurden in 118 Kästchen (auf der Spitze stehende Parallelogramme) festgehalten. Die Kästchen sind farbig ausgefüllt. 


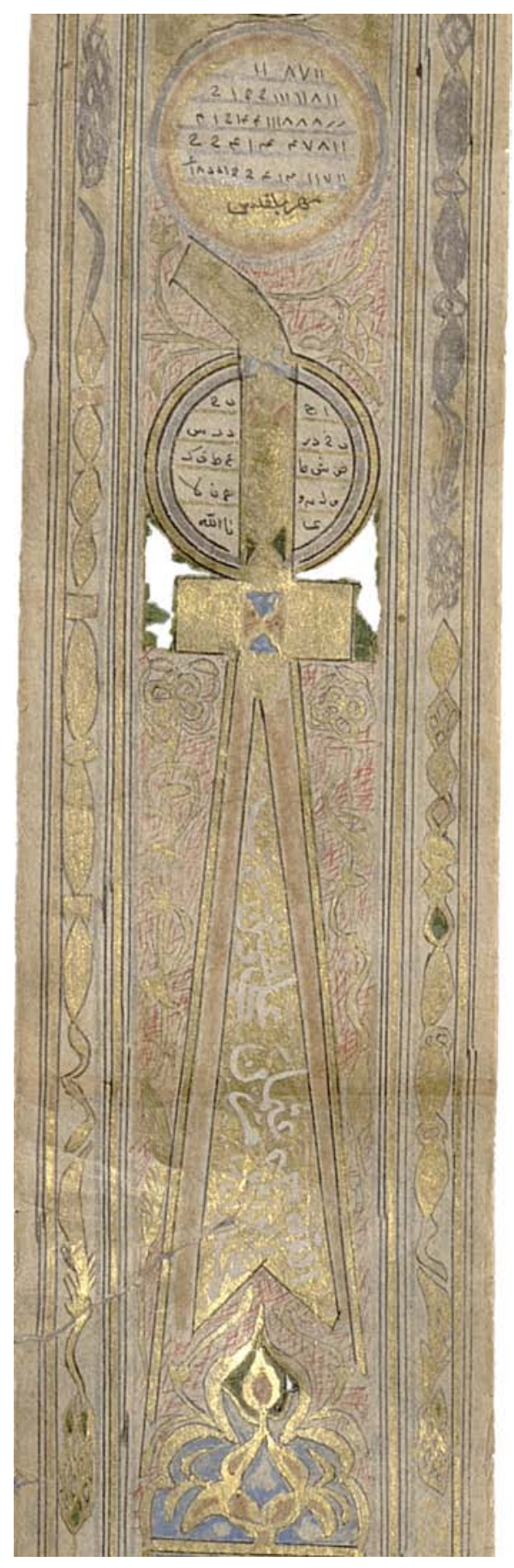

ABB. 145

Universitätsbibliothek Leipzig, B. or. 328 (vgl. vor Anm. 116, bei Anm. 169173 und 173-175): Verschiedene Dokumente in Rollenform enthalten eine Abbildung von 'Alīs Schwert D der Kopist zwischen den beiden Klingen des Schwerts die Namen der vier rechtgeleiteten Kalifen (Abū Bakr, 'Umar, 'Uțmān, 'Alī) notierte. Hier wurden ausserdem die Namen von 'Alīs Söhnen Ḥasan und Ḥusayn hinzugefügt (2. bzw. 3. Imam der Schiiten). 


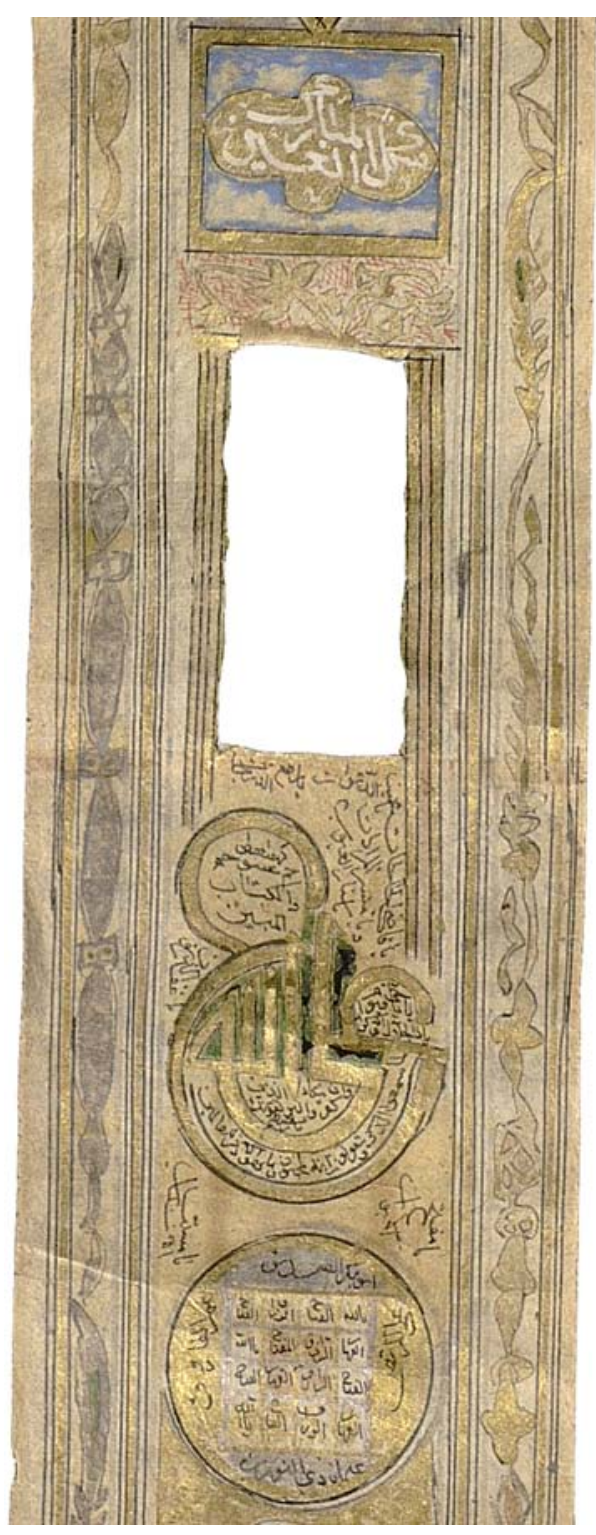

ABB. 146

Universitätsbibliothek Leipzig, B. or. 328 (vgl. bei Anm. 118-163): Auch das Dokument aus Leipzig enthält die für die Einordnung dieser Rolle besonders wichtige Figur des Šakl-i 'ayn-i 'alī (hier: Šakl al-'ayn almubārak). Man beachte, dass vor dieser Figur selbst ein Abschnitt der Rolle fein säuberlich herausgeschnitten wurde. Er dürfte Angaben enthalten haben, die einem späteren Besitzer des Dokuments nicht mehr opportun schienen (vgl. AB B. 142, 159, 16o). 


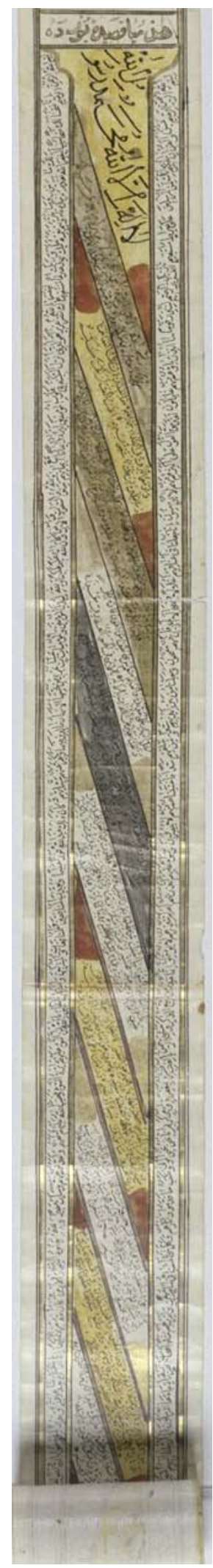

ABB. 147

Badische Landesbibliothek, Karlsruhe, Hs. Rastatt 204 (vgl. Abschnitte mit Anm. 13-20 und Anm. 24-26): Būṣīīs Qaṣīdat al-Burda wurde auch auf dem zweiten Teil des Belegstücks aus der Badischen Landesbibliothek in Karlsruhe kopiert; vgl. damit Ав B. 137, 143, 158. 


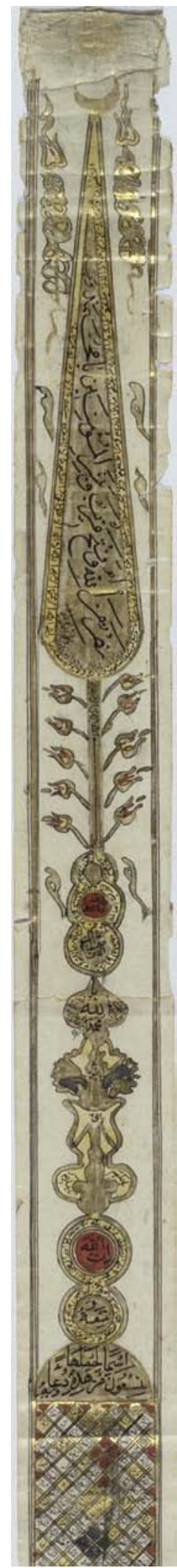

ABB. 148

Badische Landesbibliothek, Karlsruhe, Hs. Rastatt 204 (vgl. Abschnitt mit Anm. 30-43, bei Anm. 175191, bei Anm. 205f., bei Anm. 218): Am Anfang des Exemplars aus Karlsruhe befindet sich ein Baum (Zypresse), in dessen Krone ein Auszug aus Q 61:13 steht („Nașr min Allāh wa-fath qarīb wa-baššir almu’minīn yā Muḥammad“). Diese Krone ruht auf einem mehrteiligen Stamm, der in einem Gitter mit den Schönen Namen Gottes wurzelt. Dem Rand der Krone entlang steht der Thronvers (Q 2:255). Es spricht vieles dafür, dass es sich hier um den Baum der Futuwwa (šağarat al-futuwwa) handelt. Ganz am Anfang lässt sich eine Abbildung von Sonne und Mond erkennen. 


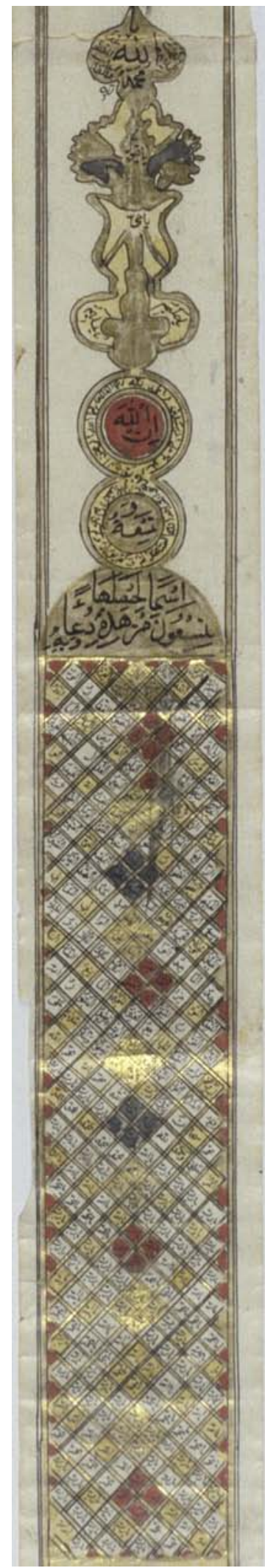

ABB. 149

Badische Landesbibliothek, Karlsruhe, Hs. Rastatt 204 (vgl. Abschnitt mit Anm. 30-37, vor Anm. 43, bei Anm. 9o-92 und bei Anm. 189-19o): Gemäss verschiedenen Darstellungen wurzelt der Baum der Futuwwa in den Eigenschaften Gottes. Auf der Karlsruher Rolle wächst der Baum am Anfang der Rolle gewissermassen aus einem Gitter heraus, in dem die Schönen Namen Gottes notiert sind. 


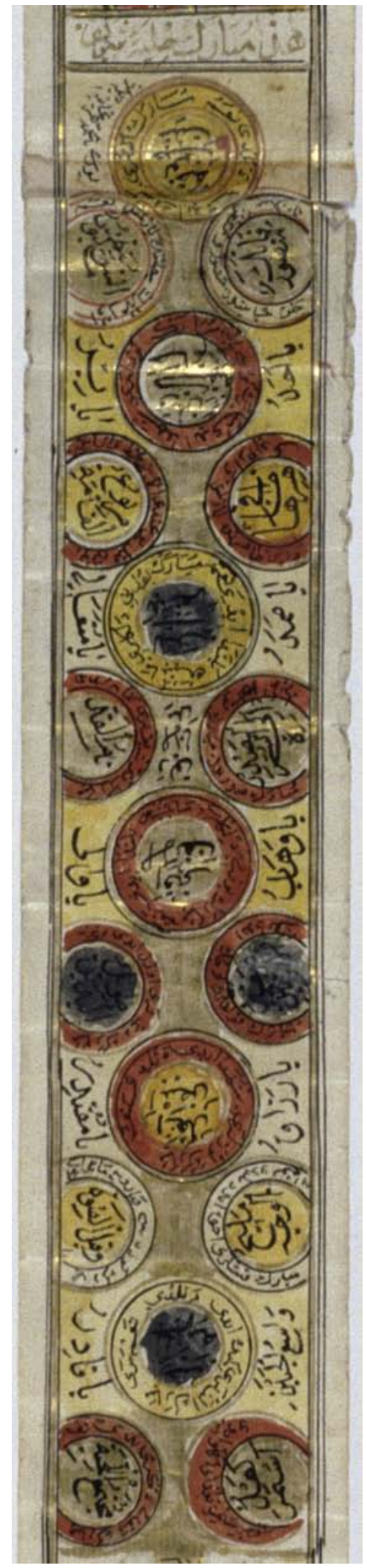

ABB. 150

Badische Landesbibliothek, Karlsruhe, Hs. Rastatt 204 (vgl. bei Anm. 96-10o): Die Dokumente aus dem Osmanischen Reich enthalten oft einen Abschnitt mit den Löblichen Eigenschaften Muhammads. Sie sind auf dem Exemplar aus Karlsruhe im Mittelfeld von 18 Medaillons enthalten, die ihrerseits in drei Spalten angeordnet sind. 


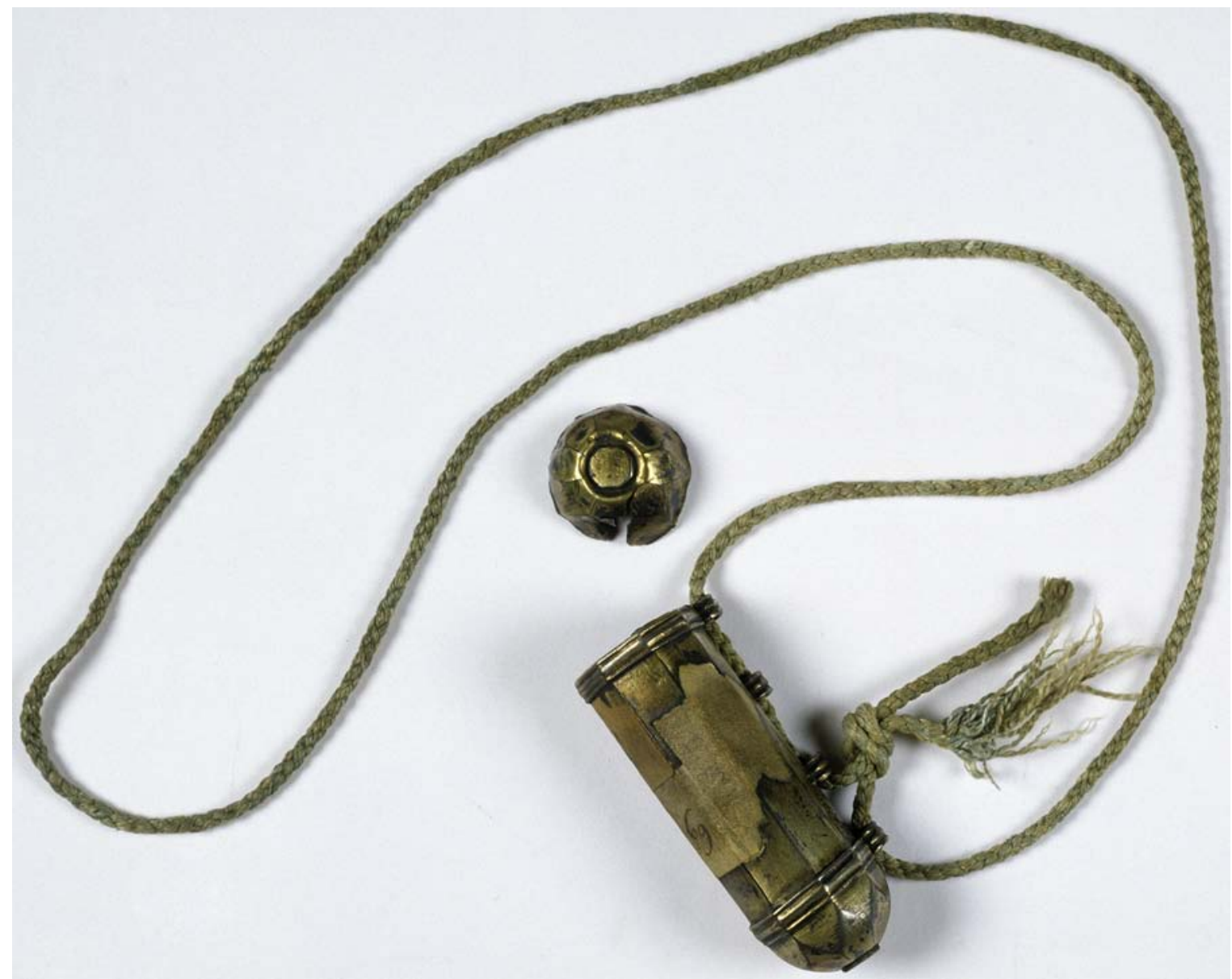

ABB. 151

Badische Landesbibliothek, Karlsruhe, Hs. Rastatt 204 (vgl. bei Anm. 231): Zusammen mit der Karlsruher Rolle blieb ein Behältnis erhalten. Auf diesem Behältnis lässt sich eine tugraähnliche Marke feststellen, die es erlaubt, die Büchse in die Zeit Sulțān Ibrāhīms zu datieren (regierte 1640-1648). 


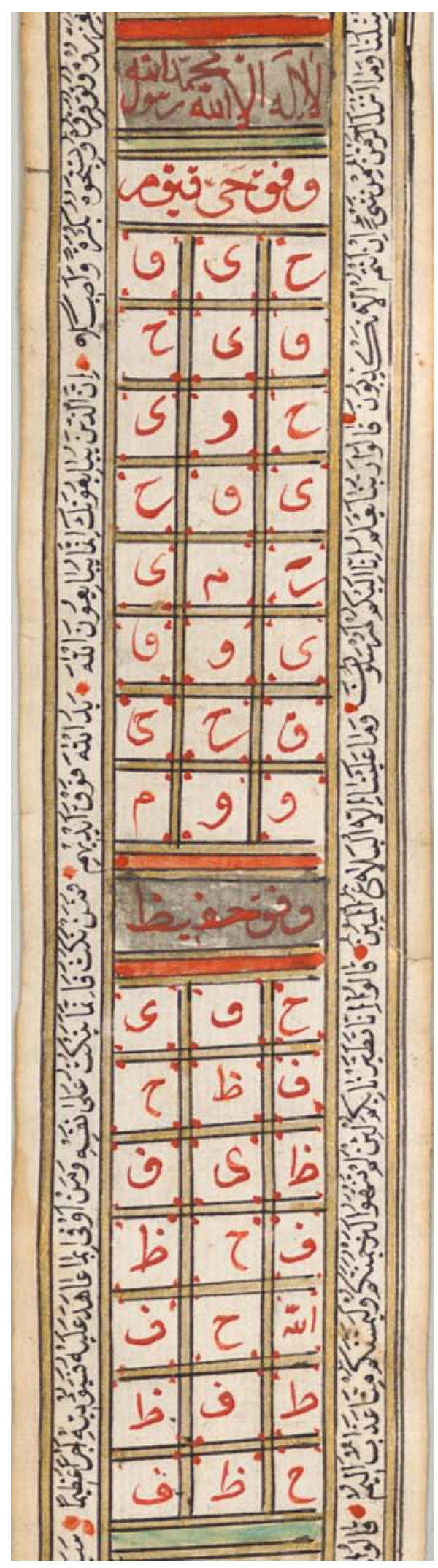

ABB. 152

Bayerische Staatsbibliothek, München, Cod. arab. 206 (vgl. Abschnitt mit Anm. 75-77): Dokumente von der hier vorgestellten Art enthalten oft Zellenquadrate. Auf dem gezeigten Belegstück aus München handelt es sich um Rechtecke. Die Überschrift zum ersten Rechteck lautet Wafq Hayy Qayyūm, jene zum zweiten Rechteck Wafq Hafız. 


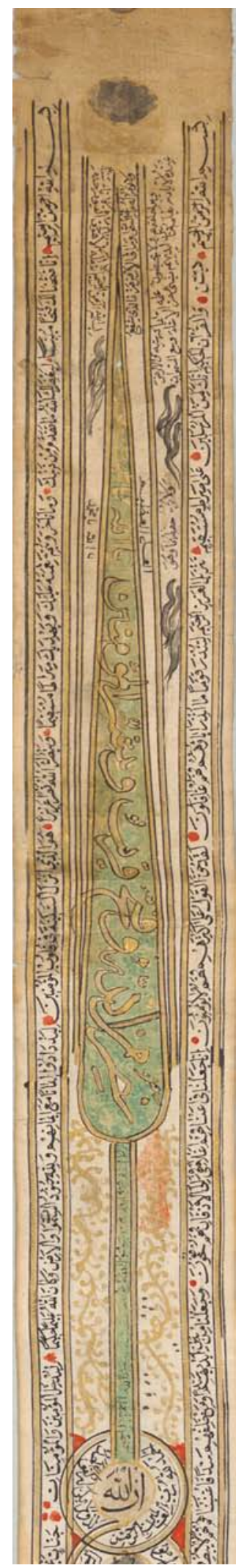

ABB. 153

Bayerische Staatsbibliothek, München, Cod. arab. 206 (vgl. vor Anm. 191, bei Anm. 205f., bei Anm. 218): Der Anfang der Rolle zeigt eine Lanzette bzw. die Krone einer Zypresse. In der grünen Krone wurde Q 61:13 notiert (aufsteigend). Man beachte auch das kreisrunde Element ganz am Anfang (goldener Hintergrund, mit eingefügtem silbernem Teil; siehe dazu nach Anm. 218). 


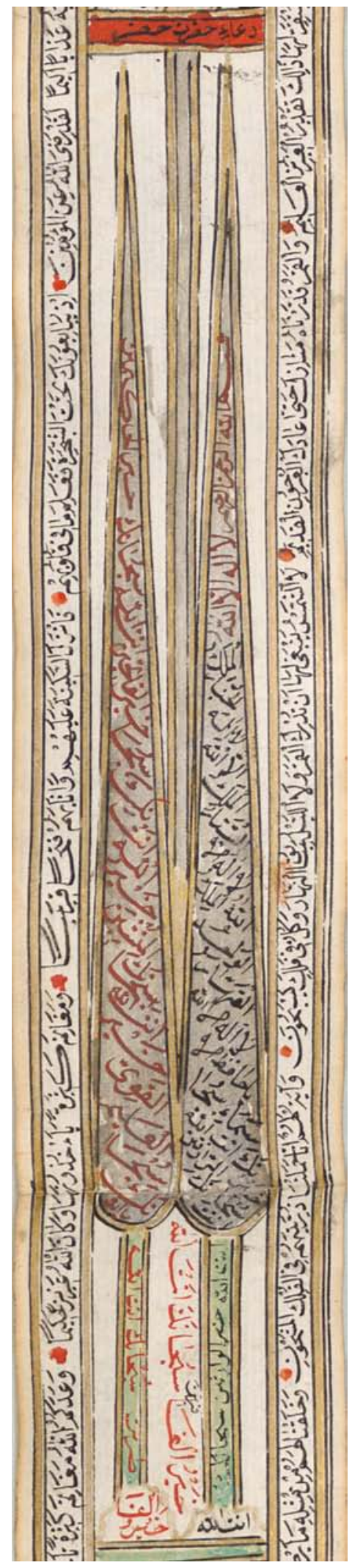

ABB. 154

Bayerische Staatsbibliothek, München, Cod. Arab. 206 (vgl. nach Anm. 215): Ein Abschnitt auf Cod. arab. 206 appelliert an den Propheten Hiḍr. Das entsprechende Gebet wird direkt nach einem roten Titelbalken (Du' $\bar{a}^{\prime}-i$ Haḍat-i Hiḍr) angeführt und wurde in eine Doppelzypresse eingefügt. 


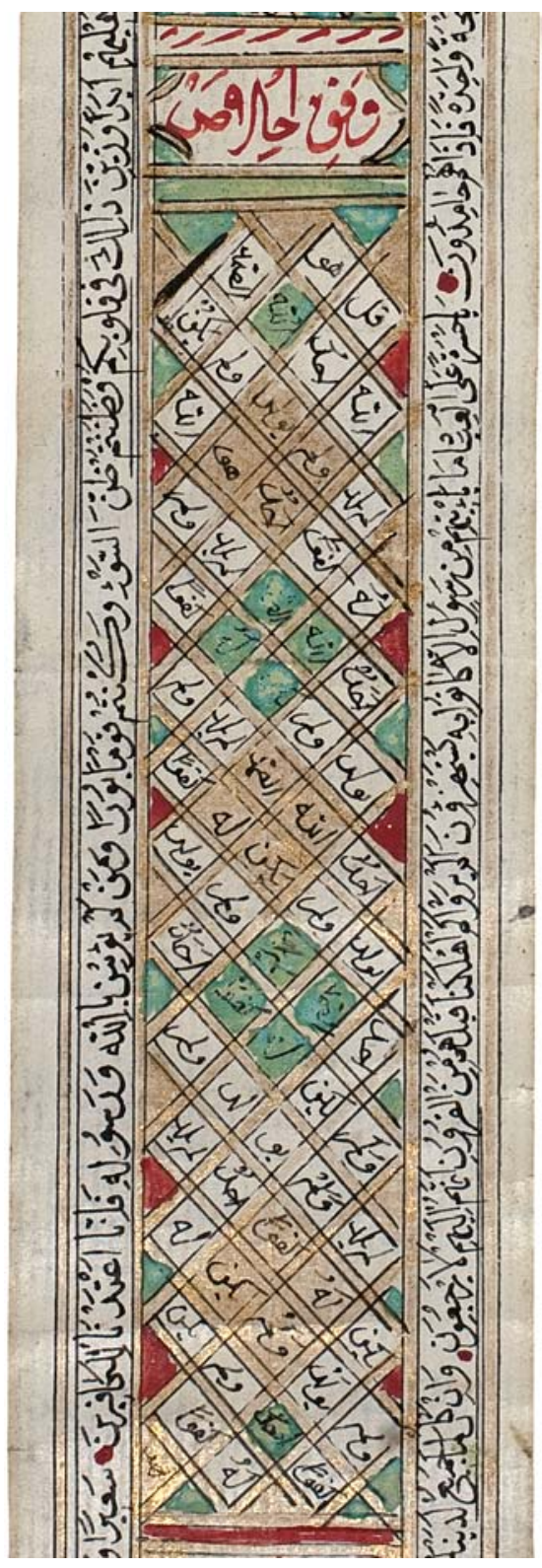

ABB. 155

Württembergische Landesbibliothek, Stuttgart, Cod. or. $8^{\circ} 83$ (vgl. vor Anm. 83): Das gezeigte Stuttgarter Belegstück enthält ein Rechteck mit auf der Spitze stehenden Zellen. In Übereinstimmung mit der Überschrift (Wafqi Ihlāsṣ) notierte der Schreiber in diesem Abschnitt Q 112 (Sūrat al-Ihlāṣ). 


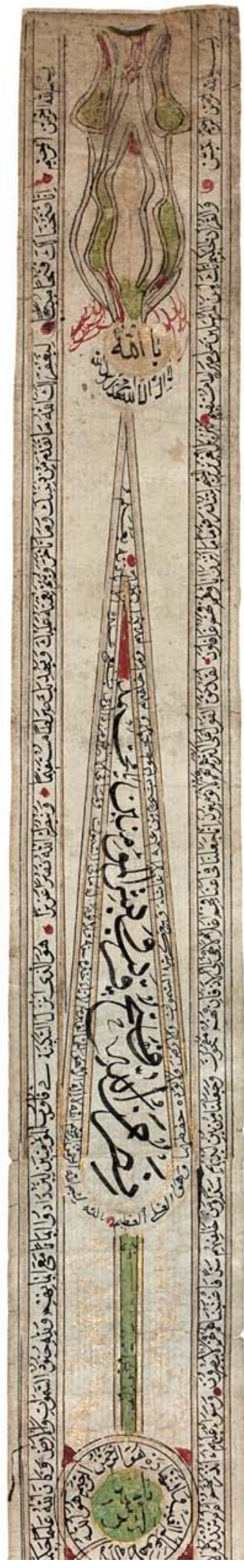

ABB. 156

Württembergische Landesbibliothek, Stuttgart, Cod. or. $8^{\circ} 83$ (vgl. bei Anm. 191, bei Anm. 205f.): Q 61:13 figuriert oft am Anfang der Belegstücke aus dem Osmanischen Reich. Dies ist auch auf einem Belegstück aus Stuttgart der Fall, das aus dem Jahr 1682 datiert. Q 61:13 ist in der Lanzette selbst notiert (aufsteigend); im schmalen Textband um diese Lanzette herum steht Q 2:255 (Thronvers). 


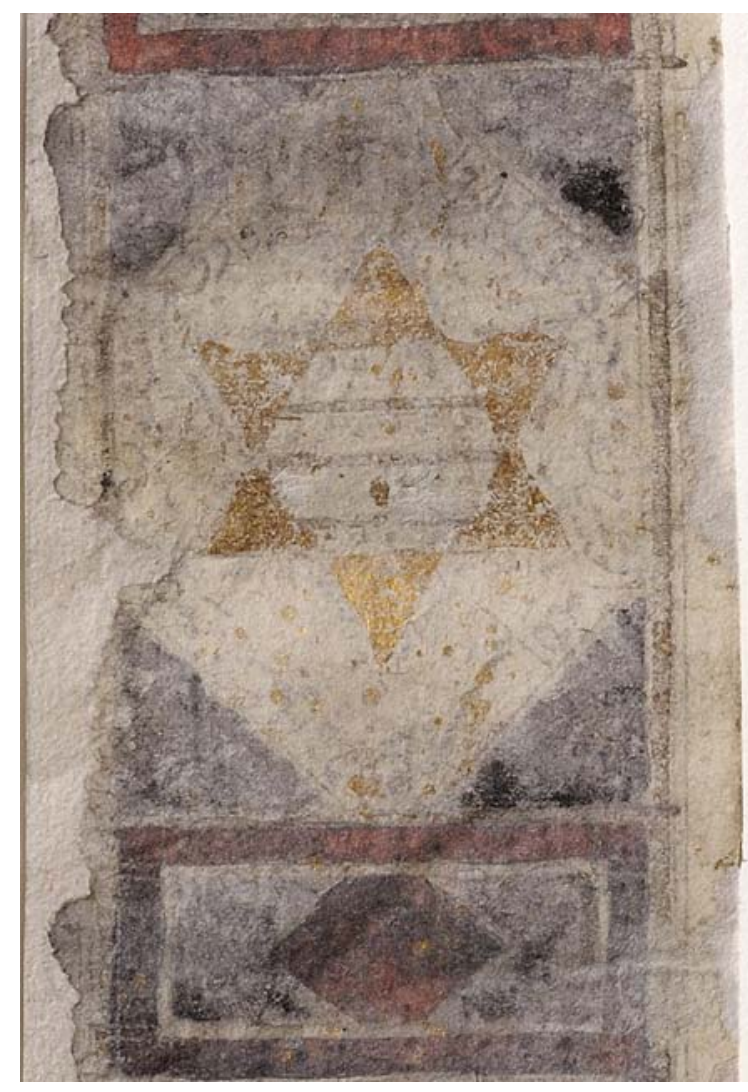

ABB. 157

Historisches Museum, Budapest, Bтм Kо 99.119.3 (vgl. Abschnitt nach Anm. 57): Das Hexagramm auf dem Belegstück aus Budapest spielt auf den Propheten Salomon an. Es appelliert an seine Schutzmächtigkeit. Salomon wird in der islamischen Welt als Bezwinger alles Dämonischen besonders geschätzt. 


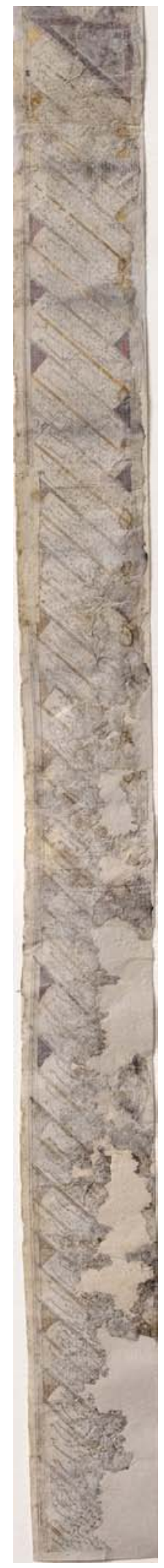

ABB. 158

Historisches Museum, Budapest, Bтм Ko 99.119.3 (vgl. vor Anm. 17): Auch im zweiten Teil des Belegstücks aus dem Historischen Museum, Budapest, wurde Būṣīīs Qașìdat al-Burda (Mantelode) kopiert. Ebenso wie auf späteren Dokumenten wurde der Text in geneigten Kästchen notiert (vgl. AB B. 137, 143, 147). 


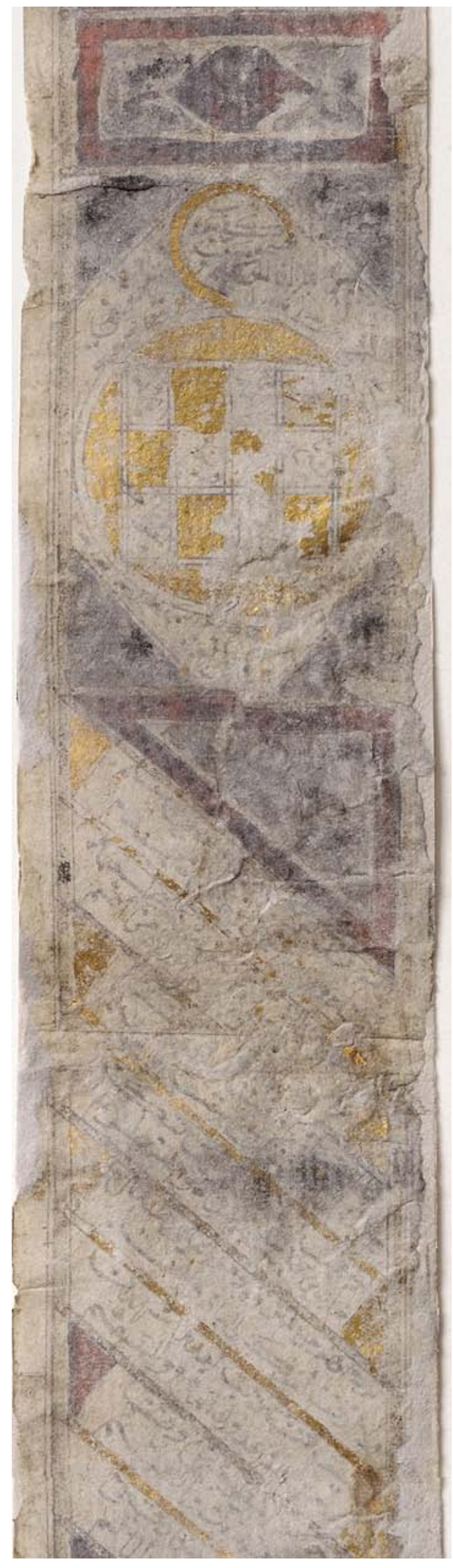

ABB. 159

Historisches Museum, Budapest, втм ко 99.119.3 (vgl. zwischen Anm. 118-163): Die Figur des Šakl-i 'ayn-i 'alī'AAl̄ lässt sich bereits auf dem Dokument aus Budapest nachweisen. Sie ist darauf einfacher ausgeführt als auf den dazu bekannten Parallelstücken aus Zürich und Leipzig (vgl. Авв. 142, 146, 160). 

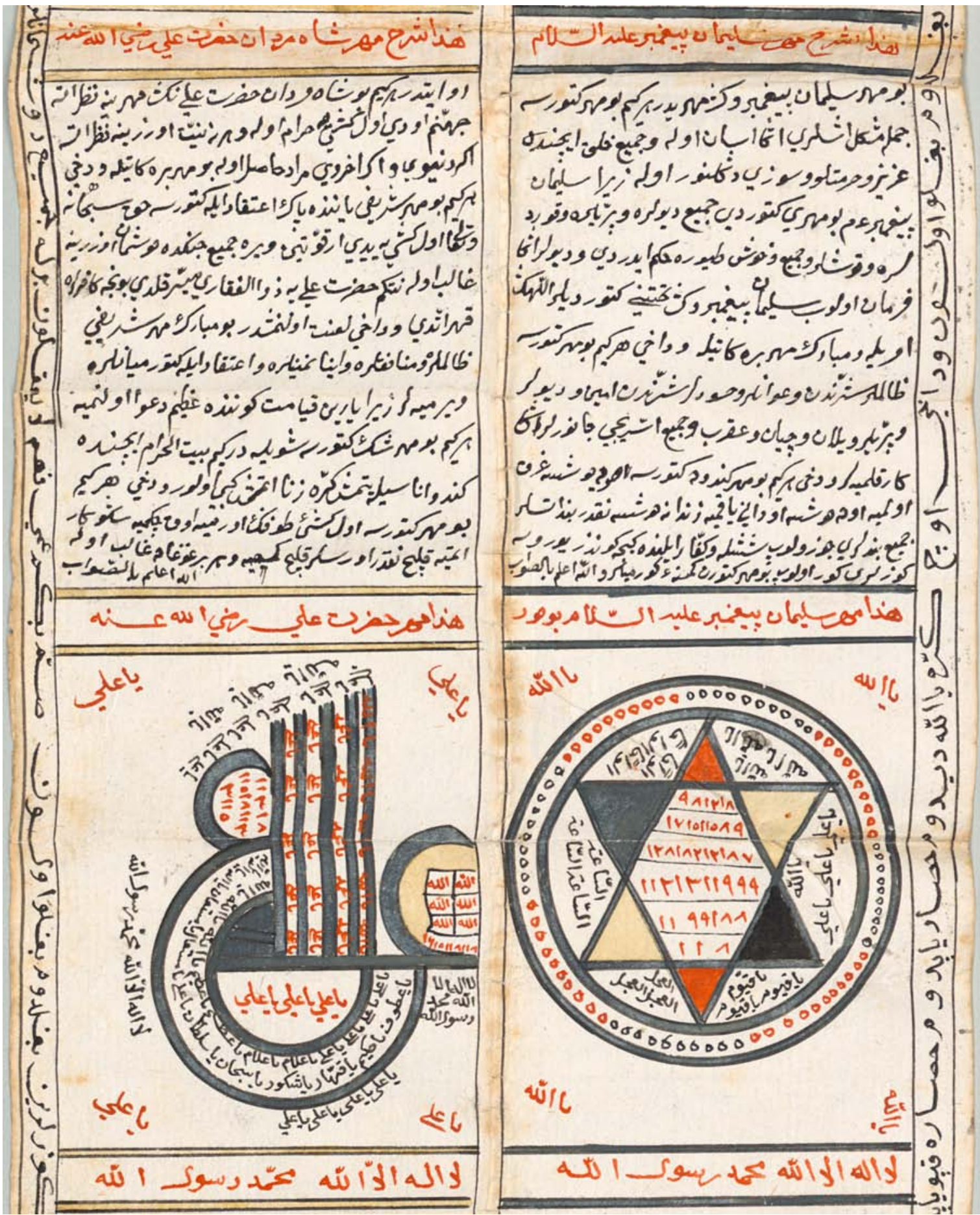

АвB. 160 Bayerische Staatsbibliothek, München, Cod. arab. 207 (vgl. bei Anm. 58, 118-163, 201): Im Gegensatz zu den in diesem Kapitel 6 untersuchten Dokumenten wurde Cod. arab. 207 auf starkes Papier kopiert. Der Text ist hier in zwei Spalten angeordnet. Auf diesem Belegstück fällt ein Abschnitt auf, der einen sechsstrahligen Stern (Hexagramm, als Anspielung auf Salomon) und eine als Šakl-i 'ayn-i 'alī/'Alī bekannte Figur enthält (vgl. AB B. 142, 146, 159). 